\title{
Un extrait de la Hidaya d'Abū Bakr al-Bāqillānī : le Kitāb at-tawallud, réfutation de la thèse mu'tazilite de la génération des actes
}

\section{Daniel Gimaret}

\section{(2) OpenEdition \\ Journals}

Édition électronique

URL : http://journals.openedition.org/beo/76

DOI : $10.4000 /$ beo. 76

ISBN : 978-2-35159-316-5

ISSN : 2077-4079

\section{Éditeur}

Presses de l'Institut français du Proche-Orient

\section{Édition imprimée}

Date de publication : 1 septembre 2009

Pagination : 259-313

ISBN : 978-2-35159-143-7

ISSN : 0253-1623

\section{Référence électronique}

Daniel Gimaret, « Un extrait de la Hidaya d'Abū Bakr al-Bāqillānī : le Kitāb at-tawallud, réfutation de la thèse mu'tazilite de la génération des actes », Bulletin d'études orientales [En ligne], Tome

LVIII | Septembre 2009, mis en ligne le 01 octobre 2010, consulté le 20 avril 2019. URL : http:// journals.openedition.org/beo/76 ; DOI : 10.4000/beo.76 


\title{
UN EXTRAIT DE LA HIDĀYA D'ABŪ BAKR AL-BĀQILLĀNĪ : LE KITĀB AT-TAWALLUD, réfutation de la thèse mu'tazilite de la génération des actes
}

\author{
Daniel GIMARET
}

Directeur d'études émérite (EPHE)

PREMIÈRE PARTIE : LA HIDĀYA, SON INTÉRÊT, SON CONTENU

\section{La HidĀYA, ULTIME OUVRAGE DE BĀQILLĀNī ET SANS DOUTE LE PLUS IMPORTANT}

Lorsqu'il s'agit d'évoquer l'œuvre proprement théologique ${ }^{1}$ de Bāqillānī, on songe aussitôt, et presque exclusivement, au Tamhīd, objet de deux éditions successives ${ }^{2}$, et de fait, de tous les ouvrages conservés du Qādī Abū Bakr, le seul à offrir un panorama complet des questions traditionnelles du 'ilm al-kaläm et des réponses que prétend y apporter la doctrine ašarite. Or il y a maintenant bien longtemps, j'avais fait remarquer ${ }^{3}$ qu'à s'en tenir au contenu du Tamhid, on s'y trouvait en divers points en contradiction avec les positions qu'attribuent au Qāḍ̂̄ les auteurs postérieurs tels que Ǧuwaynī (imām al-haramayn), Abū l-Qāsim al-Anșārī disciple du précédent, Šahrastānī lui-même disciple d'Anșārī. C'est le cas en particulier de la théorie des "états" (ahwāl) empruntée à Abū Hāšim al-Ğubbā'̄î, objet d'une attaque en règle dans le Tamhīd ${ }^{4}$, alors qu'au dire de Ğuwaynī ${ }^{5} \mathrm{~B}$. aurait fini, après de longues hésitations, par s'y rallier entièrement. J'avais rappelé également que selon les biographes ${ }^{6}$ il aurait composé le Tamhīd lors de son séjour à Šīrāz à la cour de 'Adud addawla ${ }^{7}$, et qu'il s'agirait donc bien d'un ouvrage de jeunesse. Cela ne veut pas dire que, par la suite, Bāqillānī l'ait totalement renié, loin de là. Dans la Hidāya, sa dernière œuvre (voir

1. Car il fut aussi un théoricien du droit, comme l'a encore rappelé récemment la publication (très partielle) de son K. at-Taqrïb wa l-iršăd fì ușūl al-figh (3 vol., Beyrouth, 1998).

2. En premier lieu celle publiée au Caire en 1366/1947 par M.M. AL-HuḌAYRĩ et M.'A. ABū RīDA, malheureusement fondée sur l'unique manuscrit de Paris où manque près d'un tiers du texte; puis celle de R.J. McCARTHY (Beyrouth, 1957), édition critique établie à partir de trois mss (Paris et deux mss d'Istanbul) mais amputée - pour des raisons peu convaincantes - de la quasi-totalité de la partie relative à l'imamat.

3. Dans un article du Journal asiatique (1970, 76-77), puis dans mes Théories de l'acte humain (Paris, 1980, p. 94-95).

4. Éd. McCarthy 200-202.

5. Ǎs-Šāmil fĭ ușūl ad-dīn, éd. 'A.S. an-Naššār, F.B.'Awn, S.M. Muhtār, Alexandrie, 1969 (ci-après Šm), 294.

6. Qāḍī 'Iyāẹ cité dans l'éd. égyptienne du Tamhīd, 250 ; Iвn 'AsākIR, Tabyīn kadilib al-muftarī, Damas, 1347, 120 ; AlLARD, Le problème des attributs divins, Beyrouth, 1965, 296.

7. Probablement autour de 360/970, soit environ quarante ans avant sa mort en 403/1013. 
plus loin), il y renvoie concernant la réfutation des chrétiens ${ }^{8}$. Mais ce qui est sûr, c'est que dans la bibliographie du Qādīi, le Tamhīd ne mérite nullement cette place éminente que le destin chaotique des manuscrits se trouve lui avoir conférée. Cela se voit clairement chez les auteurs postérieurs. Dans ce qui nous est parvenu du Šāmil de Ğuwayni ${ }^{9}$, où abondent, et pour cause, les références au Qādī Abū Bakr et à ses œuvres (car le Šāmil n'est autre chose qu'un commentaire de son Šarh al-Luma ${ }^{\prime 10}$ ), le Tamhìd n'est cité en tout et pour tout que deux fois, alors que sont cités sept fois le Šarh al-Luma', neuf fois la Hidāya, onze fois l'ouvrage intitulé Naqd an-naqd ou an-Naqd al-kabir (sur lequel voir plus loin). Dans ce qui reste du Šarh al-Iršād d'Abū l-Qāsim al-Anșāāī ${ }^{11}$, le Tamhīd n'est jamais cité, alors que la Hidāya l'est sept fois. Bāqillānī lui-même marque cette différence : dans tout ce qui subsiste de sa Hidāya, le Tamhìd n'a droit qu'à une seule mention alors que le Naqd an-naqd en totalise douze.

Le Tamhīd n'est donc pas, tant s'en faut, l'ouvrage le plus important de Bāqillānī en matière de 'ilm al-kalām. S'il en est un, par contre, qui mérite ce titre, c'est sans aucun doute la Hidāya, et cela pour deux raisons. D'une part du fait de son ampleur. "Kitāb kabïr" dit, à son propos, le Qādī 'Iyāḍ. À en juger ne serait-ce que par les dimensions du Kitāb an-Nubuwwāt, dont les 250 folios (soit 500 pages) du ms du Caire ne contiennent que les deux derniers tiers, l'expression ne parait pas surfaite. Il faut imaginer, en volume, un ouvrage comparable au Muginī de 'Abd al-Ğabbār, et peut-être destiné à lui faire pièce (à moins que ce ne soit l'inverse) ${ }^{12}$. D'autre part, il semble établi que la Hidāya a été, sinon la dernière œuvre, du moins l'une des toutes dernières de Bāqillānī : "āhir mușannafātihi" dit d'elle carrément Abū l-Qāsim al-Anșārī ${ }^{13}$, probablement d'après Ğuwaynī. L'examen des fragments conservés confirme amplement cette assertion : il n'est quasiment aucun des ouvrages importants du Qādī qui n'y soit mentionné au moins une fois : le Tamhīd, le Naqd an-naqd, mais aussi le Šarh al-Luma', al-Farq bayna l-mu'ğizāt wa l-karāmāt, al-Intișār li-l-Qur'ān, les Daqā'iq al-kalām, les deux livres sur l'imamat, les traités d'ușūl al-figh ${ }^{14}$. D'où le mérite spécifique de cette ultime somme, en ce qu'elle est censée représenter le dernier état d'une pensée qui fut et resta souvent hésitante ${ }^{15}$. Ainsi c'est dans la Hidāya que Bāqillānī se prononce sans ambiguïté en faveur de la théorie des aḥāl (Šm 294). Sur la question de

8. Šm 570, peut-être d'après Hidāya, ms du Caire 62b. Il renvoie également au Tamhīd dans le Bayān, éd. McCarthy 88.

9. Dans l'édition d'Alexandrie indiquée plus haut (Šm), à quoi s'ajoutent les chapitres redécouverts par R. Frank et publiés à Téhéran en 1360/1981 (ci-après Šm.T.).

10. Cf. Šm.T. 3. Lequel Šarh al-Luma est lui-même le commentaire par Bāqillānī du K. al-Luma d'Abū l-Ḥasan alAš́arī.

11. Ms Princeton Univ. ELS 634.

12. Le Naqd an-naqd dont il sera question plus bas atteste bien la compétition entre les deux maîtres.

13. Šarh al-Iršād, $35 b$.

14. Un seul absent de taille : le K. I'ḡāz al-Qur'ān. Absence d'autant plus surprenante que, dans le ms du Caire, la question de l'íğăz, partie intégrante du Kitāb an-Nubuwwāt, fait l'objet d'un examen détaillé... Le K. I'ğāz al-Qur'ān serait-il postérieur à la Hidāya? Mais alors pourquoi, ayant traité à fond de ce sujet dans ce dernier ouvrage, B. aurait-il éprouvé le besoin d'y revenir dans un livre à part? Si, en revanche, l'ouvrage est antérieur, comment expliquer que B. n'y fasse jamais référence, alors qu'il le fait si volontiers pour ses autres livres?

15. Raddada ğawābahu disent fréquemment du Qāḍ̄ les auteurs postérieurs. 
savoir si les qualifications (șifät) attachées aux existants en vertu de leur essence même - comme le fait, pour une substance, d'occuper un espace et d'être porteuse d'accidents sont ou non l'œuvre d'un agent (bi-l-fā'il) - autrement dit, sont ou non créées par Dieu -, il répond finalement cette fois par l'affirmative, alors que dans le Naqd an-naqd il soutenait encore le point de vue contraire, en accord sur ce point avec les mu'tazilites (Šm.T. 27-28; Šarh al-Iršăd 52b). S'agissant de savoir si toute science "contrainte" (darūrî), qu'elle relève ou non du kamāl al-'aql, peut être acquise par raisonnement, il opte en fin de compte pour un distinguo qu'il se refusait à faire dans ce même Naqḍ an-naqụ (క̌m.T. 93). Parallèlement, sur la question cruciale du statut de l'acte humain, créé par Dieu, "acquis" par l'homme, c'est sans aucun doute dans la Hidāya que nous pouvons espérer trouver confirmation ou non de la position qu'attribueront à Bāqillānī, concernant la nature du kasb, les auteurs postérieurs, Šahrastānī notamment ${ }^{16}$.

\section{LES FRAGMENTS CONSERVÉS}

À ce jour, seuls deux fragments de la Hidāya nous sont accessibles, conservés l'un à Fès, l'autre au Caire.

1. Le manuscrit de Fès (ci-après F) ${ }^{17}$, Qarawiyyīn 692. Sans en-tête ni colophon. 168 ff. ${ }^{18}$, à raison de 17 lignes par page. Écriture maghrébine très régulière, avec de part et d'autre des marges parfaitement rectilignes. Le ms est malheureusement très dégradé : les premiers et derniers folios sont inutilisables, et la lecture des débuts et fins de pages est souvent aléatoire.

Le contenu est fait de trois éléments. Le premier (ff. 1-95b) représente l'extrême fin de ce qui devait s'appeler bāb al-kalām fi halq al-af'āl ${ }^{19}$; le deuxième (95b-140b) est le kitāb at-tawallud, qu'on lira plus loin; le troisième (140b-159) le tout début du bāb al-kalām fí l-istițāa.

Les 39 premiers folios contiennent la fin de ce qui devait être un très long chapitre consacré à la réfutation des arguments invoqués par les adversaires mu'tazilites (toujours appelés qadariyya) ${ }^{20}$. À quoi fait suite, en clôture de ce kitāb halq al-af'āl, un autre très long chapitre où l'auteur - la polémique sur ce point est traditionnelle - s'emploie à démontrer que ce sont bien précisément les mu'tazilites à qui s'applique ce terme de qadariyya dont un hadith dit qu'ils sont "les mages de cette nation ${ }^{21}$ ".

Viennent ensuite, comme dit plus haut, le $k$. at-tawallud, puis, à partir du fo $140 \mathrm{~b}$, le début du bāb al-istițāa $a$. Ces quelque vingt derniers folios sont, de toute évidence, d'une

\footnotetext{
16. Cf. mes Théories de l'acte humain 104-118.

17. Je dois le microfilm de ce ms à mon ancien élève Abdallah Boumiz, que je remercie chaleureusement.

18. Apparemment 159, mais comme on le verra dans l'extrait publié plus loin, une inadvertance du conservateur responsable de la pagination lui a fait ajouter à la suite du premier folio 99 une nouvelle série de 91 à 99 .

19. Comme le laisse entendre $\mathrm{F} 112 \mathrm{~b}$ et $114 \mathrm{~b}$. La phrase de conclusion dit : wa hā wa fìd-dalālati 'alā anna llāh ta'ālā huăliq li-af'ầl 'ibādihi.

20. Le dernier de ces arguments est annoncé aux ff. 17b-18a : 'illat ${ }^{u n}$ lahum uhrā fì nafy halq al-afäl allatī hiya a'māl al-ibāad.

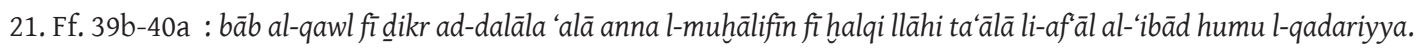


importance capitale : Bāqillānī s'y explique en détail sur ce qu'il faut entendre par "puissance d'acquérir" (qudrat al-iktisāb) et en quoi consiste l'efficience (ta'tîr) de cette puissance, apportant ainsi la réponse attendue aux questions que suscite sur ce point le rapport de Šahrastānī. Malheureusement, à mesure qu'on s'approche de la fin du manuscrit, les folios sont de plus en plus dégradés, et leur exploitation s'avère quasiment impossible ${ }^{22}$.

2. Le manuscrit du Caire (ci-après C), al-Azhar III 337, 'ilm al-kalām [21] 342. Ms complet, daté de 457 (soit un demi-siècle seulement après la mort de l'auteur). 250 ff. ${ }^{23}$, à raison d'environ 20 lignes par page. Écriture nashī très irrégulière, parfois soignée, parfois au contraire tout à fait relâchée. L'état du ms est généralement bon, à l'exception d'une dizaine de folios (87-96). D'une présentation très différente de celle de $F$, le ms est divisé en douze cahiers, numérotés de 6 à 17, de dimensions sensiblement égales (entre 20 et $24 \mathrm{ff}$. par cahier).

Comme indiqué plus haut, le ms C contient les deux derniers tiers du Kitāb anNubuwwāt ${ }^{24}$. Chaque cahier commence en page impaire (même au prix d'une page blanche au fo précédent), avec un titre en pleine page, soigneusement calligraphié, comportant le numéro du cahier, le titre du "livre", le titre de l'ouvrage, le nom de l'auteur. Ainsi au fo 1a : as-sādis min Kitāb an-Nubuwwāt min Hidāyat al-mustaršidīn tașnîf al-qāḍ̄̄ al-ğalī Abī Bakr Muhammad bn aț-Ṭayib al-Aš́arī raḥmatu llāhi 'alayhi. Le copiste donne ici le titre semicomplet, Hidāyat al-mustaršidìn, rarement attesté ${ }^{25}$. Les cahiers 7, 10, 12, 13 et 16 donnent à l'ouvrage un titre encore plus long : Hidāyat al-mustaršidīn wa l-muqni' fì márifati ușūl addìn. Quant à l'auteur, il lui est donné pour nisba non pas al-Bāqillānī mais al-Aš‘arī, selon un usage fort répandu chez ses biographes ${ }^{26}$.

La table des matières, limitée aux principales rubriques, est la suivante :

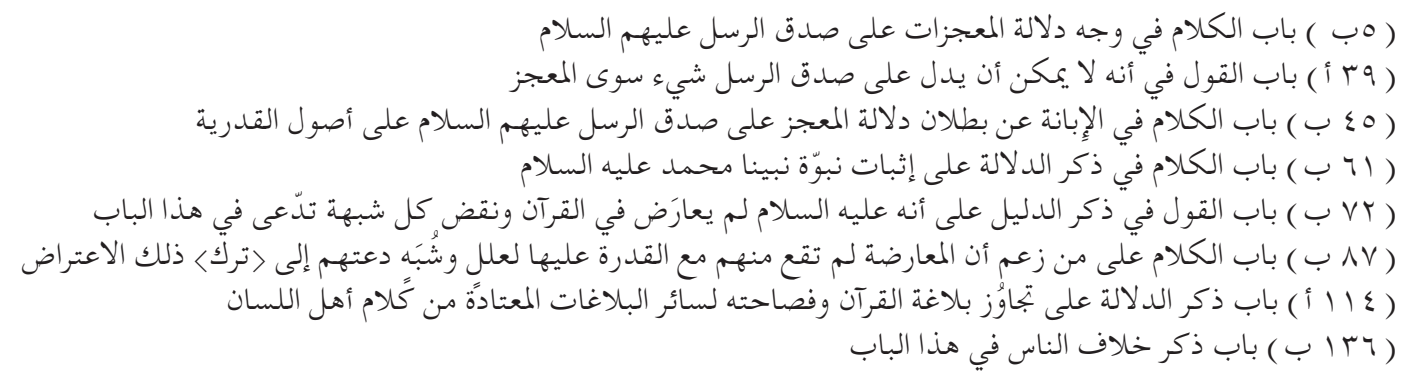

22. De ce que l'on peut grappiller des ff. 152-155, il semble ressortir que la position de B. en la matière ne différait guère de celle affichée après lui par son disciple Abū Ğa‘far as-Simnānī, cf. mes Théories 101-102.

23. Sic après plusieurs vérifications, et non 248 comme le porte le catalogue. Je précise que sur le microfilm dont je dispose les folios ne sont pas numérotés et ne l'étaient donc pas non plus au moment de l'élaboration dudit catalogue.

24. Dans l'ensemble de l'ouvrage, ce "livre" vient à la suite des parties concernées par le ms F. À plusieurs reprises, l'auteur y renvoie à ce qu'il a dit précédemment dans le bāb al-istițāa

25. Ibn Taymiyya est l'un des rares à le citer sous cette forme.

26. Cf. notamment la notice du Tabyīn d'IBN 'AsĀKIR. Cette même nisba se retrouve sur le ms du K. I'ğāz al-Qur'ān de la British Library ; sur le ms d'Istanbul du K. al-Intișār ; sur le ms de Tübingen du K. al-Bayān. 


$$
\begin{aligned}
& \text { ( ع \& أ ) باب الكلام على من قال إن جهة إعجاز القرآن ما تضمّنه ودل عليه من صحة المعاني والأحكام التي إذا أُعمل النظر } \\
& \text { فيها صحت وسلمت كاب كلها على السبر و الامتحان }
\end{aligned}
$$

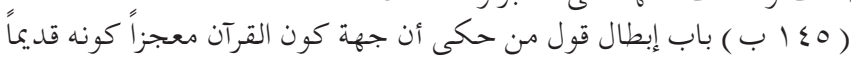

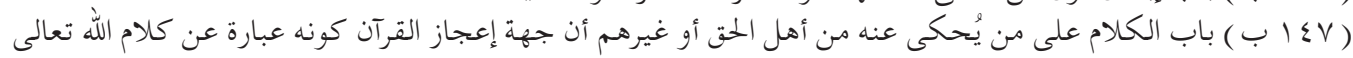

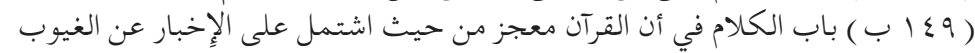

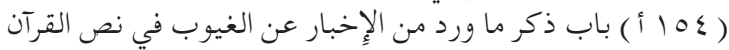

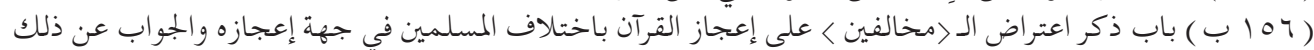

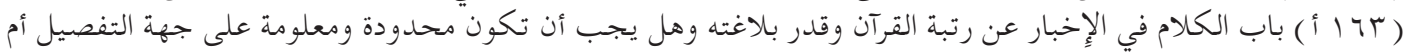

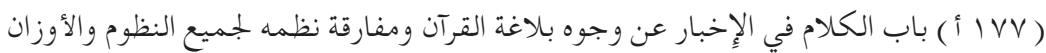

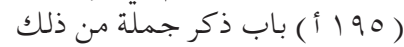

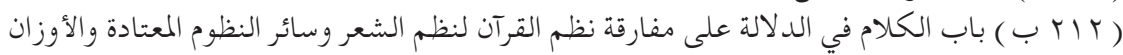

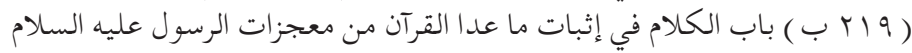

Au terme du kitāb an-nubuwwāt, le copiste indique, comme il se doit, le titre du "livre" suivant : yatlūhu bāb al-kalām fīl-amr bi-l-ma'rūf wa n-nahy 'ani l-munkar.

III. LA BIBLIOGRAPHIE DE BĀQILLĀNĪ À LA LUMière DE LA HIDĀYA.

En conclusion de la longue notice qu'il lui consacre dans ses Madārik, le Qāḍ̄ 'Iyāḍ donne une liste des œuvres de Bāqillānī ${ }^{27}$. Cette liste est manifestement incomplète, il y manque notamment le Naqḍ an-naqd que pour sa part, dans sa courte liste de la Tabșira ${ }^{28}$, Abū l-Muẓaffar al-Isfarāīnī (m. 471) cite en deuxième position, aussitôt après la Hidāya. Les parties conservées de ce dernier ouvrage, grâce aux nombreuses références qu'y fait B. à ses œuvres antérieures, permettent d'ajouter à la liste des Madārik de substantiels compléments ${ }^{29}$.

\section{Livres cités par le Qāḍ̄ 'Iyāḍ.}

- Daqā’iq al-kalām. Le titre complet est donné en C 151a: Daqā’iq al-kalām wa r-radd 'alā man hâ̄lafa l-haqq min al-Awā'il wa muntahilī l-islām. B. dit y avoir réfuté longuement les thèses des astrologues (al-munağğimūn) ${ }^{30}$.

27. Le texte du Qāḍī 'Iyāẹ doit être lu tel que l’ont publié les éditeurs égyptiens du Tamhīd (257-259), plutôt que dans l'édition libano-libyenne des Madārik (2/601-602) que gâtent de grosses fautes de lecture (lire at-tağwīr au lieu d'at-tağrīh ; al-imāma au lieu d'al-amāna ; al-ma'dūm au lieu d'ar-rūm).

28. Éd. Kawțarī, Le Caire, 1359/1940, 119.

29. Les informations tirées du ms $C$ ont déjà été mises à profit par Aḥmad Șaqr dans la préface de son édition du K. I'ğāz al-Qur'ān.

30. Rappelons qu'IBN TAYMIYYA cite ces mêmes Daqāiq al-kalām dans son livre Bayān muwāfaqa șarịh al-ma'qūl li-șahịh h. al-manqūl à propos des divergences entre falāsifa. Rappelons aussi que, dans le langage des théologiens, l'expression daqīq al-kalām, doublet de lațîf al-kalām, désigne les questions de caractère "philosophique" (lois de la substance et de l'accident). 
- Al-Imāma al-kabìr ${ }^{31}$, al-Imāma aș-șagìir. Deux fois dans le ms du Caire B. mentionne "les deux livres sur l'imamat ${ }^{32 " ~(k i t a ̄ b a y ~ a l-i m a ̄ m a) . ~ E n ~ C ~ 72 b, ~ i l ~ d i t ~ y ~ a v o i r ~ d e ́ m o n t r e ́ ~ q u e ~}$ le prophète Muhammad ne s'est jamais vu opposer un rival du Coran (lam yu'äraḍ bi-mițli l-Qur'ān) ; il renvoie également sur ce point au Kitāb al-Ahbār de ses Ușūl al-fiqh (voir plus bas) ${ }^{33}$. En C 229a, il dit y avoir traité longuement de la question du miracle de la lune fendue (inšiqāq al-qamar, cf. Cor. 54,1) et de la réponse à l'objection : "si le phénomène s'est réellement produit, comment expliquer qu'il n'ait pas été universellement observé et rapporté ?". On voit donc - non sans surprise - que ces deux livres sur l'imamat, y compris celui de faibles dimensions, incluaient une démonstration détaillée de la prophétie de Muhammad à partir des différents miracles censés l'attester.

- Al-Intișār li-l-Qur'ān ${ }^{34}$. Tel est le titre indiqué par le Qāḍ̄ 'Iyāḍ, et c'est celui, en effet, que porte l'unique manuscrit d'Istanbul ${ }^{35}$ : on le retrouve aussi, notamment, sous la plume de Subki ${ }^{36}$. Mais la Hidāya nous montre que B., pour sa part, usait d'un titre plus ajusté. Quand il cite l'Intișār (ce qu'il fait à quatre reprises dans le fragment du Caire), il ajoute chaque fois au libellé ci-dessus le mot naql. Car ce qu'il entend pour le coup "faire triompher", ce n'est pas, à proprement parler, le Coran lui-même mais la transmission qui en a été faite depuis les premiers califes. Il s'agit de montrer - contre les chiites tout spécialement - que le Livre a bien été transmis tel qu'il a été révélé, sans altération ni mutilation. Le titre correct serait donc, sous sa forme la plus simple, celui qui figure en $C$ 156b et 175b : al-Intișār li-naqli l-Qur'ān ${ }^{37}$. En C 66a, l'intention de l'ouvrage est précisée par un deuxième élément de titre ajouté au premier : al-Intișār li-naqlil-Qur'ān wa r-radd 'alā man nahalahu l-fasād bi-ziyāda aw nuqșān. Elle est précisée d'une autre façon en C 143a, où cette fois le livre est intitulé : al-Intișār li-șihhati naqli l-Qur'ān. Cette dernière référence est, du reste, particulièrement intéressante, $B$. ayant jugé bon pour l'occasion de l'accompagner d'un substantiel sommaire de l'ouvrage, ainsi rédigé ${ }^{38}$ :

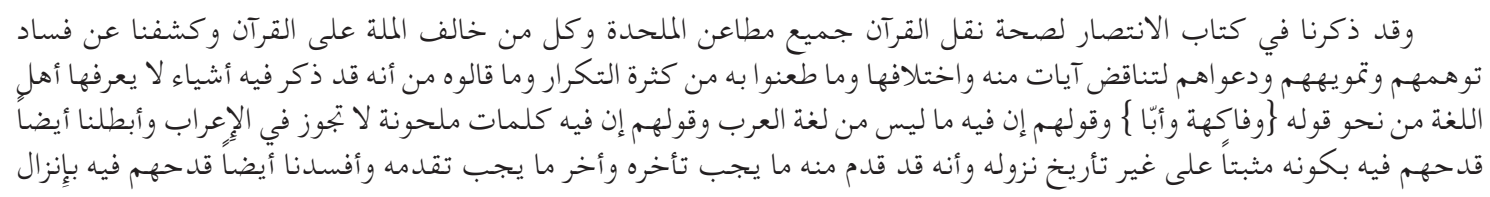

31. C'est ainsi qu'il faut lire, et non al-kabīra ; et de même aṣ-ṣagìir au lieu d'aṣ-șagìira.

32. Il s'exprime pareillement au t. 1 du K. al-Intișār, éd. al-Qiyyām (voir ci-dessous), 28, 90, 149. Mais curieusement, au t. 2 du même ouvrage, c'est le singulier qu'il emploie : Kitāb al-Imāma (48, 61, 71).

33. Remarquons que, sur cette question de la mu'ārada, B. ne juge pas utile de renvoyer à ce qu'il en dit dans le Tamhìd (éd. McCarthy, 144-150).

34. Et non fïl-Qur'ān comme l'ont lu les éditeurs égyptiens du Tamhīd, sans doute à l'imitation d'Ibn Hazm qui cite toujours ainsi l'ouvrage de B.

35. Voir la photographie de la page de titre dans l'excellente édition (mais, hélas, dépourvue d'index) publiée récemment par 'U. H. AL-QIYYĀM (Beyrouth 2004).

36 Dans ses Ṭabaqāt aš-Šāfitiyya, Le Caire 1965, 3/258.

37. Titre que confirme celui donné par ABŪ 'ABD ALLĀH AṢ-ṢAYRAFĪ à son Abrégé de l'Intișār : Nukat al-Intișār li-naql alQur'ān.

38 Ce passage a déjà été publié par AḤMAD ȘAQR (avec quelques différences de lecture) dans l'introduction au K. I'ǧāz al-Qur'ān. 


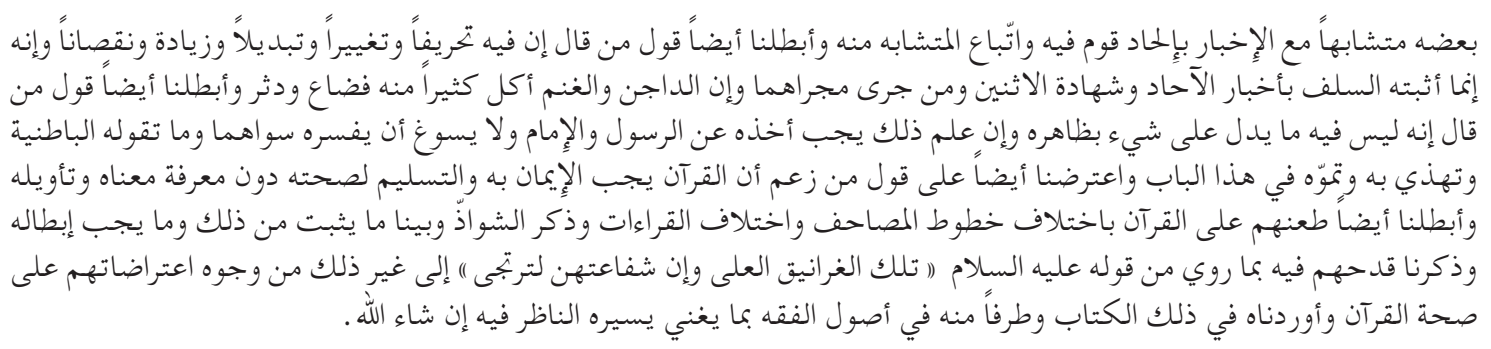

À lire cette copieuse "table des matières", on s'aperçoit qu'en réalité le contenu du livre s'étend bien au-delà de son propos initial, celui d'établir la validité du texte coranique tel qu'actuellement connu. Et si B. se trouve y faire référence dans son Kitāb an-Nubuwwāt, c'est sur une question encore différente, non mentionnée ci-dessus, et qui, à première vue, n'y a guère sa place, celle de l'íğāz prophétique ${ }^{39}$. En C 66a, il dit y avoir établi la réalité du défi (tahaddī) lancé aux Arabes par Muhammad de lui opposer un rival du Coran. En C 156b, il dit y avoir traité en détail des paroles du Prophète attestant son pouvoir miraculeux de prédire l'avenir (al-ihbār 'ani l-g̈uyūb). Enfin, en C 175b, c'est sa réponse à une objection arguant de l'impossibilité de connaître le caractère miraculeux du Coran qu'il dit y avoir longuement développée.

- Šarh al-Luma', commentaire, rappelons-le, du K. al-Luma d'Ašarī. En F 62a, B. dit y avoir énuméré quantité de points sur lesquels les mu'tazilites (qadariyya) se trouvent en accord avec les Mages ${ }^{40}$.

- At-Tamhīd. En C 61b, B. renvoie à ce qu'il y a dit contre les juifs, les chrétiens et les mages.

- Tașarruf al-'ibād. B. donne en F $112 b$ le titre complet : K. Ahkām tașarruf al-'ibād. Il y renvoie concernant la différence que l'homme ressent spontanément entre un mouvement contraint et un mouvement "acquis".

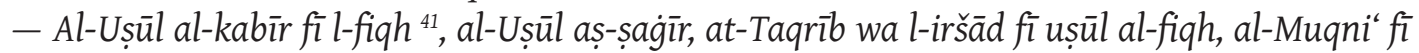
ușūl al-figh. B. ne mentionne nommément aucun de ces titres, mais parle globalement de ses "livres d'ușūl al-figh" (C 184a et 246a). En F 70b-71a, il dit y avoir expliqué la formule prêtée notamment au calife "Umar lorsque celui-ci avait recours à son jugement personnel (ra'y) pour trancher d'un point de droit: "Si <ma décision> est juste, elle vient de Dieu ; si elle est erronée, elle vient de moi". Selon lui, l'erreur en question ne pouvait concerner que la conduite de l'iğtihād, non le jugement (hukm) auquel aboutit cet iğtihād dès lors qu'il est correctemnt mené, le principe étant qu'en matière de droit positif tout muğtahid dit juste

39. Mais de fait, dans la préface de l'Intișār, B. annonce bien qu'il abordera cette question : tumma nubayyinu anna l-Qur'ān mu'ǧizat un li-r-rasūl șl'm wa dalālat ${ }^{u n}$ 'alā șidqihi. Nous connaissons même par Ibn Hazm le titre du chapitre concerné (al-Fișal, Le Caire 1317-1321, 4/222) : bāb ad-dalāla 'alā anna l-Qur'ān mu'ǧiz li-n-nabì șl'm. Précisons que cette partie relative à l'i $i^{\prime} \bar{a} z$ ne figure pas dans le ms d'Istanbul, qui ne comprend malheureusement que la première moitié du livre.

40. Sur le contenu du Šarh al-Luma', outre les références du K. al-Intișār (2/71, 192, 259) et du K. al-Bayān (§ 104), on notera particulièrement celles du Šāmil de Ğuwaynĩ qui, rappelons-le, n'en est lui-même qu'un commentaire, cf. Šm 123, 192, 211, 221, 273.

41. Dont Abū l-Muẓaffar al-Isfarā'īnī dit qu'il comportait 10000 feuillets. 
(un principe rappelé à nouveau en C 245a). En C 72b, B. mentionne l'existence, dans ses Ușūl al-fiqh, d'un Kitāb al-Ahbār ; il y avait démontré là aussi qu'il n'y a jamais eu mu'âraḍa visà-vis du Prophète. En C 184a, traitant de l'éloquence (balāga) du Coran, il dit avoir exposé "dans les livres d'uṣūl al-fiqh" en quoi consiste le bayān (autre terme signifiant l'éloquence) et quelles en sont les différentes sortes. Enfin en C 246a, il dit y avoir distingué les diverses catégories d'actes du Prophète (aqsām af'āl ar-rasūl) selon qu'ils entraînent ou non pour le fidèle obligation de les imiter. Précisons qu'aucun des points ci-dessus mentionnés ne figure dans ce qui a été publié du K. at-Taqrīb ${ }^{42}$.

\section{Livres non cités par le Qāḍ̄ ‘Iyāḍ.}

- Al-Farq bayna l-mu'ǧizāt wa l-karāmāt, ou al-Farq bayna mu'ğizāt an-nabiyyīn wa karāmāt aṣ-șālihịn. Je considère en effet que les deux titres figurant dans la liste du Qāḍ̄ì 'Iyāḍ, et fort éloignés spatialement l'un de l'autre (fì l-Mu'ǧizāt, puis 13 titres plus bas : al-Karāmāat) ne peuvent être tenus véritablement comme une attestation du Farq, même s'ils peuvent en être un lointain souvenir ${ }^{43}$.

Les titres donnés au livre dans la Hidāya sont en réalité des formules abrégées ${ }^{44}$. Le titre véritable, ici encore, est beaucoup plus long, et c'est celui que porte l'unique manuscrit actuellement connu - le manuscrit de Tübingen édité par McCarthy (Beyrouth 1958) - à savoir K. al-Bayān 'ani l-farq bayna l-mu'ğizāt wa l-karāmāt wa l-hiyal wa l-kihāna wa s-siḥr wa $n$-nāranğăt ${ }^{45}$. Titre doublement confirmé par Ibn Taymiyya qui, dans son K. an-Nubuwwāt, cite à plusieurs reprises l'ouvrage du Qāḍ̄i (mais pour en faire une critique féroce). À une nuance près cependant: la première fois (Nub 44), il omet dans le titre les mots al-Bayān 'an, alors qu'il les rétablit la seconde fois ( $N u b$ 290). Un temps, j'ai pensé qu'il pourrait s'agir là en réalité de deux livres différents, d'autant qu'au début du Bayān (§ 4), B. dit avoir déjà quelques années auparavant dicté un "discours" (kalām) sur le même sujet, et s'il y revient maintenant, dit-il, c'est parce qu'on lui a demandé des éclaircissements sur certains chapitres de son exposé (šarh al-qawl fífusūul hād eu d'abord un Farq, puis plus tard un Bayān 'ani l-Farq. Mais l'hypothèse est manifestement à rejeter, si l'on en juge par les nombreux extraits qu'Ibn Taymiyya dit tirer du K. al-Farq, et qui se retrouvent quasi littéralement dans le Bayān ${ }^{46}$. Il n'en va pas de même, il est vrai,

42. La question des actes du Prophète y est abordée dans le "deuxième tome" annoncé au terme du troisième volume.

43. Dans son K. an-Nubuwwāt (Beyrouth 1405/1985, 372), Ibn Taymiyya attribue à B. un Kitāb al-Mu'ğizāt. Est-ce pour lui une autre façon de désigner le Farq auquel il a fait antérieurement maintes références (voir ci-après) ou s'agit-il d'un ouvrage différent?

44. Tout comme celui fourni par Taqrïb 1/439 : al-Farq bayna mu'ǧizāt ar-rusul wa karāmāt al-awliyā'.

45. Ainsi, bizarrement, ce terme est-il vocalisé dans le ms, tant dans le titre que dans le corps du texte, alors que la forme correcte (issue du pehlevi) est nīranğāt. Voir sur ce point le commentaire de McCarthy, Bayān, introduction arabe 17 n. 18. Ibn Taymiyya, pour sa part, a bien lu nìranğāt (voir ci-après).

46. Nub 47,3-7 = Bayān 72,17-73,6; Nub 47,8-13 = Bayān 73,9-16; Nub 47,19-48,4 = Bayān 94,6-95,5; Nub 48,5-15 = Bayān 95,12-96,11; Nub 48,16-49,5 = Bayān 93,3-94,7; Nub 206,23-207,3 = Bayān 55,4-11; Nub 208,1-7 = Bayān 45,1146,6 . 
d'autres citations ${ }^{47}$, mais c'est sans doute qu'elles renvoient à des parties manquantes du Bayān : car il faut rappeler que le ms de Tübingen est incomplet et ne contient peut-être que le premier tiers du livre.

Le Farq est mentionné trois fois dans la Hidāya. Si la première référence (F 27b) ne fait que rappeler l'objet du livre, les deux autres renvoient, elles aussi, à des parties manquantes du Bayān. En C 243a, B. dit avoir expliqué dans le Farq la signification du mot nabì à partir des deux étymologies qu'on en donne ("action d'annoncer", "élévation de terrain"). À la même page, il dit y avoir aussi exposé "l'ensemble des qualités (sifiāt) que les Envoyés doivent avoir en propre"; puis au terme de cinq pleines pages reprenant l'énumération de ces qualités, il répète avoir déjà dit tout cela dans le Farq (C 244b).

- Ğawābāt Abī Sa'd ${ }^{48}$ az-Zāhid an-Nīsābūrī. En F 27b, l'auteur dit s'être longuement étendu dans ces "Réponses" sur la distinction à opérer entre mu'ğiza et karāma. Abū Sa'd an-Nīsābūrī, m. 407, est un contemporain de Bāqillānī et appartient à la même "classe" de théologiens aš‘arites ${ }^{49}$. Il a écrit sur "les preuves de la prophétie ${ }^{50 " ~(d a l a ̄ i l ~ a n-n u b u w w a) . ~}$

- Ibāna 'ağz al-qadariyya 'an ițbāt dalä’il an-nubuwwa. Titre mentionné deux fois sous cette forme (F 27b et 119b). Un titre différent, mais désignant très probablement le même livre, apparaît en C 11a : Ta'rî́' 'ağz al-mu'tazila 'an tașhīh dalā'il an-nubuwwa ${ }^{51}$. L'idée que les mu'tazilites, en vertu de leurs thèses mêmes, sont dans l'incapacité d'établir ce qui, pour les théologiens musulmans, constitue le fondement de la croyance en la prophétie - à savoir que le miracle est la preuve que les Envoyés disent vrai (dalālat al-mu úgiz 'alā șidqi r-rusul) - est un thème cher à Bāqillānī. Il y a consacré un chapitre du Bayān (éd. McCarthy $\S \S 76-81$ ), et il y revient, on l'a vu, dans un chapitre de la Hidāya (45b-61b). Ce n'est pourtant pas là que se situent les références relevées ci-dessus. En F 27b, B. cite l'Ibāna à côté du Farq comme l'un des deux ouvrages où il a traité longuement de la différence entre le miracle d'une part, la magie, la divination, etc. d'autre part. En F 119b, c'est au cours de la discussion du tawallud qu'il rappelle avoir montré, dans l'Ibāna, que l'incapacité en question frappe en particulier ceux des mu'tazilites qui, comme notamment Ǧăhiz, admettent la notion de "nature" (al-qā'ilīn bi-fi'li ț-tibāa), une démonstration qu'il refera le moment venu (C 60b). Enfin en C 11a, il dit avoir abondamment répondu (ašba'nā l-qawl fi hādihi l-mas'ala), dans ce qu'il appelle cette fois Ta'riff, à l'objection mu'tazilite selon laquelle, si rien n'est mauvais de la part de Dieu comme le soutiennent les théologiens sunnites, rien n'empêche qu'Il fasse apparaître un miracle au bénéfice d'un imposteur.

- Mã yúallalu wa mā lā yúallalu, "ce à quoi on peut attribuer une cause et ce pour quoi cela est impossible". La question du ta'līl, très présente dans les traités mu'tazilites ${ }^{52}$, a été aussi, manifestement sous l'influence des thèses d'Abū Hāšim al-Ğubbāî̀, une des

\footnotetext{
47. Notamment Nub 51,16-52,10 ; 52,14-53,3 ; 53,6-11.

48. Le ms porte fautivement $A b \bar{i} \mathrm{Sa}{ }^{\mathrm{i}} \mathrm{i} d$.

49. Cf. Tabyin 233-236.

50. Cf. le K. al-Ġunya d'ABū L-QĀsIm AL-AnȘĀRĪ, ms d'Istanbul $201 \mathrm{~b}$.

51. Autre intitulé encore dans Taqrīb 1/407: Ta'rîf 'ağzi l-mu'tazila 'an îtbāt dalā’il an-nubuwwa wa șihhatihiha 'alā madāhib al-mutbita.
}

52. Voir en troisième partie mon commentaire du $\S 35$. 
préoccupations de Bāqillānī. Les toutes premières pages du ms de Fès, hélas terriblement mutilées, y font abondamment allusion, et on y revient plus loin (F 13b - 15a) s'agissant d'établir ce qui est cause de l'inexistence de l'inexistant (ta'îl 'adam al-ma'dūm). B. a écrit aussi un $K_{\text {. }}$ al- $^{-}$Ilal $^{53}$, plusieurs fois cité dans le Šāmil ${ }^{54}$. Le K. Māyu'allalu..., pour sa part, est mentionné une fois dans le Šāmil ; selon Ǧuwaynī, B. y soutenait le même point de vue que dans la Hidāya (voir plus haut) quant au fait que même les qualifications que les existants détiennent du fait de leur essence sont l'œuvre d'un agent (kulluhā bi-l-fā'il), contrairement à ce qu'il disait auparavant, en particulier dans le Naqd an-naqd, et qui était le point de vue mu'tazilite (Šm.T. 28). Dans nos fragments de la Hidāya, l'ouvrage apparait également une fois, dans le Kitāb at-Tawallud (F 111a-b) ; B. dit y avoir réfuté longuement sur ce point les thèses des Ğubbā’̄ père et fils.

- Naqd an-naqd ${ }^{55}$. Citée le plus souvent sous ce titre énigmatique, cette "réfutation de la réfutation" n'est autre ${ }^{56}$ que la réplique de Bāqillānī au Naqḍ al-Luma - lui-même réfutation du K. al-Luma' d'Aš'arī - de son illustre contemporain mu'tazilite 'Abd alĞabbār ${ }^{57}$. Certaines références de la Hidāya sont à cet égard explicites, quand $\mathrm{B}$. donne à sa "Réfutation" des titres tels que : Naqḍ al-kitāb al-mutarğam bi-Naqd al-Luma" (F 120b), ou Naqd Naqd al-Luma“ (C 11a et 30a). D’autres références non moins précises indiquent le nom de l'adversaire mis en cause, que B. ne désigne en l'occurrence que par sa seule nisba d'al-Hamad̄ānī: Naqụ al-kitāb al-mutarğam bi-Naqḍ al-Luma' li-l-Hamad̄ānī (F 60b) ou plus simplement Naqd an-naqd 'alā l-Hamadānī (F 93b, C 119b) ou encore an-Naqḍ 'alā l-Hamad̄ānì (F 152a). Chez les auteurs postérieurs, outre le simple titre Naqd an-naqd, l'ouvrage est souvent appelé an-Naqd al-kabīr ${ }^{58}$, un intitulé auquel, à en croire Abū l-Qāsim al-Anșārī, B. lui-même aurait également eu recours ${ }^{59}$. Que ce qualificatif de kabìr soit amplement mérité, cela ne saurait faire de doute. Car contrairement à ce qu'on pourrait croire, le Naqd an-naq d n'est aucunement un opuscule de circonstance mais bien un traité de théologie en bonne et due forme et d'un volume peut-être comparable à celui de la Hidāya. On verra dans l'extrait reproduit plus loin qu'il comportait un Kitāb at-Tawallud (F 120b ; cf. également C 30a) ; B. dit y avoir "développé longuement", selon son expression habituelle (taqașsaynā l-qawl fïhi) - c'est-à-dire : plus longuement encore ? - ce qu'il redit maintenant dans la

\footnotetext{
53. Peut-être identique à l'ouvrage intitulé al-Ahkām wa l-ilal dans la liste du Qāḍ̄ì 'Iyāḍ, et dont le titre véritable pourrait être k. Ahkām al-ilal. Ǧuwaynī, rapportant qu'Ibn Fūrak ("al-ustāâd Abū Bakr") a composé un commentaire critique (tașaffuḥ) de l'ouvrage de Bāqillānī, écrit à son propos : kitāb taṣaffaha fìhi aḥkām al-'ilal li-l-Qāḍ̄ (Šm 631-632 ; cf. ibid. 692).
}

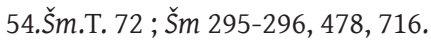

55. Cet ouvrage ne figure pas dans la liste du Qāḍ̄i ‘Iyāḍ, contrairement à ce que prétend l'éditeur du Taqrīb 1/76.

56. Cf. Ibn Taymiyya, K. an-Nubuwwāt 62.

57. Le Naqḍ al-Luma' figure dans la liste que 'Abd al-Ǧabbār donne de ses propres œuvres à la fin du Muginī (M XXb 258). Il le cite également en M VIb 71, VII 59, VIII 32, XI 454.

58. Cf. notamment Šm.T. 27, 30, 93 ; ̌̌m 570 et 630.

59. À propos des noms qu'il est ou non licite d'appliquer à Dieu, B. aurait écrit concernant un premier point de vue auquel il avait ensuite renoncé : qad nașarnā hādihi t-țarīqa fì n-Naqḍ al-kabīr wa ṣ-șaḥị 'indanā al-ān hilāfuhā. Cf. Šarḥ al-Iršād 136a, à corriger par Gunya 97a-b. 
Hidāya ${ }^{60}$. Mais il y abordait aussi quantité d'autres sujets : si, par exemple, les atomes ont une forme (šakl) (Šm 159); ce qu'il en est de la substance dans l'instant où elle vient à l'être (Šm 233) ; si les "localisations" (akwān) déterminent un "état" (hāl) de leur réceptacle (mahall)(ك̌m 630); la distinction que l'homme fait spontanément entre un mouvement contraint et un mouvement "acquis" (F 112b) ; le rapport de la puissance à l'acte (F 152a) ; celui de la volonté (F 129a); qui sont les qadariyya que le Prophète comparait aux mages (F $60 \mathrm{~b}$ et $93 \mathrm{~b})$; etc.

On voit, au terme de ce recensement, la distance qui sépare le peu que nous possédons de l'œuvre de Bāqillānī de tout ce qui d'elle nous échappe et ne nous est ainsi révélé que par quelques furtives allusions. Mais cette situation, on le sait, n'est pas propre à l'auteur de la Hidāya, elle vaut pareillement pour son maître Ašarī, et de façon plus criante encore pour ces deux théologiens mu'tazilites auxquels ils doivent tant l'un et l'autre, les Ǧubbā'̄i, et dont rien n'a survécu ${ }^{61}$.

À lui seul en tout cas, cet apport considérable qu'elle fournit d'informations bibliographiques nouvelles atteste déjà l'extraordinaire richesse de contenu de la Hidāya. Mais de cette richesse témoigne plus encore le très remarquable échantillon que constitue, dans l'ouvrage de Bāqillānī, le "livre" où celui-ci traite du classique problème de la génération des actes, et que je vais maintenant présenter.

\section{DEUXIÈME PARTIE : LE KITĀB AT-TAWALLUD, CONTREPOINT ET COMPLÉMENT DES SOURCES MU'TAZILITES ${ }^{62}$ SUR LE SUJET}

La réalité ou non du tawallud est de ces questions qui opposent rituellement théologiens sunnites et mu'tazilites ; tout traité de kalām se doit donc de l'aborder, et la Hidāya n'échappe pas à la règle. Il s'agit de savoir, rappelons-le, si l'action de l'agent humain peut s'étendre au-delà de ce qu'il produit immédiatement dans "le réceptacle de sa puissance" (mahall qudratihi), c'est-à-dire dans son propre corps ${ }^{63}$ : "actes des membres" comme marcher, lancer, frapper; "actes du cœur" comme vouloir, raisonner, connaître. Les mu'tazilites disent que oui, sauf qu'ils divergent sur la portée d'une telle affirmation ${ }^{64}$. Pour eux, l'homme a capacité d'agir sur ce qui lui est extérieur, des événements s'y produisent qui sont la conséquence d'actes qu'il accomplit en lui-même, "engendrés" par eux, et qui, de ce fait, relèvent pareillement de sa puissance. Ainsi est acte de sa part non seulement le

60. Et cf. également, toujours à propos du tawallud, F 111b, 120b, 124b, $125 \mathrm{~b}$.

61. Voir respectivement mes articles « Bibliographie d'Aš̌arī : un réexamen » (Journal asiatique, 1985) et « Matériaux pour une bibliographie des Ğubbā'̄i » (Journal asiatique, 1976).

62. J'inclus dans ces sources les deux premières parties des Maqālāt d'Ǎ̌śĀi (1-482) qui, comme l'a solidement établi ALLARD, appartiennent à la période mu'tazilite de l'auteur antérieure à sa conversion (Le problème des attributs divins, 67-72).

63. Car c'est bien de cela qu'il s'agit au départ et pour l'essentiel. Je n'oublie certes pas que parmi les actes "engendrés" il en est aussi que l'individu humain produit en lui-même, comme notamment la science qu'engendre en lui le raisonnement. Mais ce sont là des cas particuliers, qui imposent simplement d'affiner les définitions respectives de l'acte qualifié de "direct" (mubāšir) et de celui dit "engendré" (mutawallid), comme on le verra ciaprès aux $\S \S 54-55$ du texte de $B$.

64. Certains l'ont poussée à l'extrême, comme le "bagdadien" Bišr b. al-Mu'tamir, cf. ci-après § 92. 
mouvement du bras qu'il exécute pour lancer un projectile, mais aussi le mouvement dudit projectile "engendré" par ce mouvement du bras. De même en va-t-il du son que je produis en heurtant l'un contre l'autre deux corps durs, de la douleur que je fais naître en autrui en le frappant du poing: ce son, cette douleur sont tout autant mon acte.

Les théologiens sunnites refusent, quant à eux, cette façon de voir. Pour eux, ce que les mu'tazilites disent être "engendré" par telle ou telle action de l'homme est en réalité l'œuvre de Dieu. Et si nous avons l'impression d'une consécution nécessaire entre notre acte et l'effet qui parait en résulter, c'est simplement, disent-ils, parce que Dieu par habitude ('alā tarì al-'āda) - mais sans que rien ne l'y oblige - fait régulièrement se produire le second à la suite du premier.

Tel est le point de vue que, naturellement, B. s'emploie ici à faire valoir. Son kitāb attawallud comporte donc, comme il se doit, une réfutation en règle de la doctrine mu'tazilite, et cela selon la procédure habituelle des traités de kalām: d'abord l'énoncé d'arguments (adilla) montrant la fausseté de la thèse adverse (\$§ 1-28); puis la réfutation de "pseudoarguments" (šubah) invoqués en faveur de celle-ci (\$§ 29-53).

B. aurait pu s'en tenir là, comme il l'avait fait dans le passage correspondant du Tamhìd (éd.McCarthy p.297-302). Mais tel n'est pas le cas ici, et en cela résidel'intérêt tout particulier du présent $k$. at-tawallud. La réfutation (ibtāl) proprement dite n'y est, en quelque sorte, qu'une entrée en matière ; B. a jugé bon cette fois de la faire suivre d'un exposé détaillé et toujours, bien sûr, systématiquement critique - des principales questions soulevées au sein même de l'école mu'tazilite par la doctrine du tawallud: définitions diverses de l'acte "direct" et de l'acte engendré (\$§ 54-62); quels accidents sont susceptibles d'en engendrer d'autres et ont donc le statut de "causes génératrices" (asbāb muwallida) (\$§ 64-65); exposé et réfutation de thèses mu'tazilites dissidentes relativement à la vulgate ğubbā'ite et invoquant pour la plupart la notion de "nature" (§§ 66-91), un exposé où s'insèrent une longue digression visant à établir que la substance n'a pas de contraire (\$§ 81-84) ainsi qu'une analyse des thèses de Șālih Qubba (§§ 86-88); les divergences entre mu'tazilites quant à savoir quels accidents sont susceptibles d'être engendrés par d'autres (\$§ 92-104) ; si l'acte engendré, quand il existe, relève encore de la puissance de qui l'accomplit (§§ 105-108); si Dieu peut agir par voie de génération, et si ce qu'Il produit de la sorte Il peut également le produire par voie directe (\$§ 109-118); quels modes possibles de génération entre actes bons et actes mauvais (§§ 119-123); à quel moment se repentir d'un acte engendré (\$§ 124-128).

Cette abondance de matière, où rien apparemment n'est laissé de côté, est un premier trait remarquable du k. at-tawallud. Mais plus remarquable encore est la qualité de son information, comme l'atteste de multiples façons le commentaire qu'on lira à sa suite. Sur quantité de points en effet, ce que dit B. des positions mu'tazilites trouve sa confirmation dans tels passages du Muginī de 'Abd al-Ǧabbār et/ou de la Taḍkira d'Ibn Mattawayh ${ }^{65}$. Le fait est particulièrement sensible concernant "Ibn al-Ǧubbā' '̄", autrement dit Abū Hāšim, le personnage de loin le plus souvent cité (quinze fois en tout). Non seulement B. connaît

65. Je ne relève qu'une erreur véritable, à propos d'Abū 'Alī (\$ 64). Encore qu'il ne faille pas exclure, sur le point considéré, la possibilité d'une variation d'opinion (ihtiläf) comme il en existe tant d'exemples par ailleurs. 
de ce dernier, par exemple, un célèbre argument en forme d'ilzām par quoi il démontrait, contre Abū 'Alī, que la cause génératrice du mouvement n'est pas le mouvement même mais la pression, et comment à partir de là il expliquait le retour au sol d'une pierre lancée vers le haut (\$97); ou bien son spectaculaire changement d'opinion quant à la possibilité pour Dieu de produire aussi par voie directe ce qu'Il produit au moyen de causes (§§ 106107 et 116-118); ou bien encore ses incertitudes touchant le châtiment d'un acte engendré (\$128). Mais à trois reprises au moins, B. s'exprime comme s'il rapportait littéralement des dires d'Abū Hāšim (cf. $\$ \S 65,97,120)$. D'où tire-t-il ces citations, s'il s'agit bien de citations ? Peut-être de 'Abd al-Ǧabbār, dont il a lu au moins, puisqu'il en a écrit une réfutation, le Naq d al-Luma ${ }^{66}$; mais peut-être aussi, et plus probablement, des ouvrages d'Abū Hāšim en personne, alors encore en circulation. Car il faut avoir à l'esprit qu'à l'époque où $B$. compose sa Hidāya, le mu'tazilisme tient encore le haut du pavé, protégé qu'il est par le pouvoir en place (les émirs būyides), et sa littérature demeure aisément accessible ${ }^{67}$. Nous aurions donc là, si tel est bien le cas, une information de première main.

Ce qui, du même coup, conduit à prendre au sérieux diverses données fournies ici par B. et qui, pour leur part, n'ont pas leur équivalent dans nos autres sources : ainsi ce curieux argument qu'il prête aux mu'tazilites en faveur du tawallud, probablement abandonné par eux par la suite, à partir du mouvement des poils et autres parties non vivantes de l'ensemble humain (\$ 48); telle définition de l'acte "direct" admise, selon lui, par "la grande majorité d'entre eux" (al-ğumhūr minhum) (\$ 54); la thèse qu'il attribue aux Ğubbā’î̀ père et fils, selon laquelle ce qui est "générateur" au sens propre, ce n'est pas la cause (assabab) mais l'agent de la cause (fā'il as-sabab) (§ 63); deux points de vue défendus, selon lui, par 'Abbād b. Sulaymān (§§ 105 et 124); et peut-être aussi (mais B. pour le coup ne fait-il pas erreur?) l'idée assez surprenante qu'il prête à "Ibn al-Ğubbā'î et ses partisans" selon laquelle il serait impossible même à Dieu de produire un assemblage ( $\left(a^{\prime} l i \hat{f}\right)$ autrement que par génération ( $\$ 102)$.

Il est clair en tout cas que si, un jour, ce dossier du tawallud devait être repris pour quelque travail universitaire, ces pages de la Hidāya, au titre de la documentation, devraient obligatoirement être prises en compte.

Une autre source, plus convenue, a été également mise à profit par Bāqillānī, lui fournissant bon nombre de ses rubriques : les Maqālāt d'Aš̌arī, ou quelque autre répertoire de cette nature. À cet égard aussi, son texte est précieux, en ce qu'il permet, au moins sur trois points, de corriger et compléter le texte d'Ašarī tel qu'il est actuellement proposé (§§ 61-62,119 et 124).

Voici donc ce kitāb at-tawallud ${ }^{68}$, dont, comme annoncé, je proposerai ensuite un commentaire.

66. Notons au passage qu'il renvoie six fois ici à son Naqụ an-naqd.

67. Dans son Šāmil, Ǧuwaynī cite deux livres d'Abū Hāšim, al-Baġdādiyyāt et al-Abwāb (cf. Šm 471-72), peut-être d'après le Šarh al-Luma' de B. Il cite également le K. al-Abwāb dans son traité d'uṣūl al-figh intitulé al-Burhān, Le Caire $1400 \mathrm{~h}, \S 41$.

68. Sa division en chapitres numérotés est naturellement de mon fait. 


\section{كتاب التولّد}

\section{باب القول في إبطال التولّد [ ج 9 أ]}

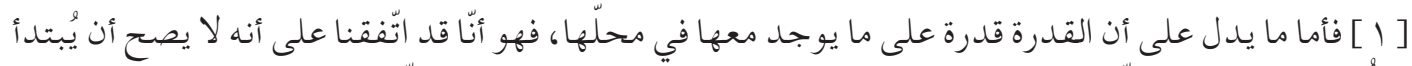

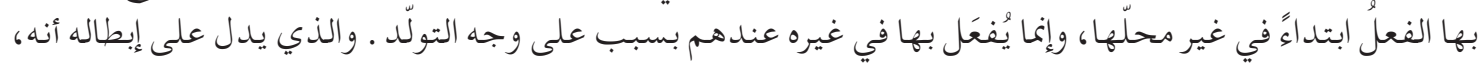

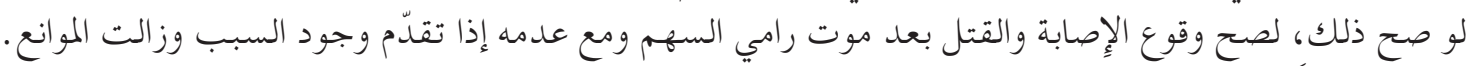

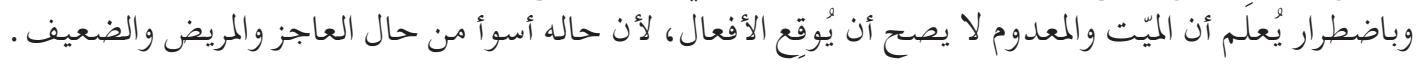

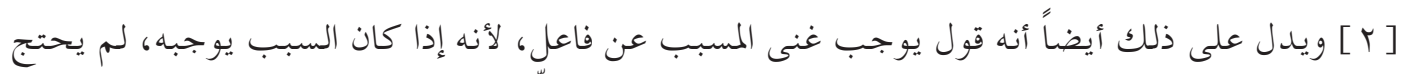

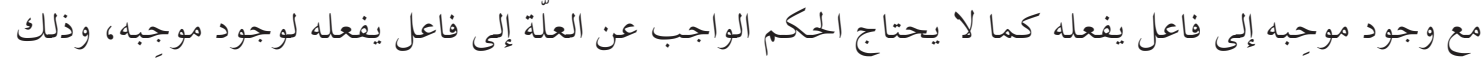

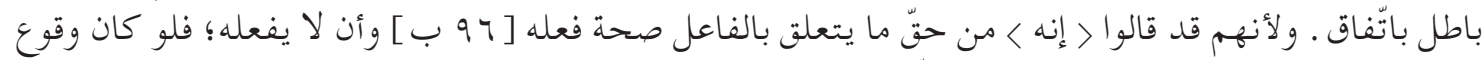

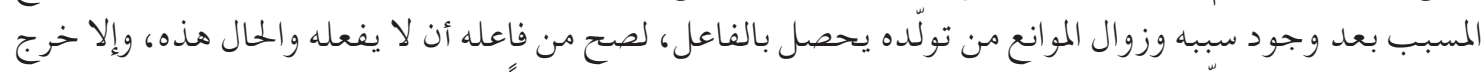

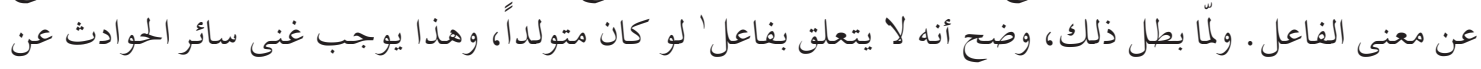

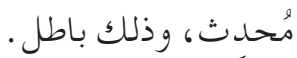

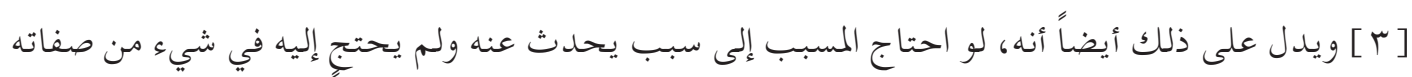

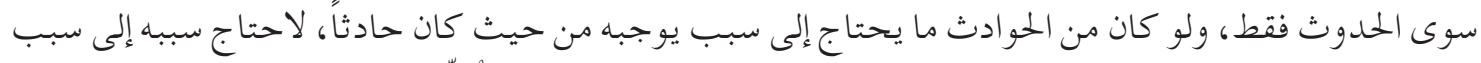

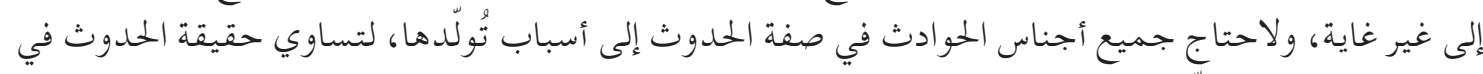

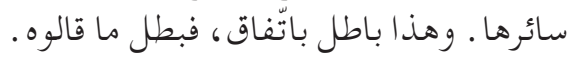

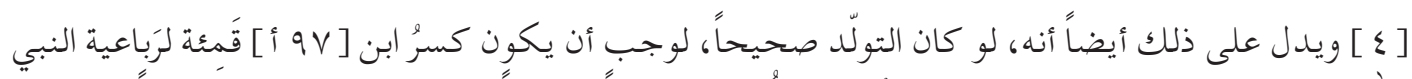

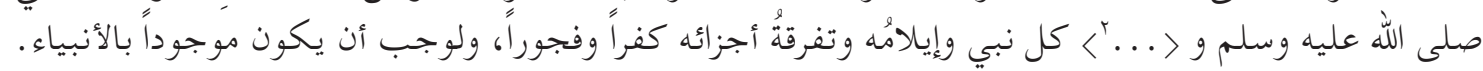

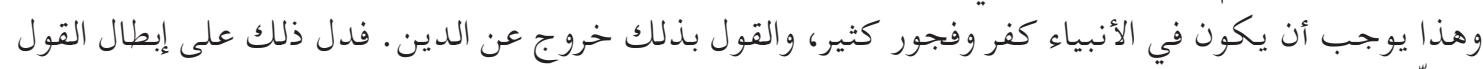

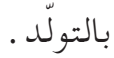

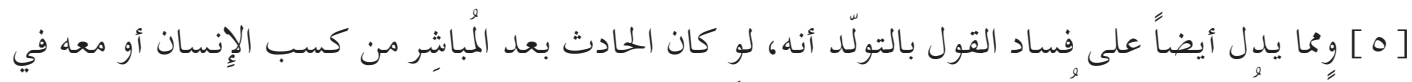

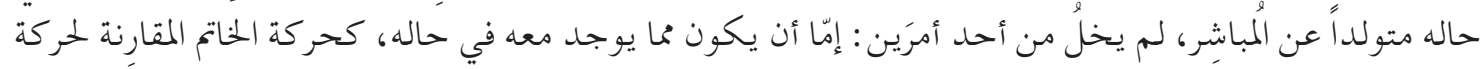

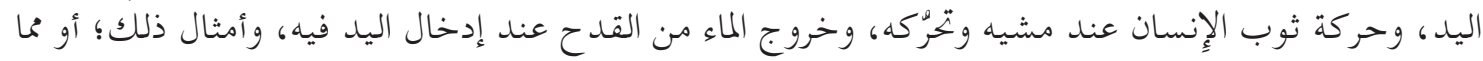

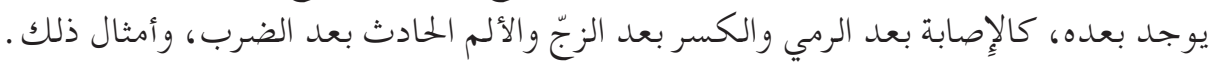

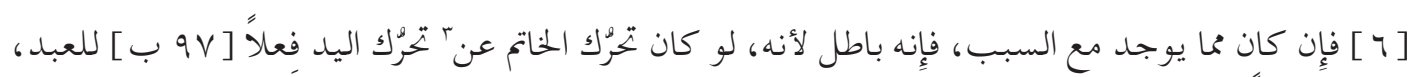

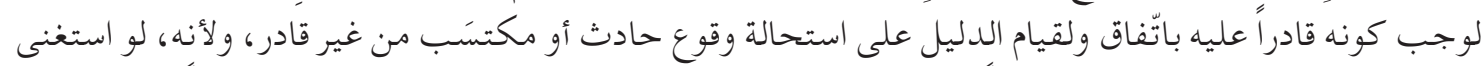

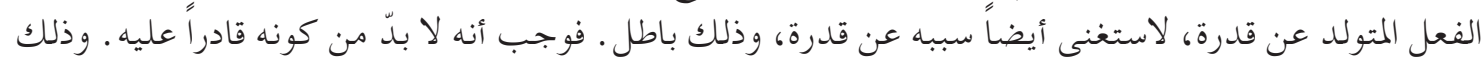


مُحال، لأنه لا يخلو أن يكون قادراً على السبب والمسبب عندهم بالقدرة على سببه، أو بقدرة غير القدرة على [ [Vإِن كان قادراً عليه بالقدرة على سببه، فذلك مُحال لأنه قول يوجب كون القدرة الواحدة الحادثة قدرةً

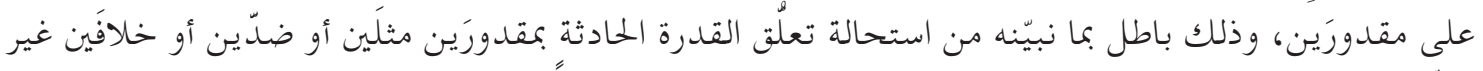

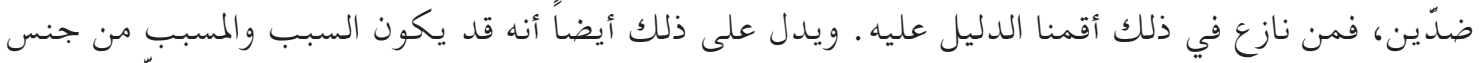

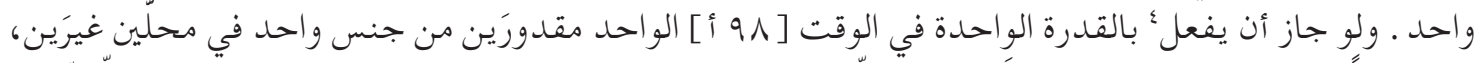

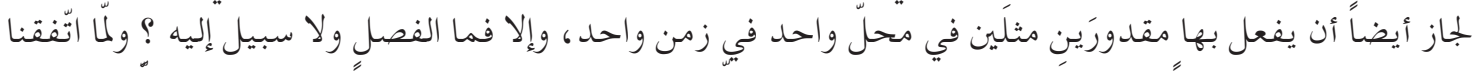

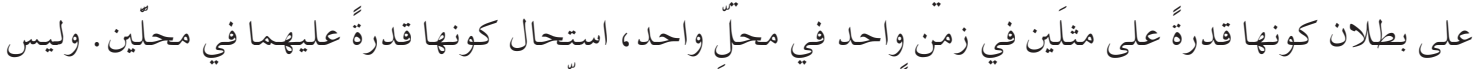

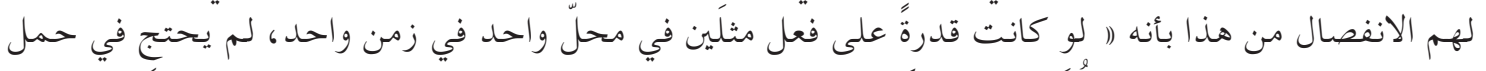

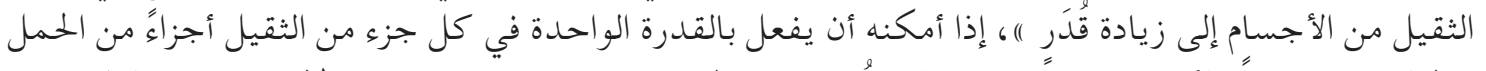

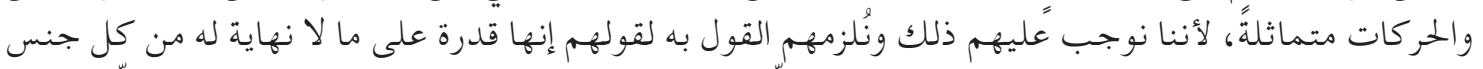

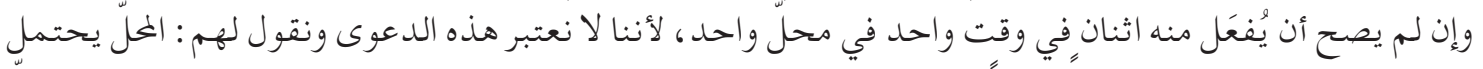

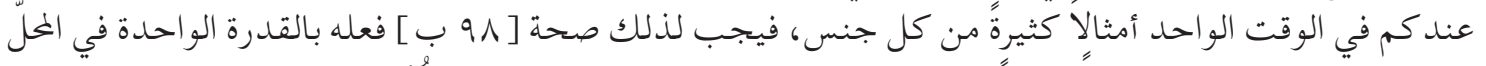

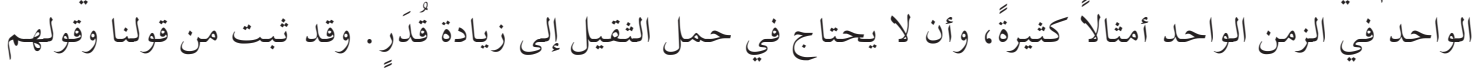

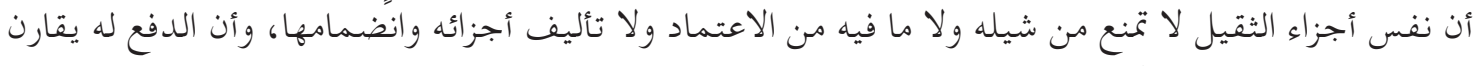

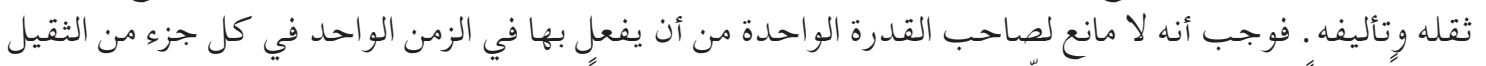

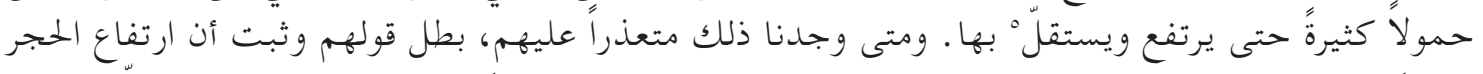

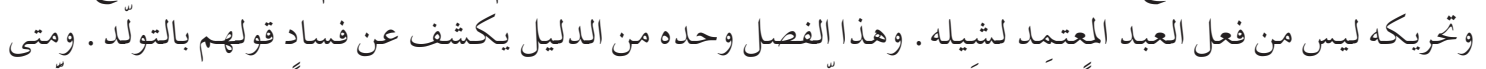

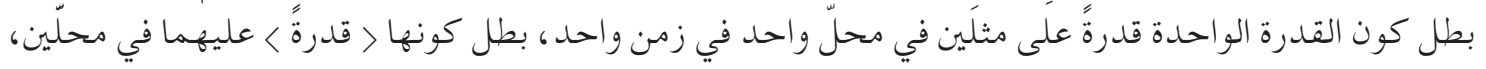

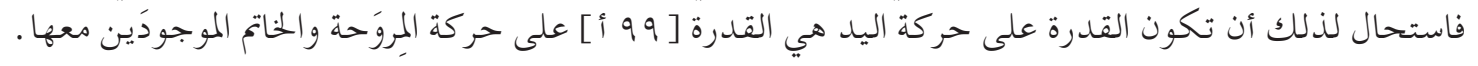

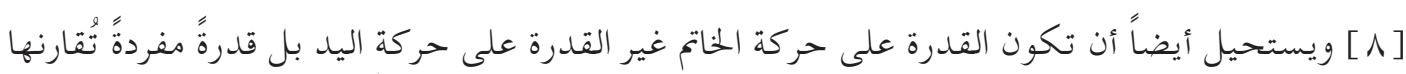

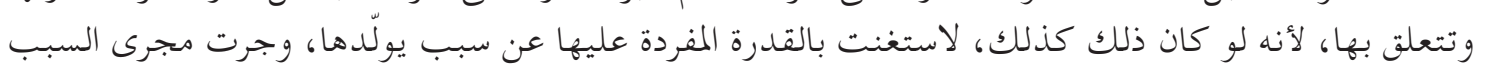

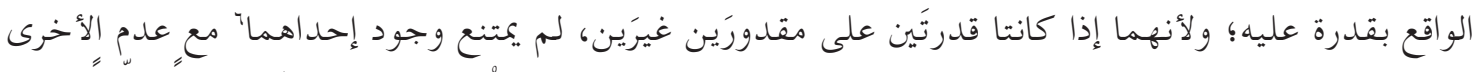

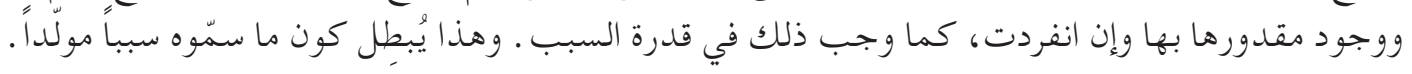

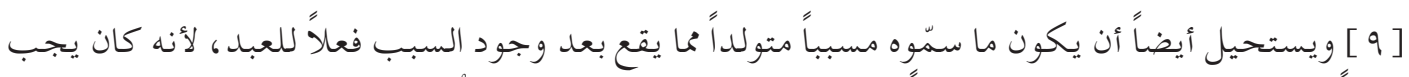

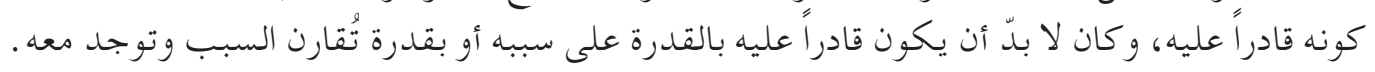

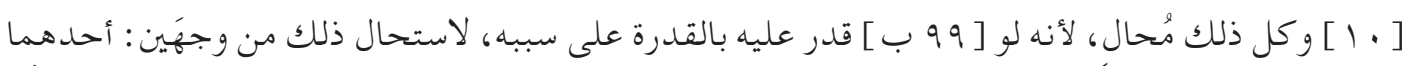

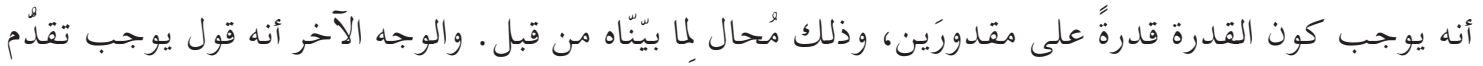

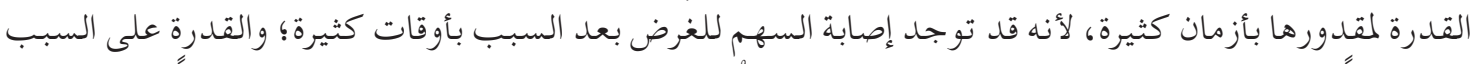

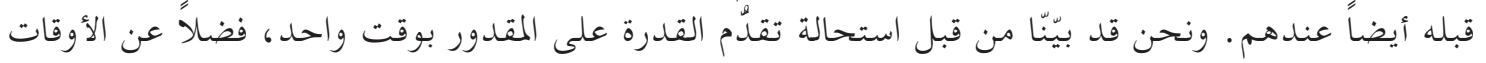

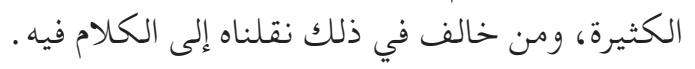


[ [11 و ويستحيل أيضاً أن يكون المسبب الواقع بعد سببه واقعاً بقدرة تُقارن القدرة على سببه لأمرَين:

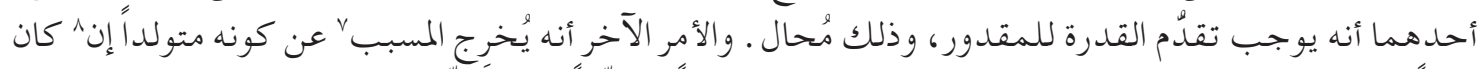

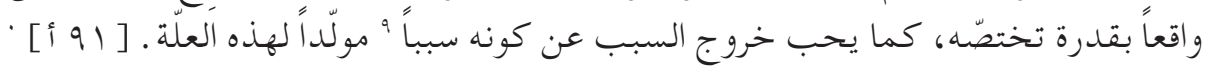

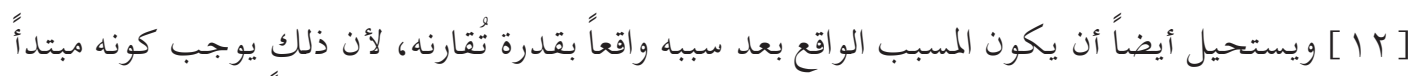

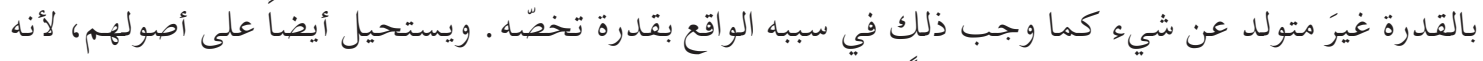

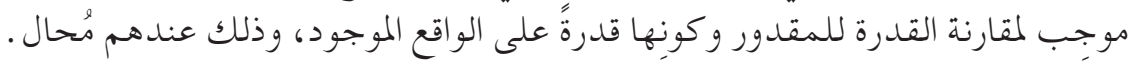

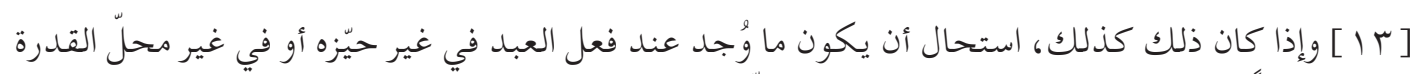

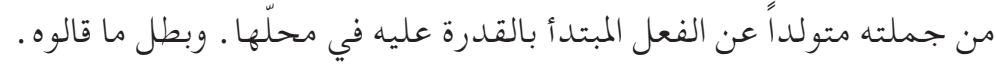

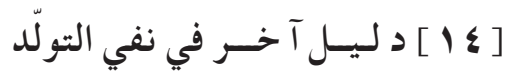

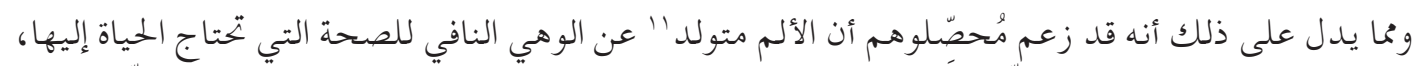

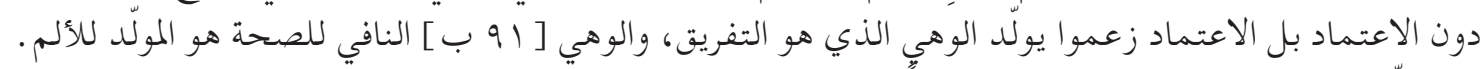

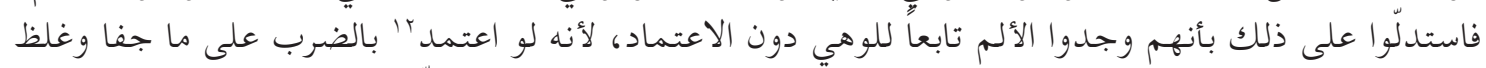

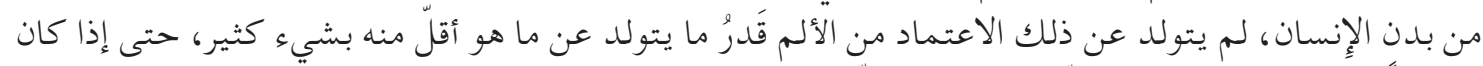

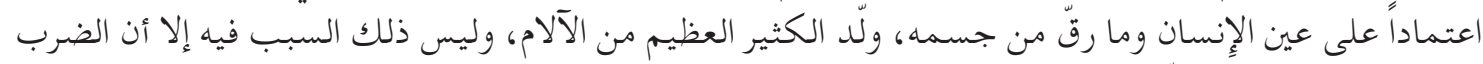

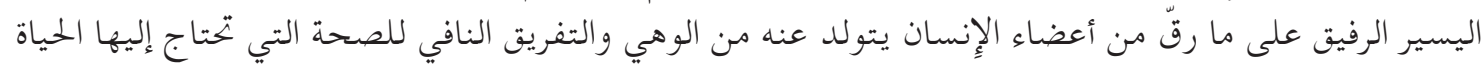

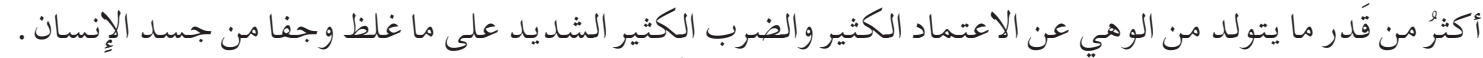

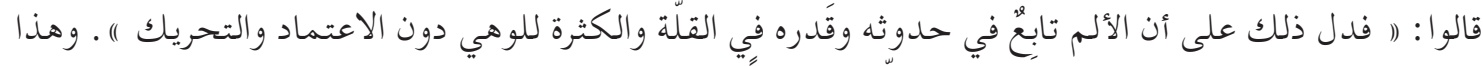

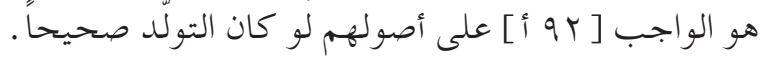

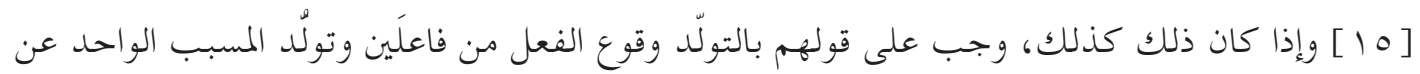

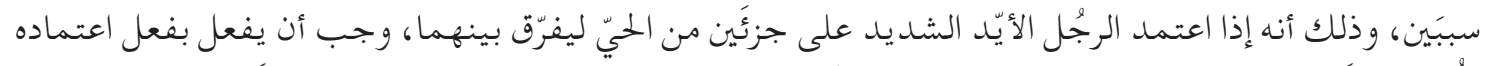

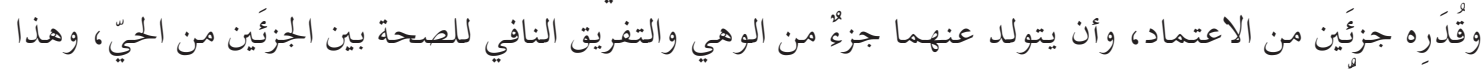

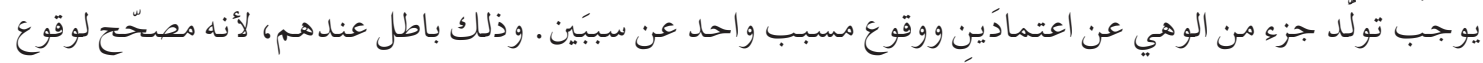

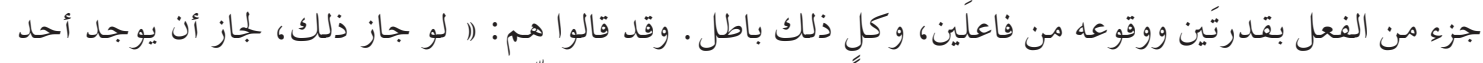

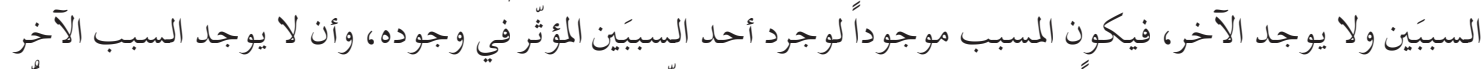

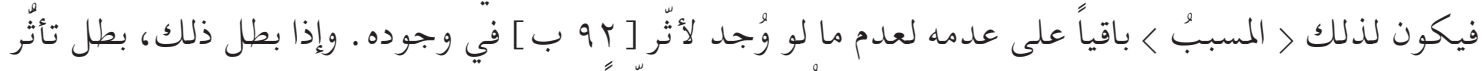

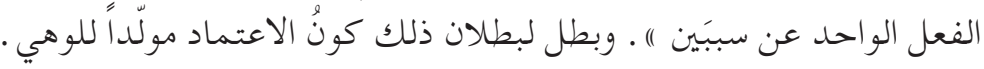

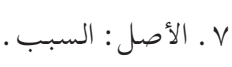

ه . الأصل : وإن.

و . الأصل : مسبباً.

.

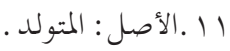

rا ب الأصل : اعمد . الأصلد. 


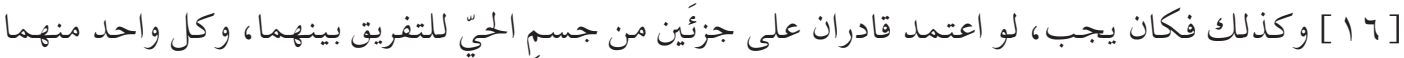

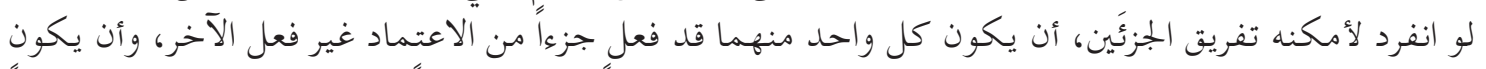

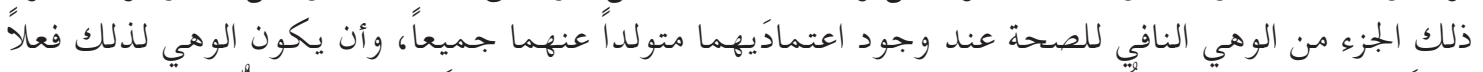

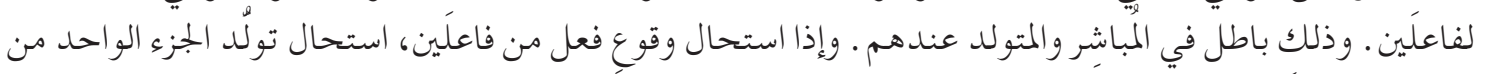

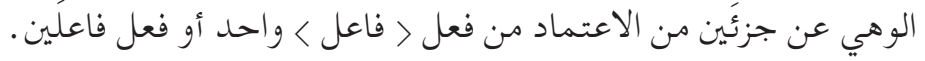

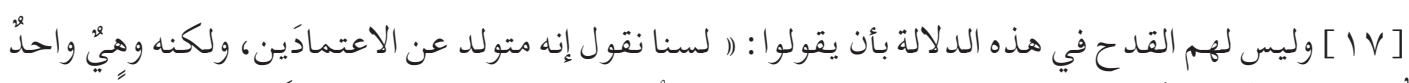

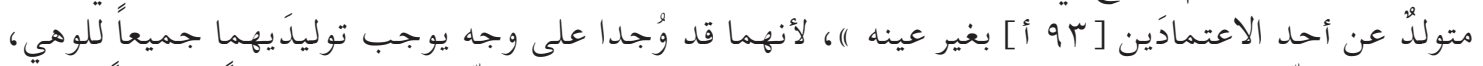

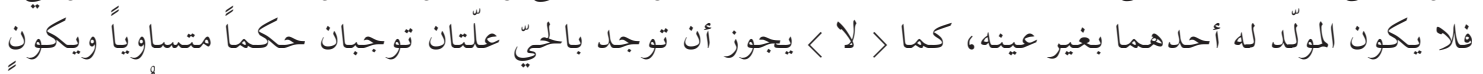

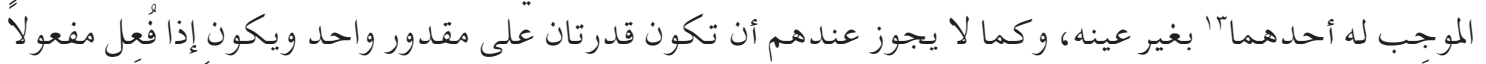

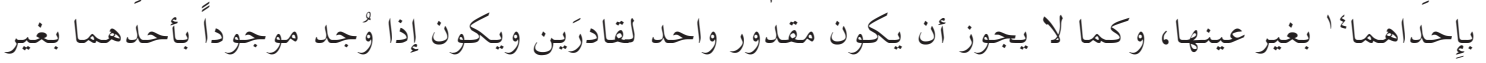

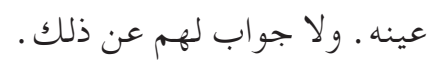

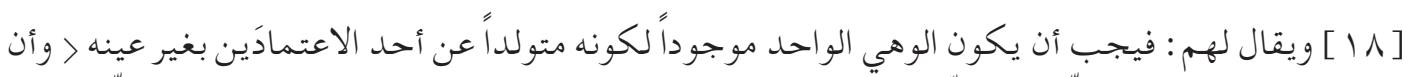

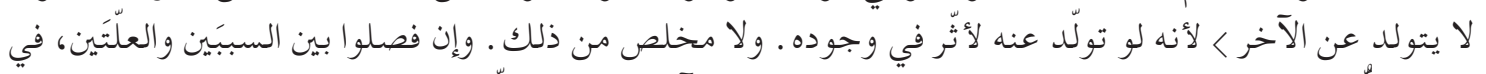

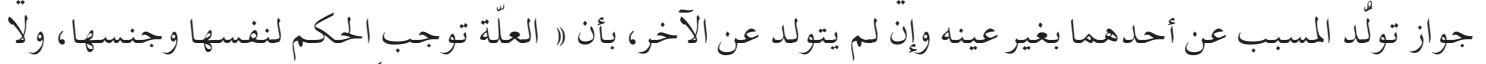

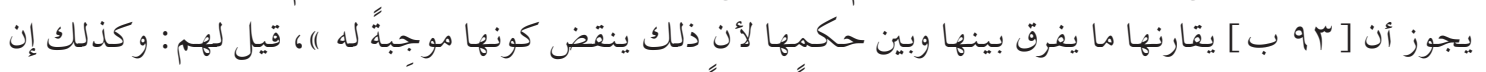

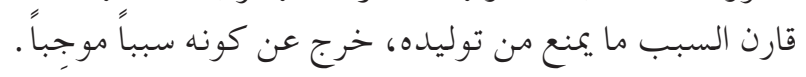

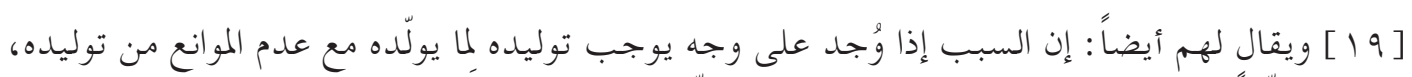

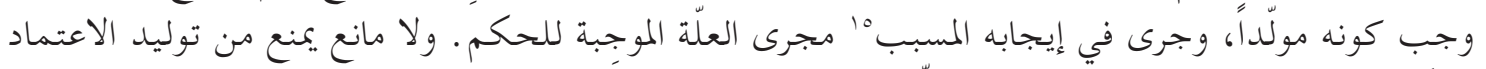

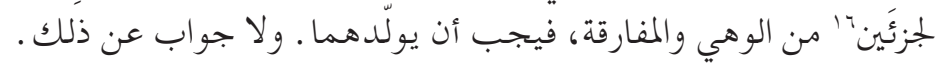

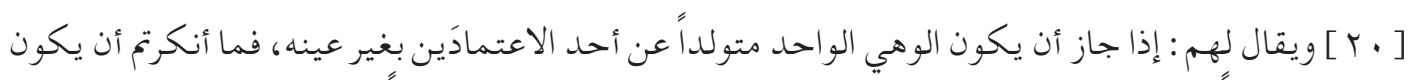

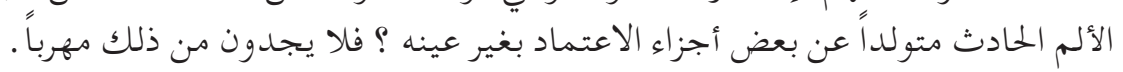

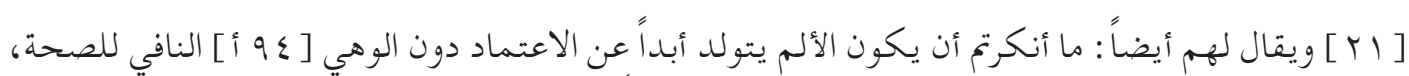

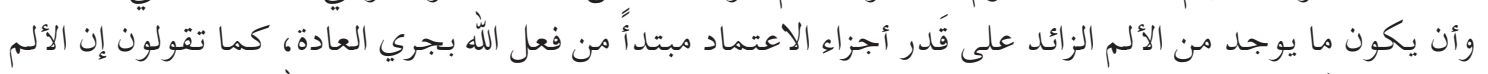

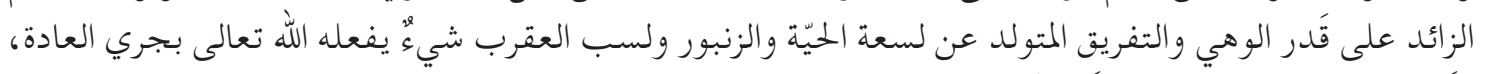

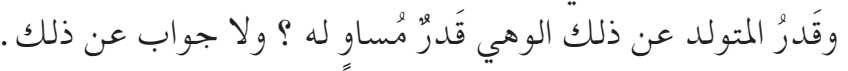

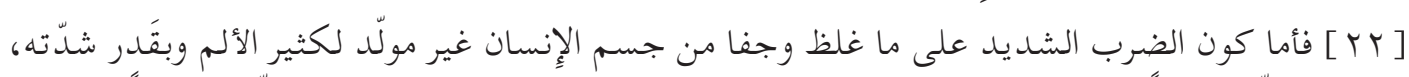

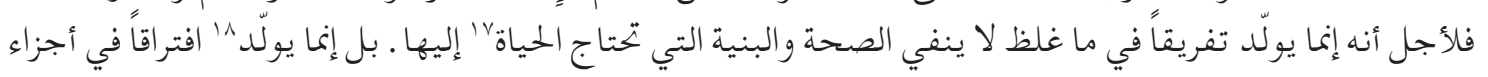


لا حياة فيها، فِاذذا بلغ الافتراقُ إلى الأجزاء الحيّة ونفى الصحة التي تحتاج الحياة إليها، كان ذلك القَدر من الافتراق وهياً

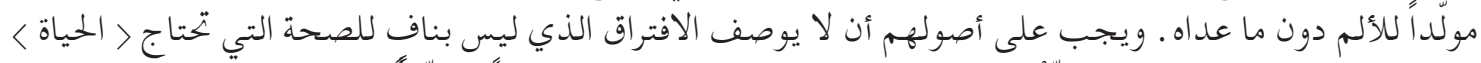

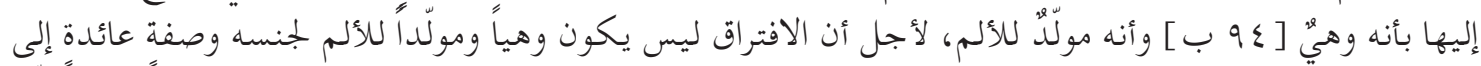

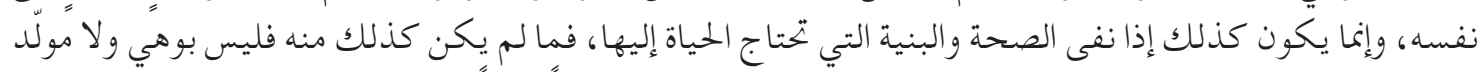

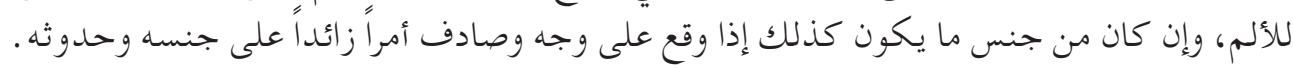

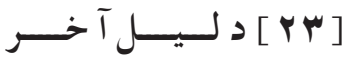

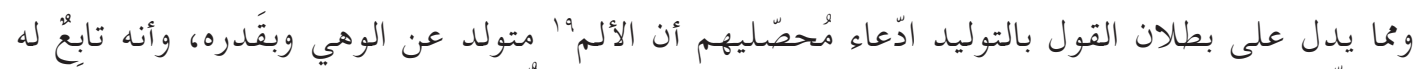

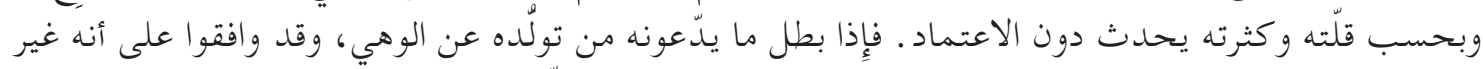

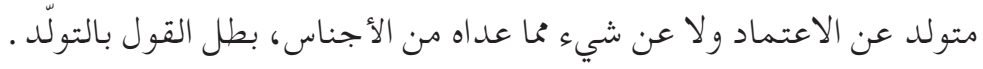

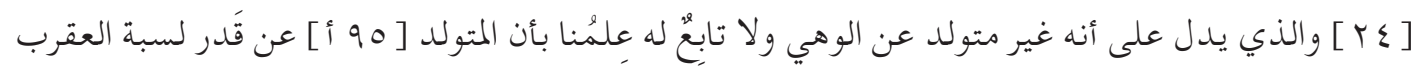

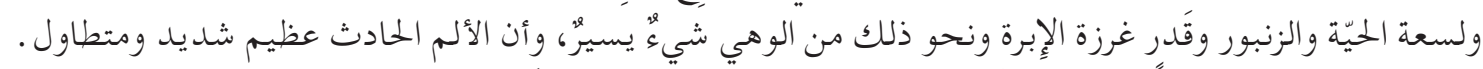

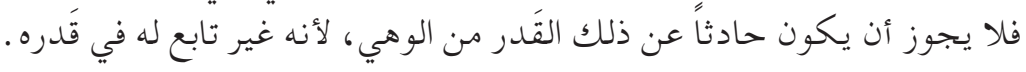

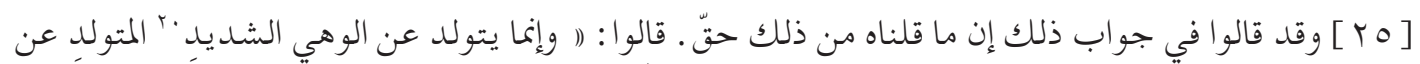

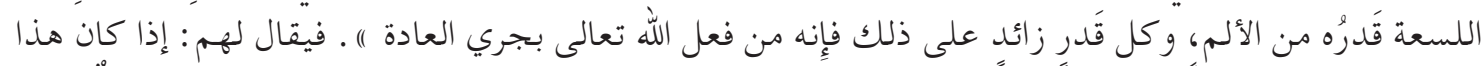

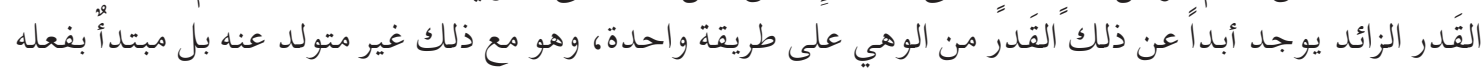

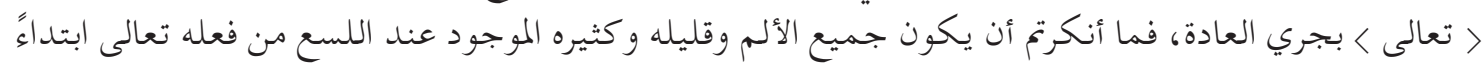

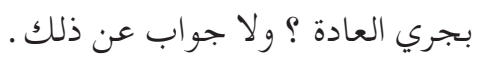

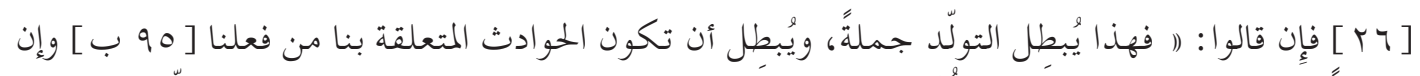

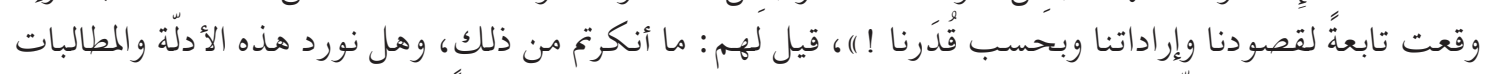

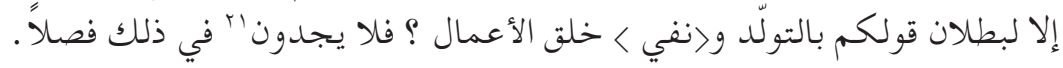

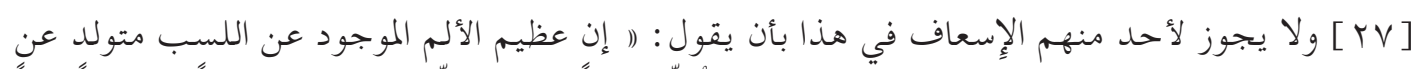

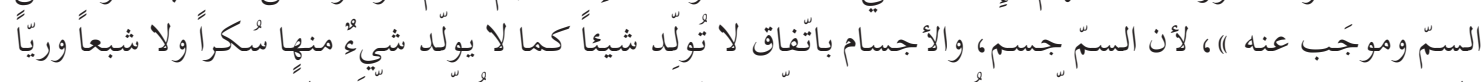

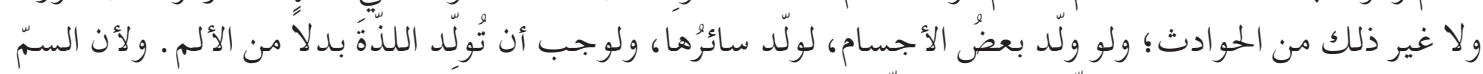

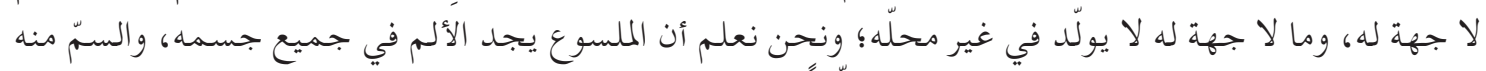

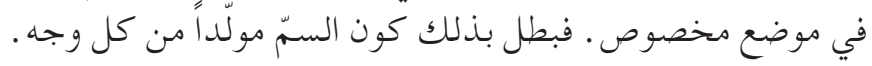

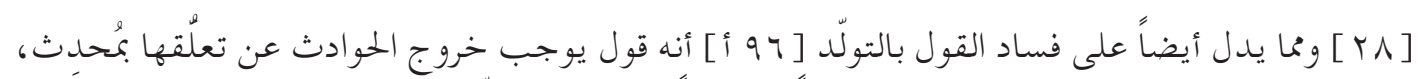

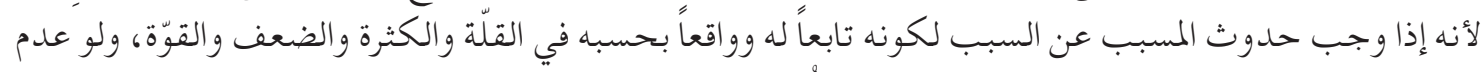

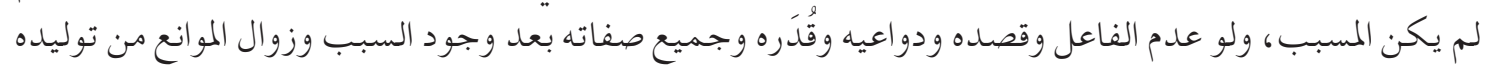




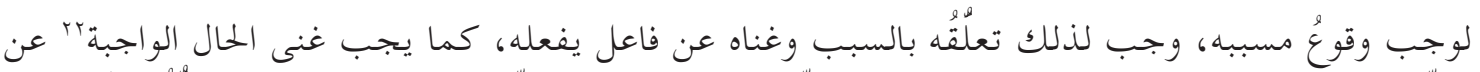

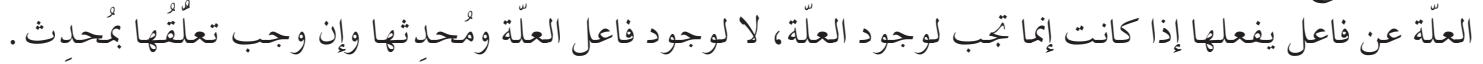

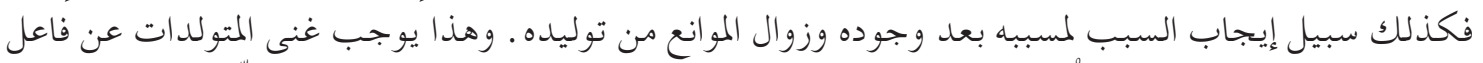

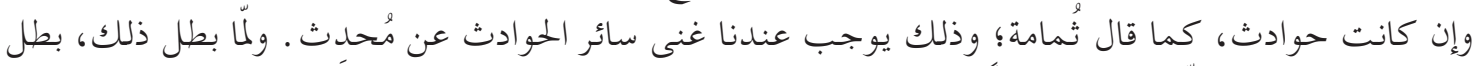

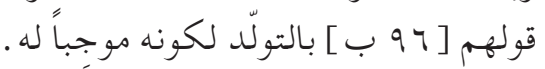

\section{فصـل \\ ذكر معتمداتهم في وجوب القول بالتولّد ، والاعتر اض عليها}

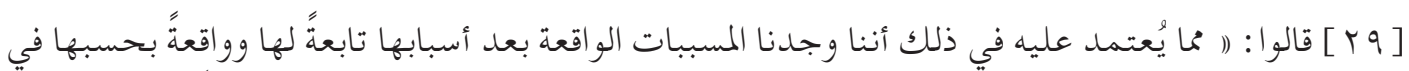

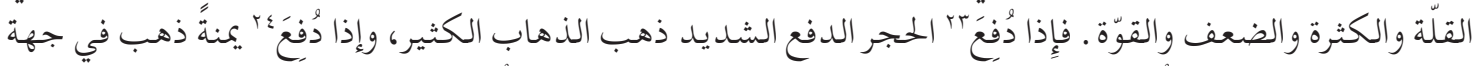

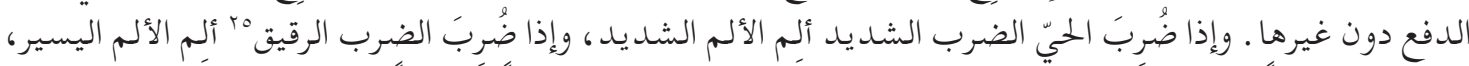

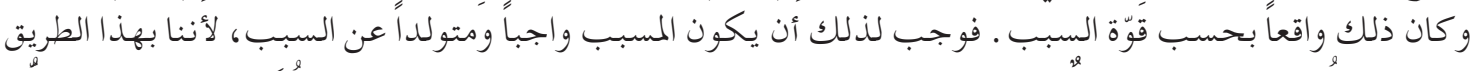

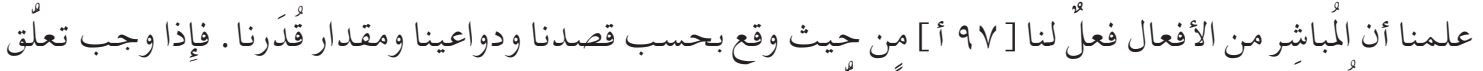

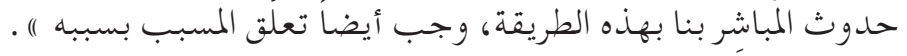

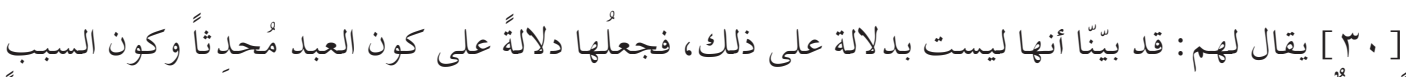

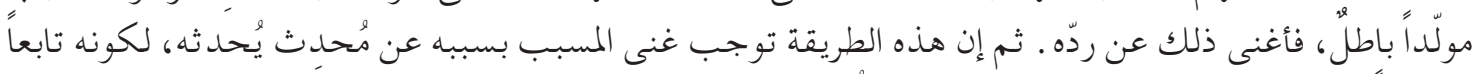

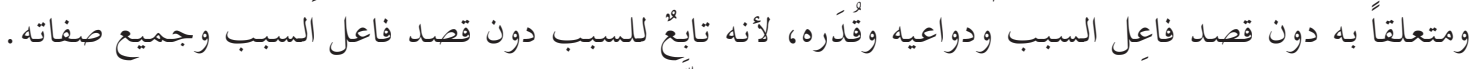

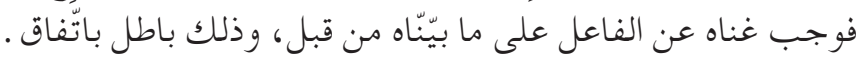

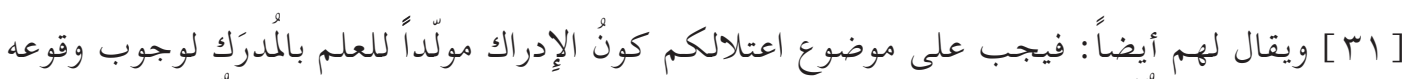

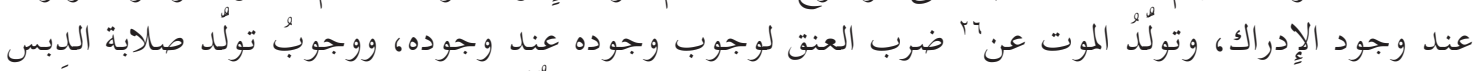

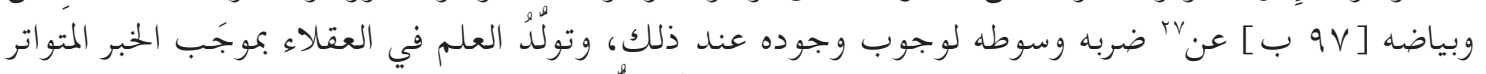

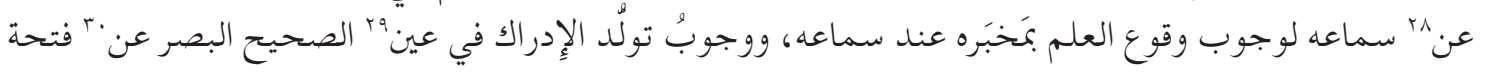

$$
\begin{aligned}
& \text { Yr ـ الأصل : الواجب. } \\
& \text { זr ـ الأصل: وقع. الاصل : الاجب }
\end{aligned}
$$

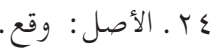

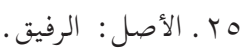

$$
\begin{aligned}
& \text { بr. الأصل : عند. }
\end{aligned}
$$

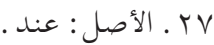

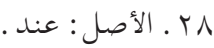

$$
\begin{aligned}
& \text { و r . الأصل : غير. } \\
& \text {. r. الأصل : عند. }
\end{aligned}
$$




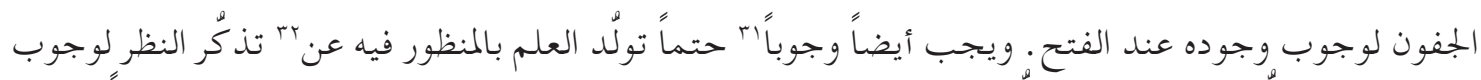

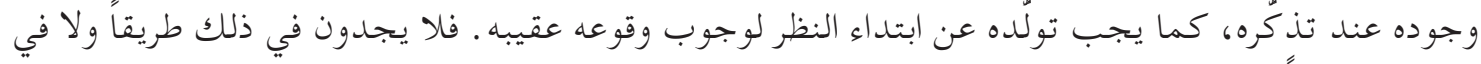

شيء منه فصلا.

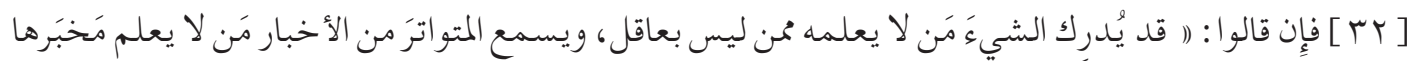

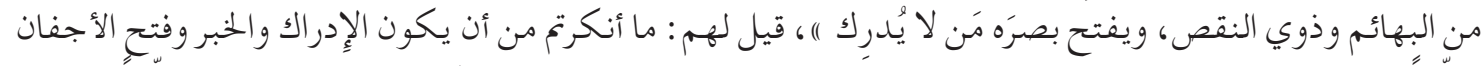

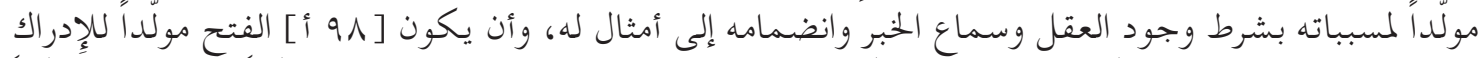

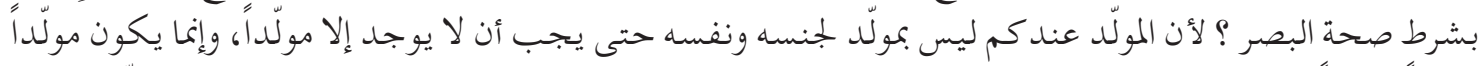

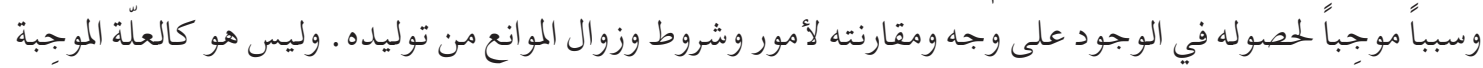

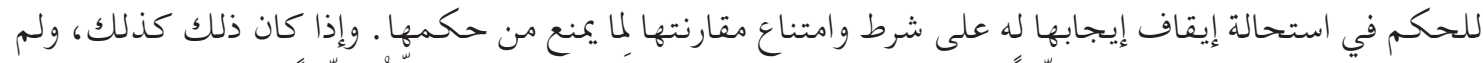

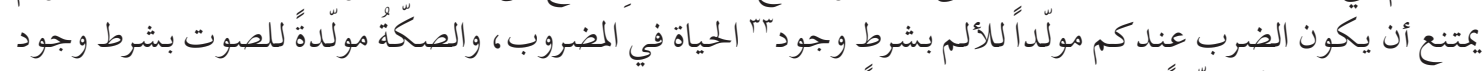

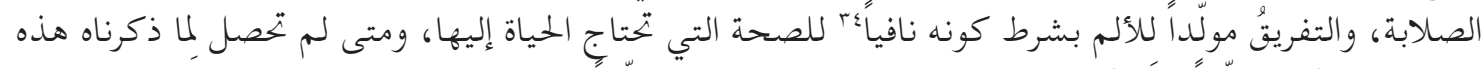

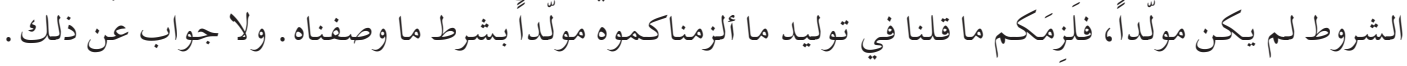

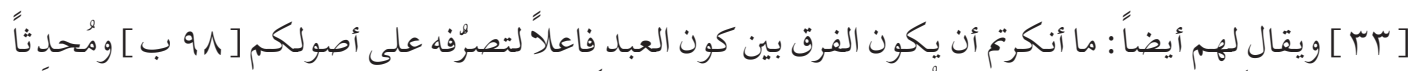

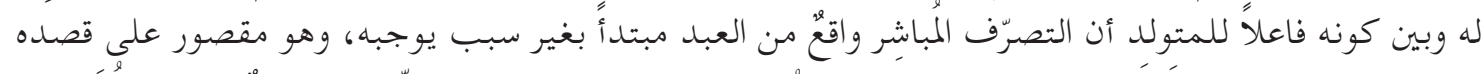

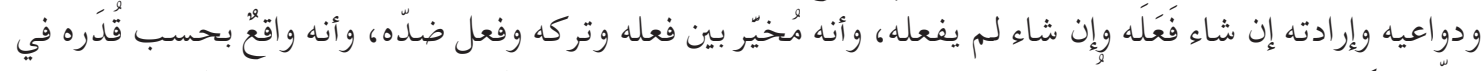

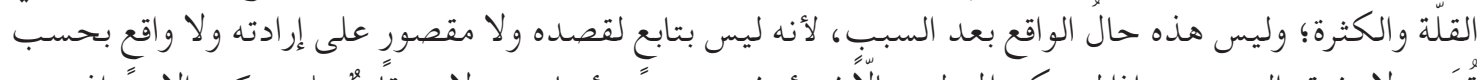

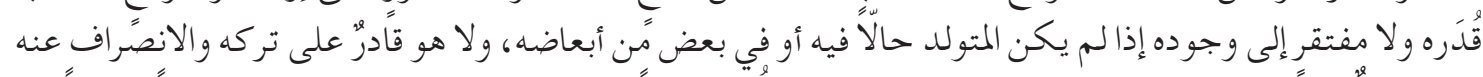

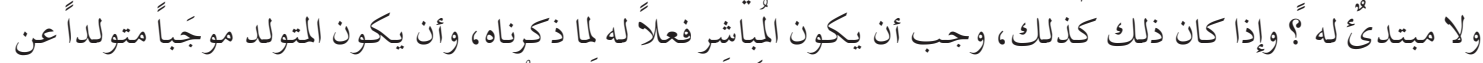

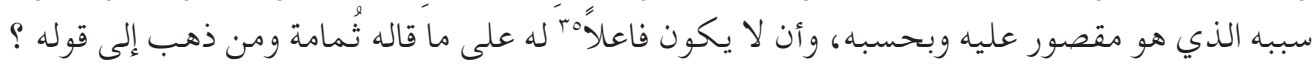

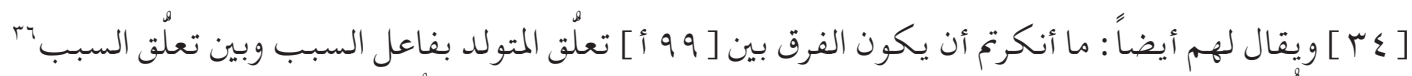

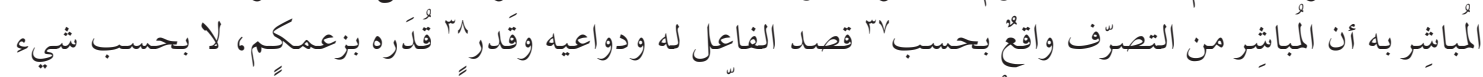

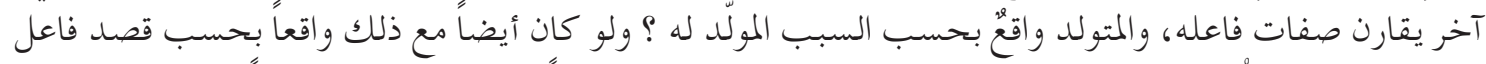

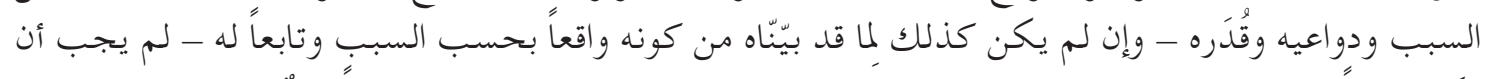

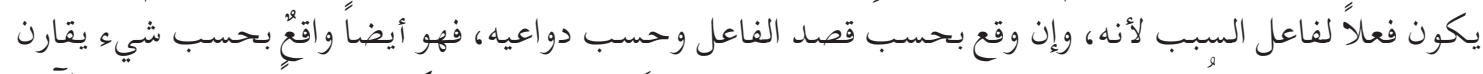

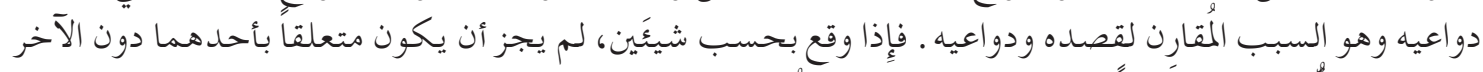

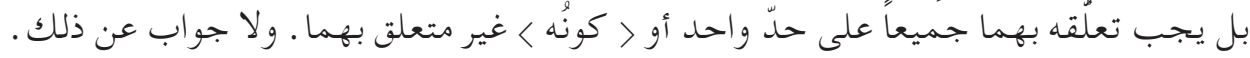

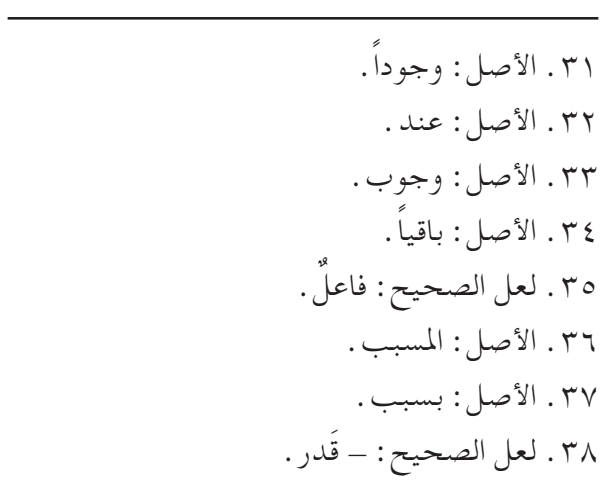




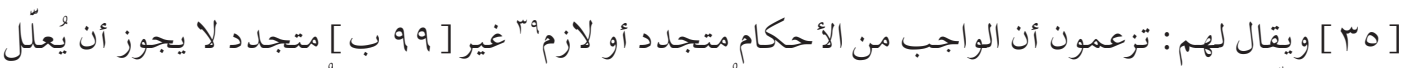

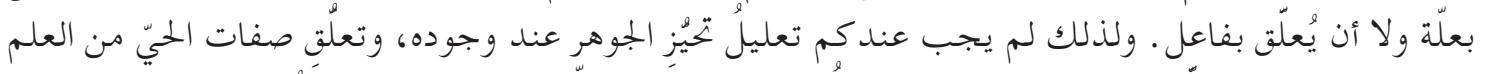

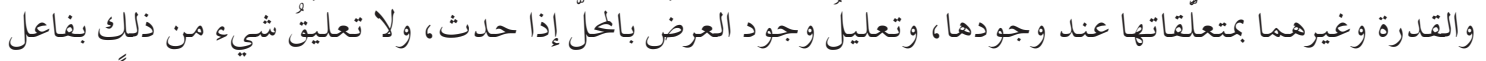

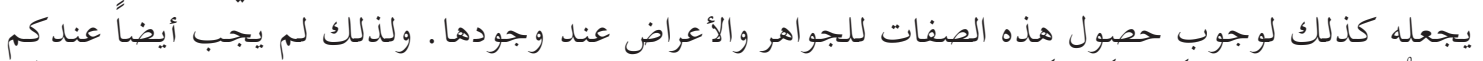

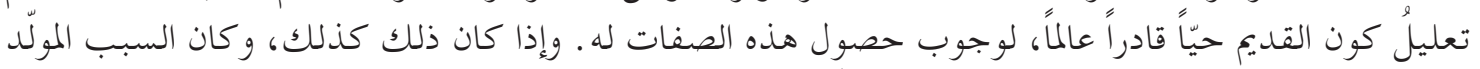

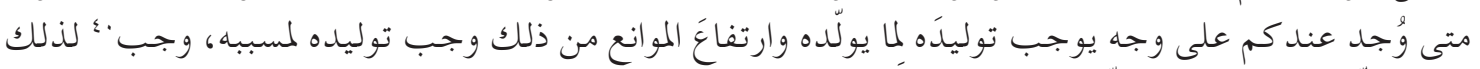

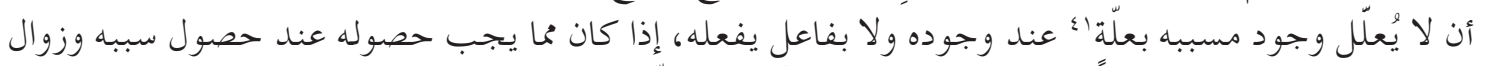

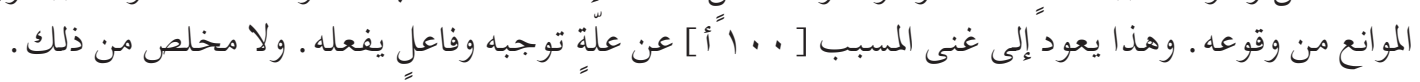

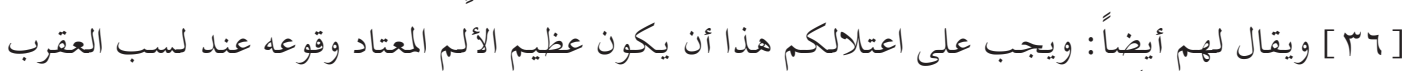

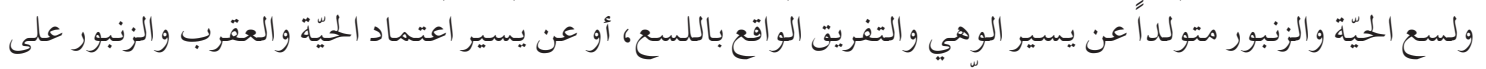

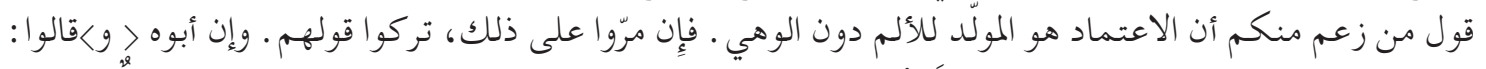

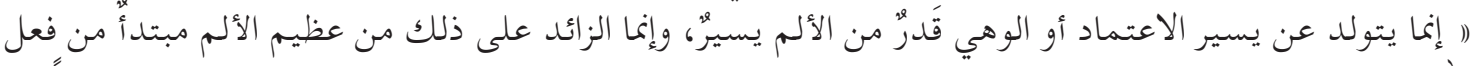

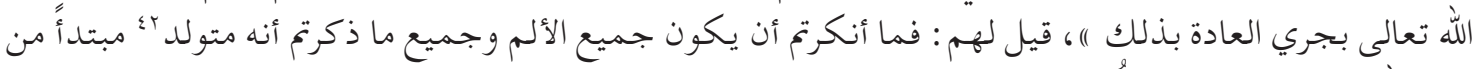

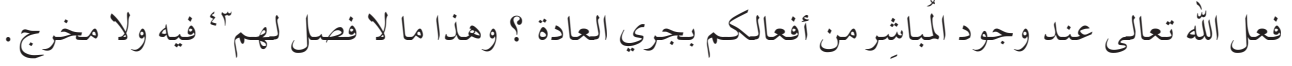

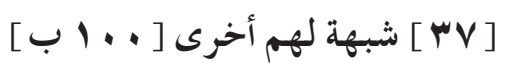

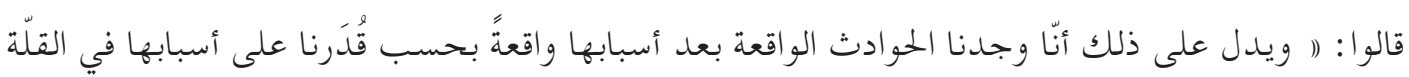

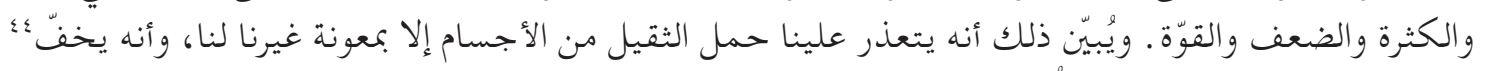

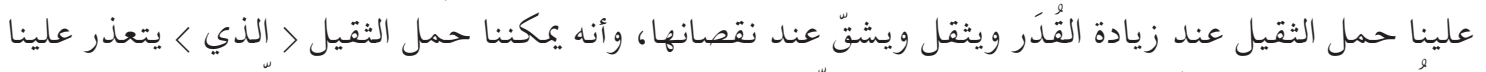

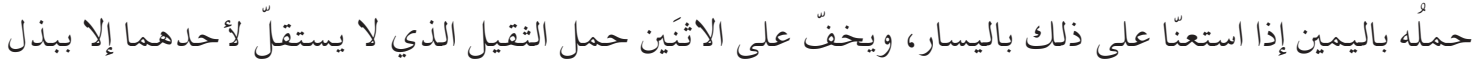

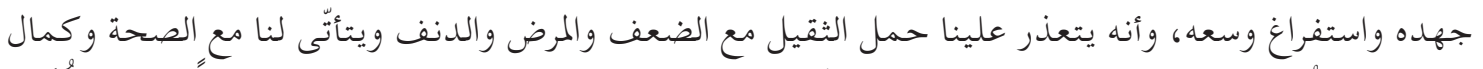

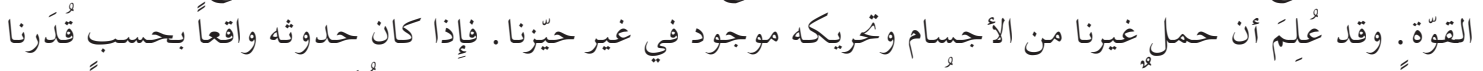

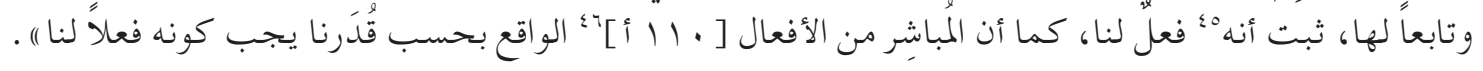

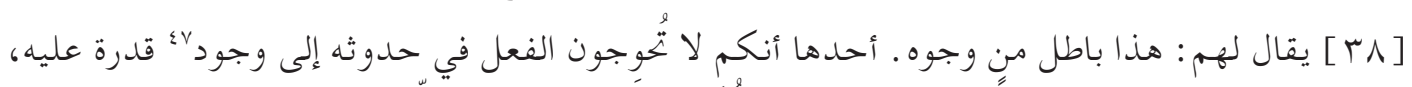

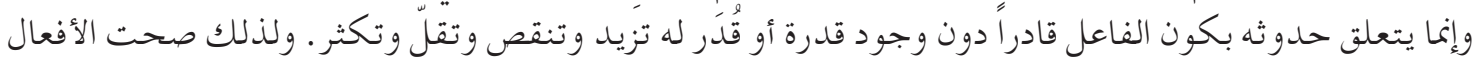

$$
\begin{aligned}
& \text { هـ ـ الأصل : لازماً. } \\
& \text { • ع . الأصل: وروجب. الاصل : لازما. } \\
& \text { اء ـ الأصل : لعلّة. } \\
& \text { با ع ـ الأصل : متولدا. } \\
& \text { بع ـ الأصل : لكم. }
\end{aligned}
$$

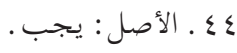

$$
\begin{aligned}
& \text { هـ ـ الأصل : أنها. }
\end{aligned}
$$

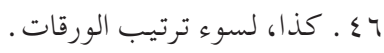

$$
\begin{aligned}
& \text { Vع ع . الأصل : وجوا، لـوء ترتيب. }
\end{aligned}
$$




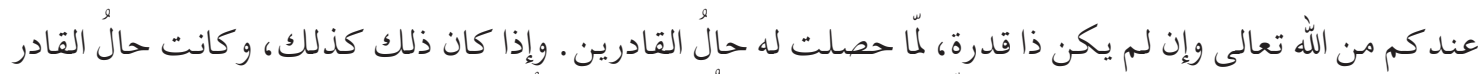

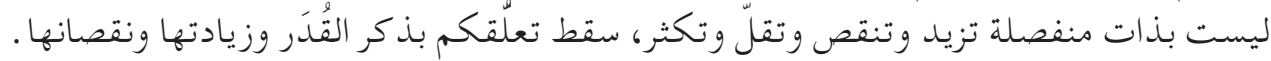

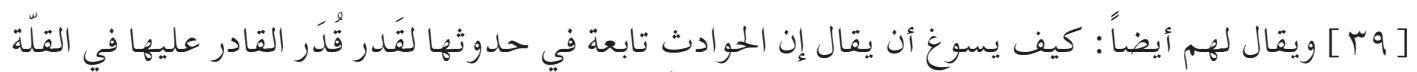

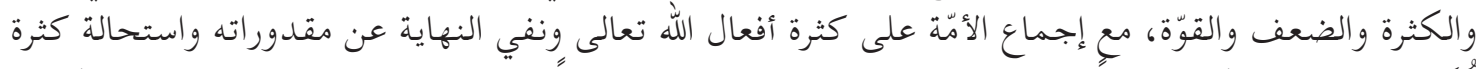

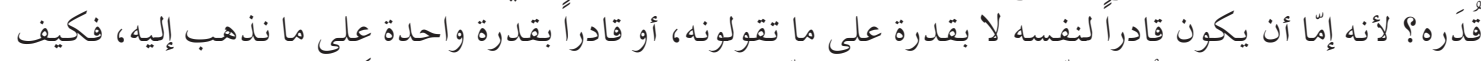

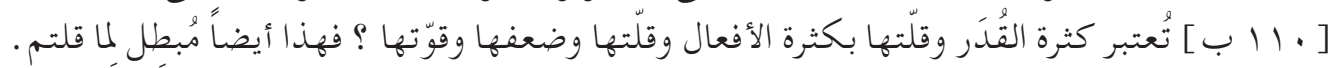

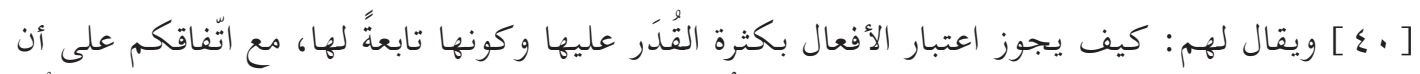

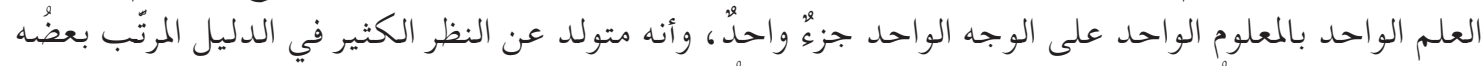

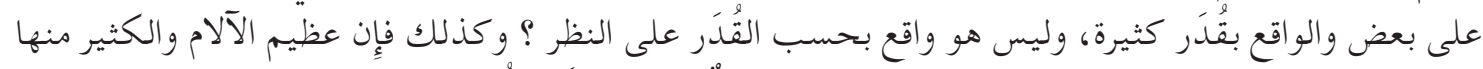

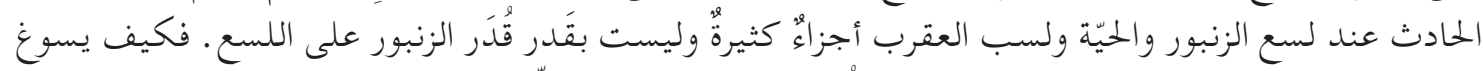

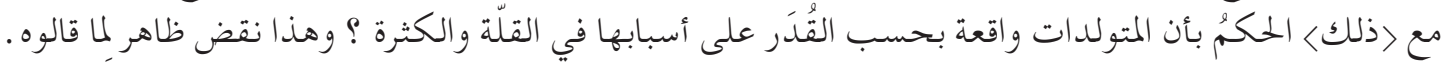

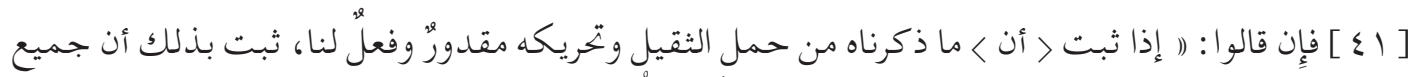

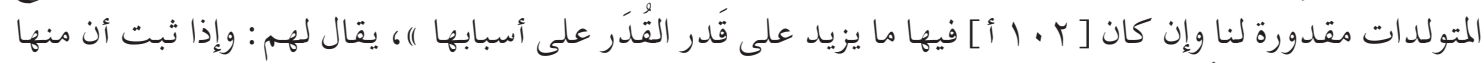

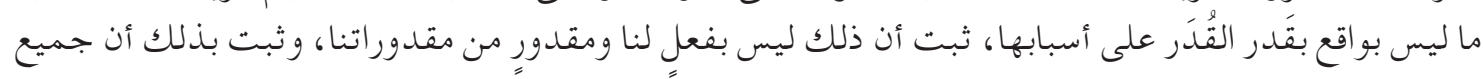

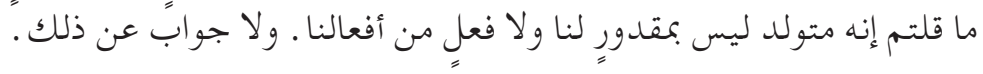

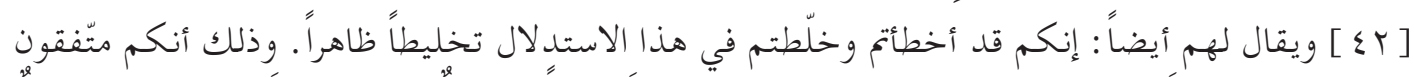

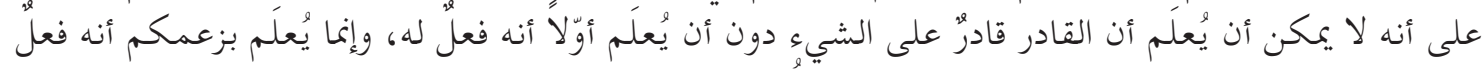

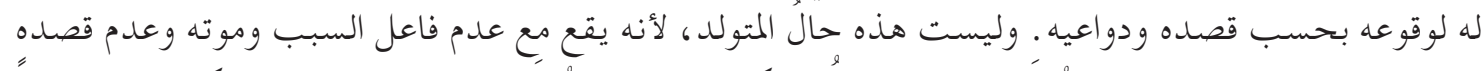

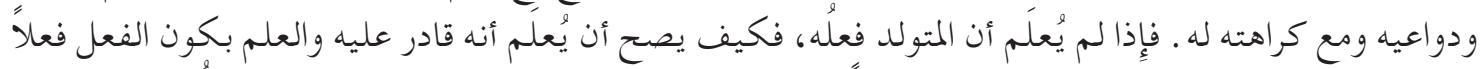

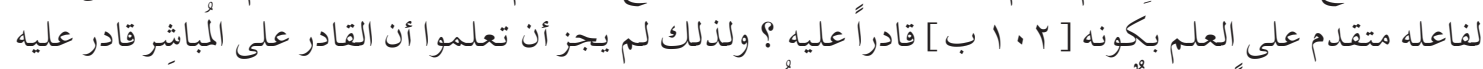

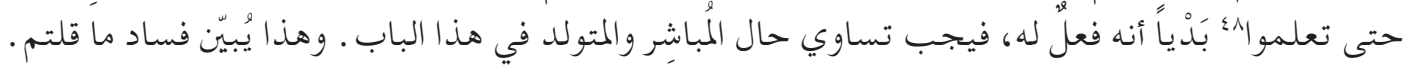

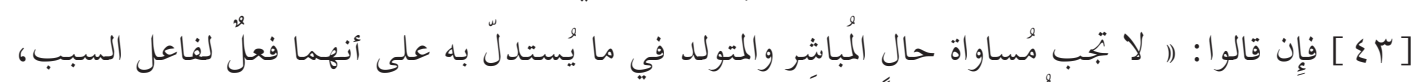

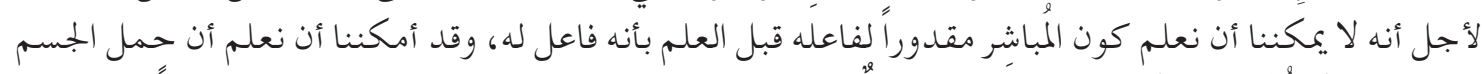

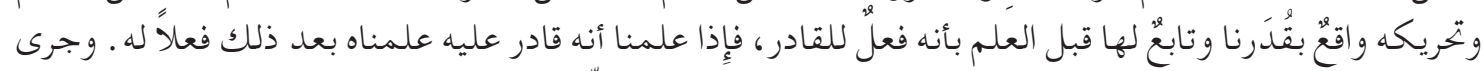

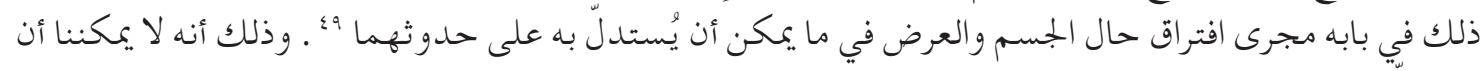

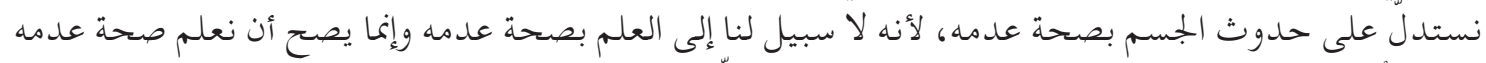

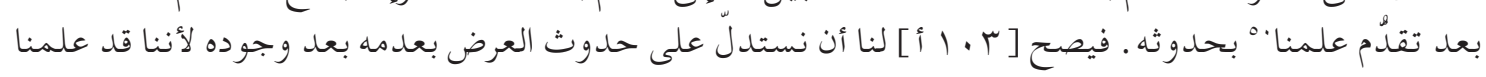

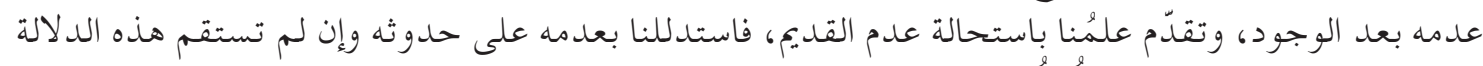

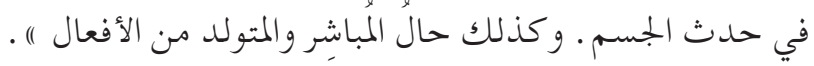

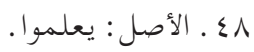

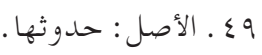

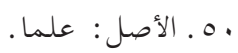




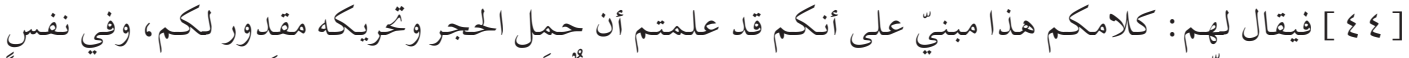

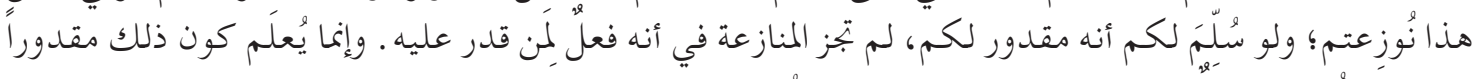

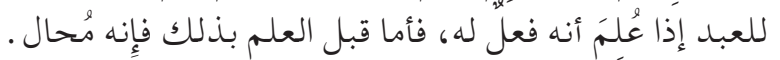

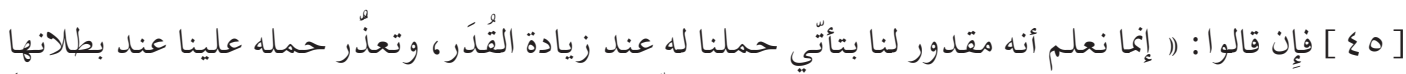

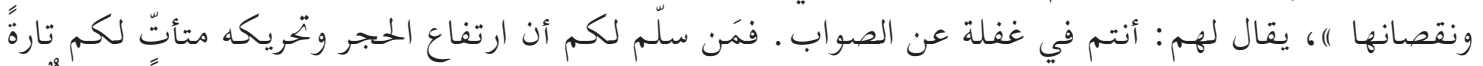

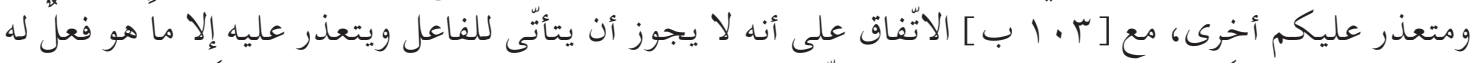

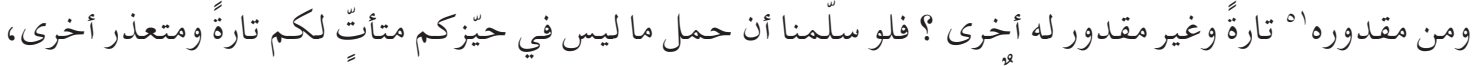

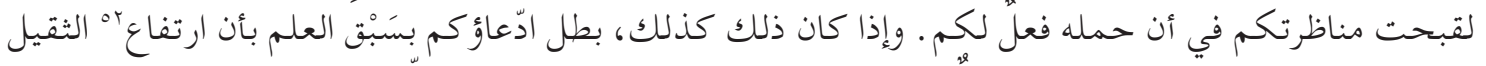

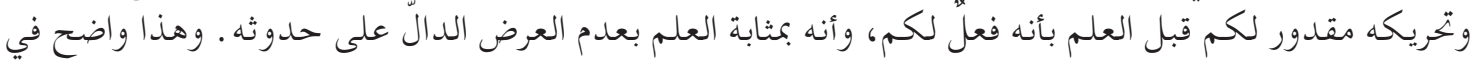
إبطال ما ظنّوه.

\section{[ ف}

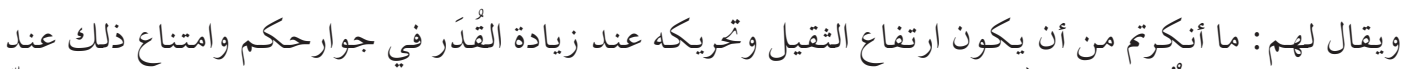

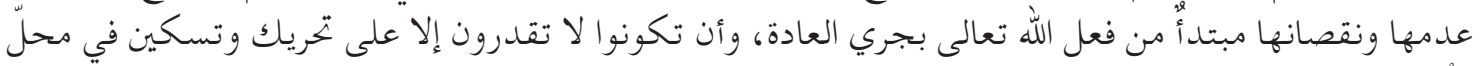

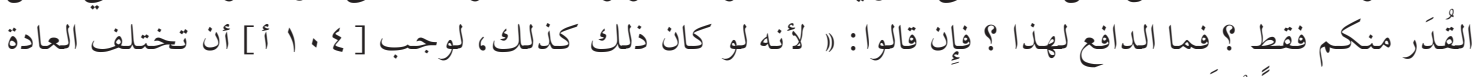

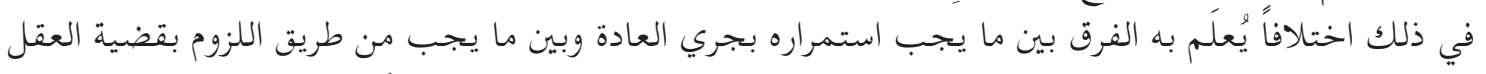

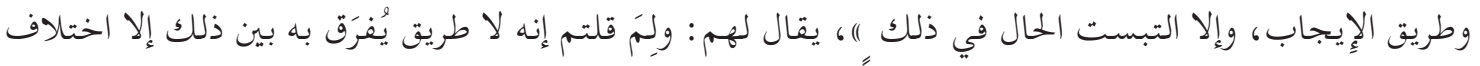

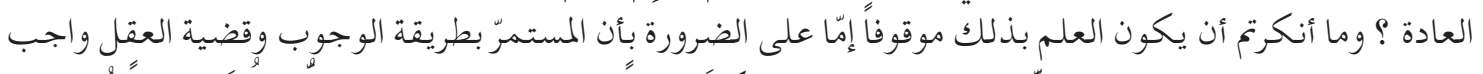

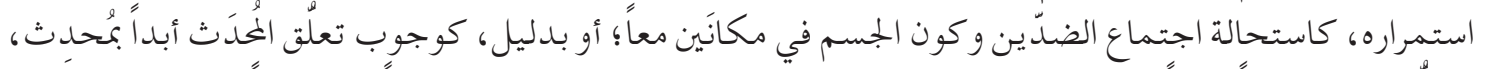

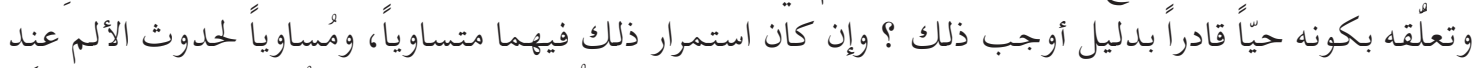

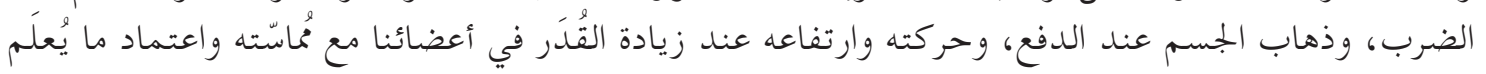

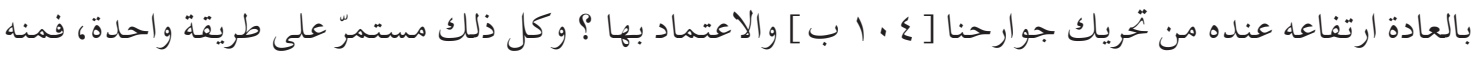

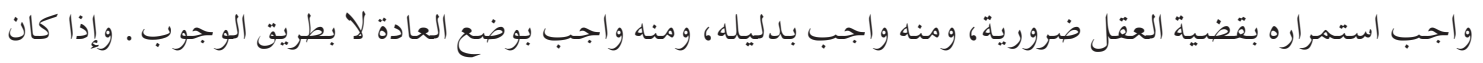
ذلك كذلك، بطل ما دفعتم به الإِلزام .

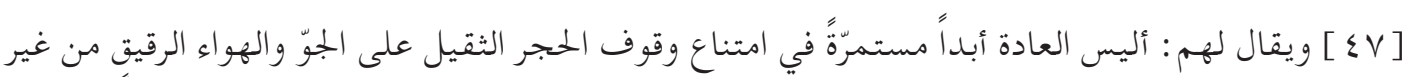

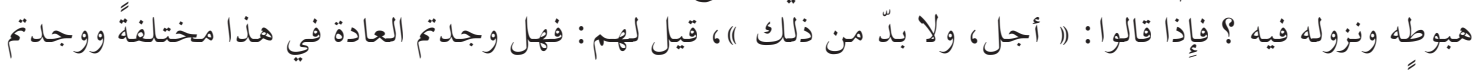

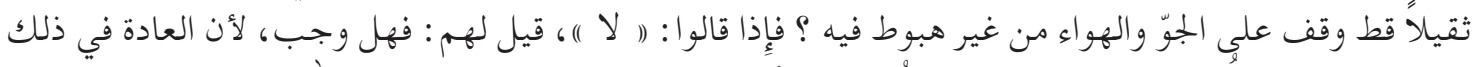

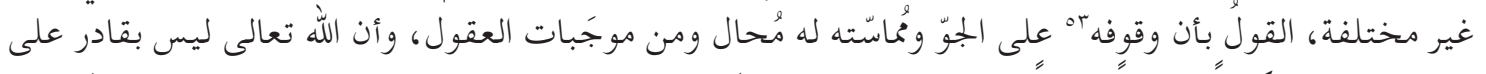

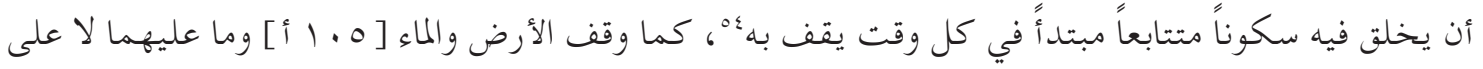

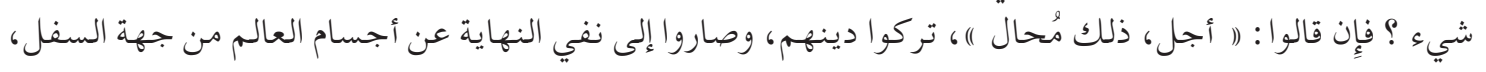

$$
\begin{aligned}
& \text { المه ه الأصل : مقدور . الأصل } \\
& \text { ror }
\end{aligned}
$$

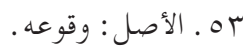

$$
\begin{aligned}
& \text { عـ الأصل : بها . الصل : وقوع. }
\end{aligned}
$$




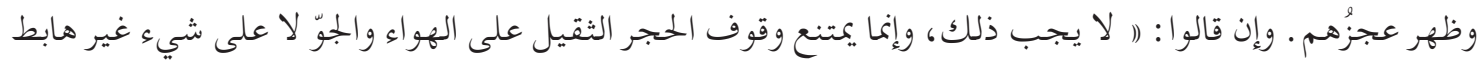

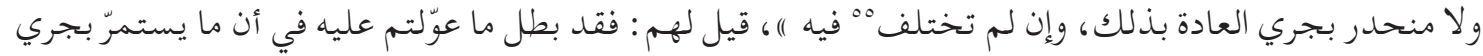

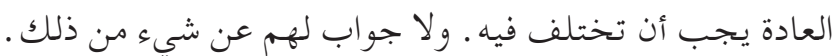

\section{] [ ف ــــ ]}

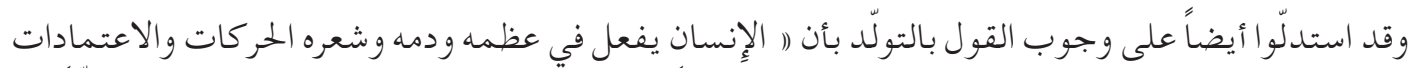

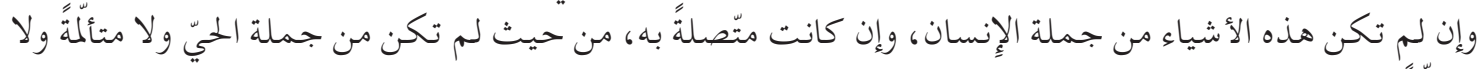

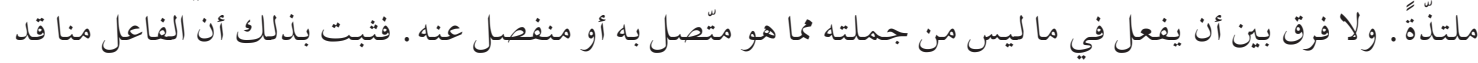

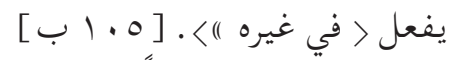

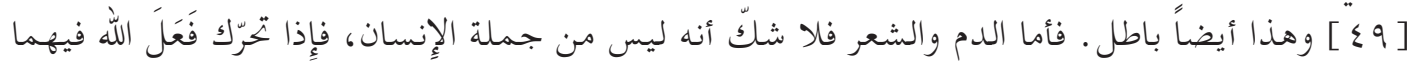

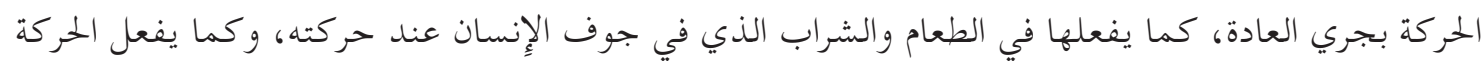

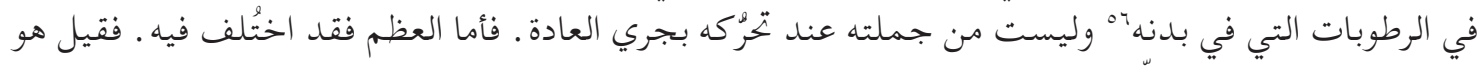

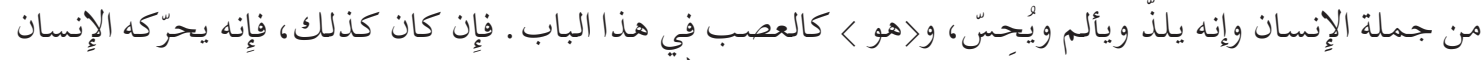

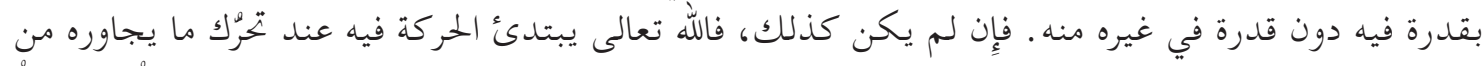

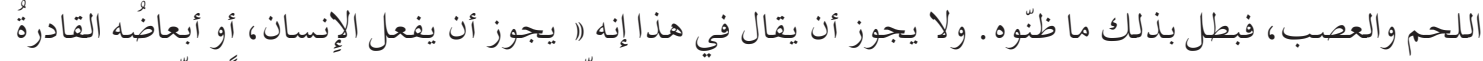

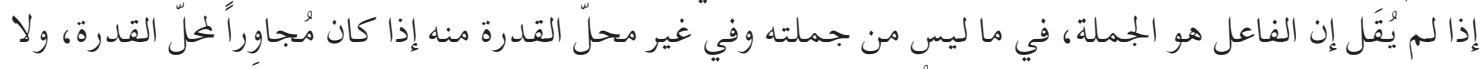

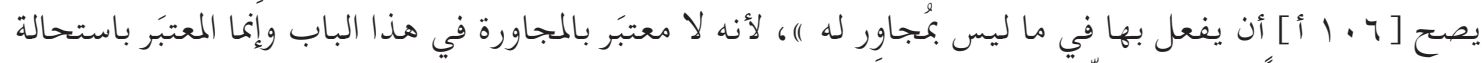

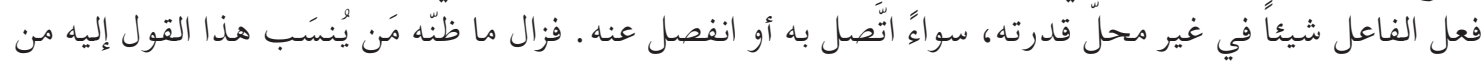
أهل الحقّ.

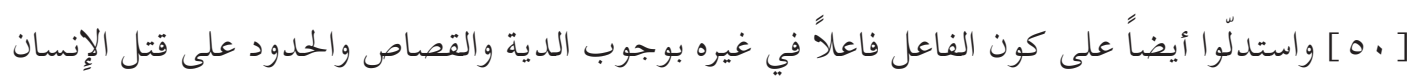

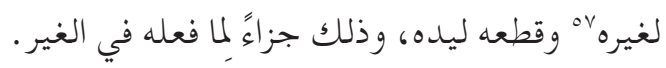

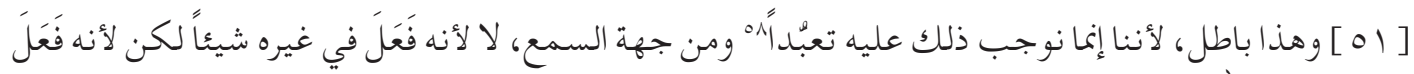

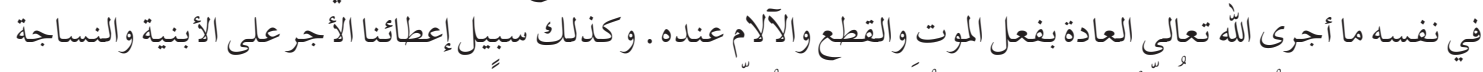

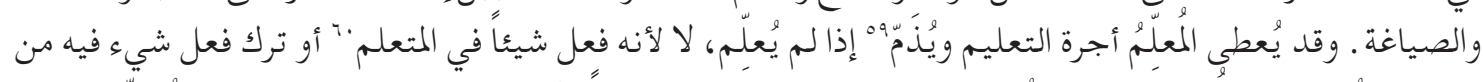

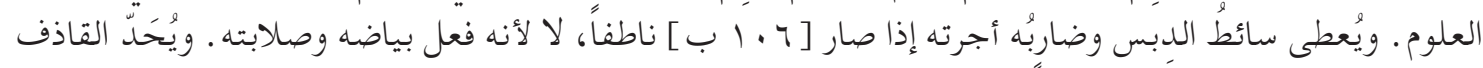

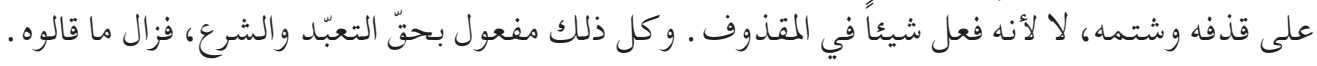

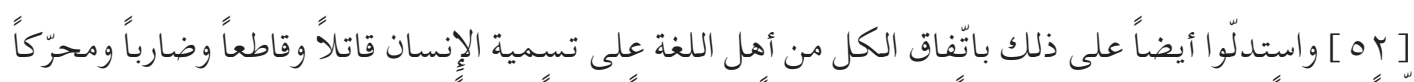

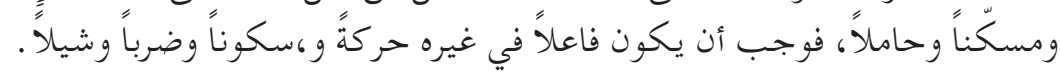

100 00

(الأصل : في يده.

مه ه . الأصل: بغيره.

همه هـ الأصل: بعيداً

هوه ـ الأصل : ويَذهمه.

ـ ـ ـ الأصل: المعلم. 


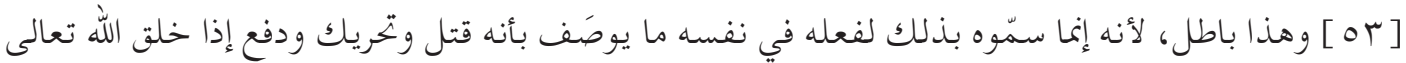

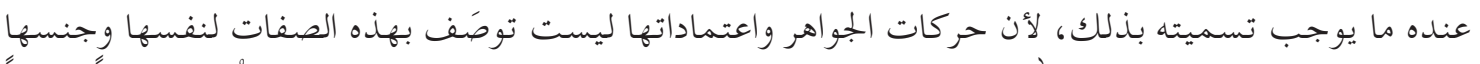

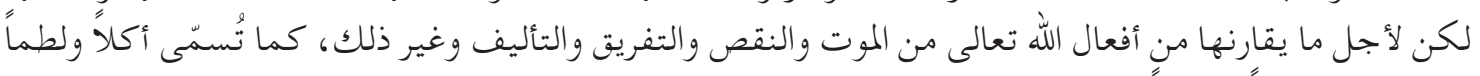

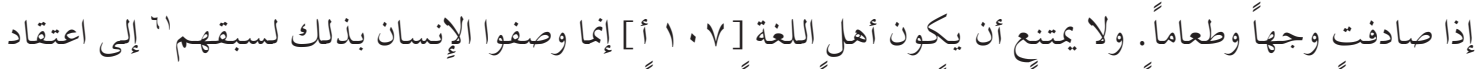

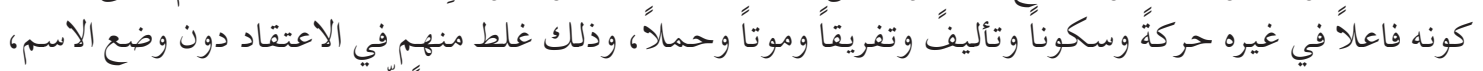

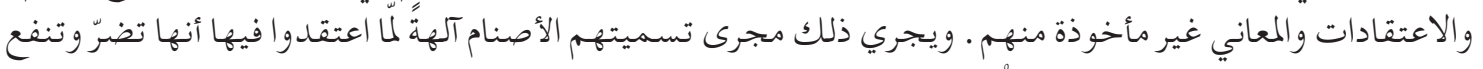

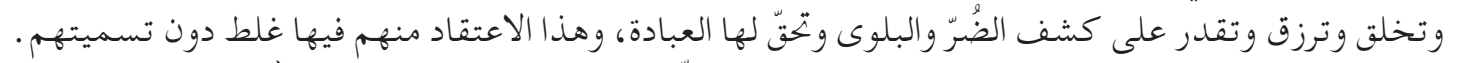

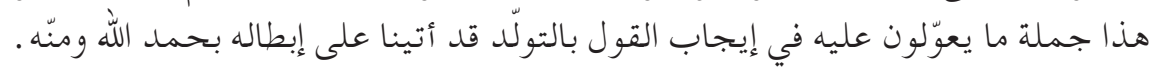

\section{باب ذكر اختلاف القدرية

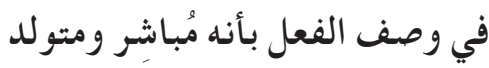

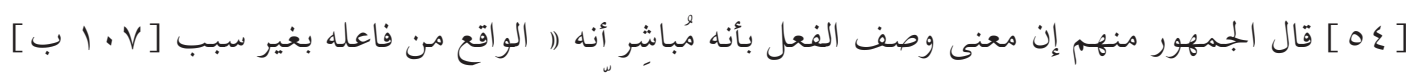

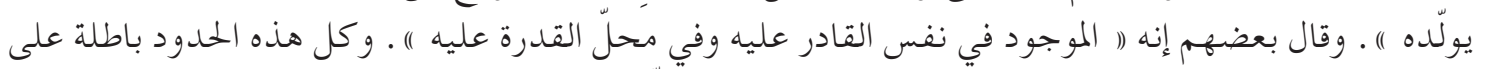

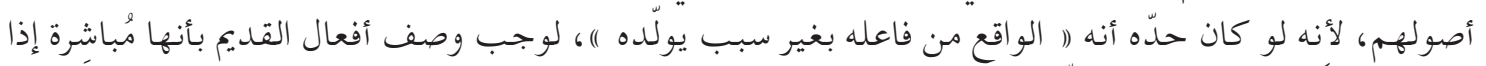

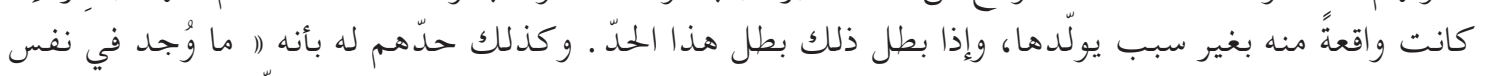

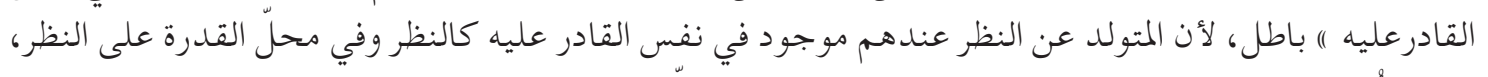

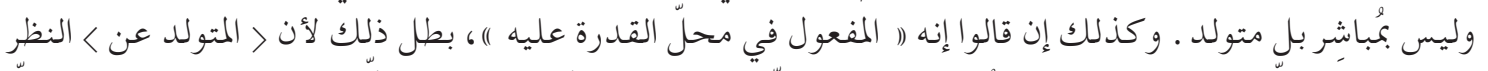

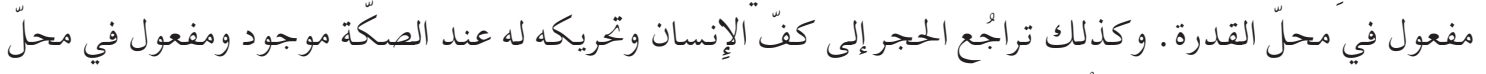

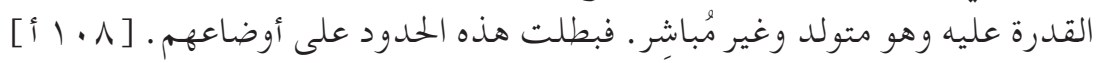

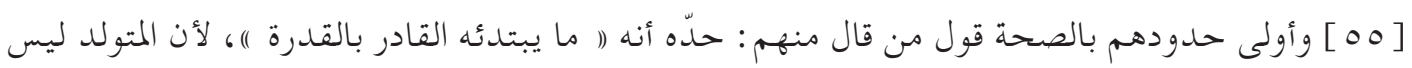

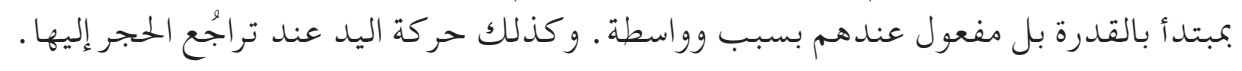

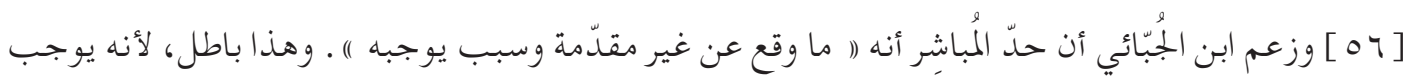

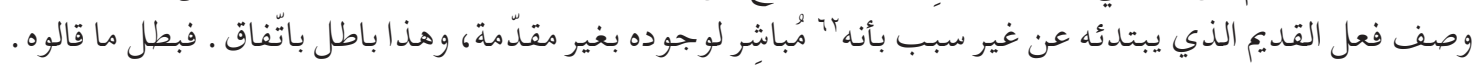

\section{القول في اختلافهم في حدّ المتولد}

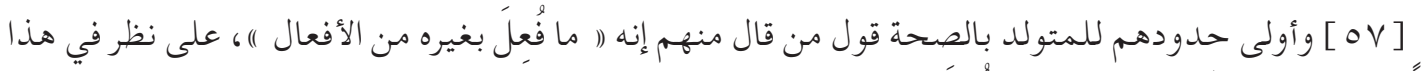

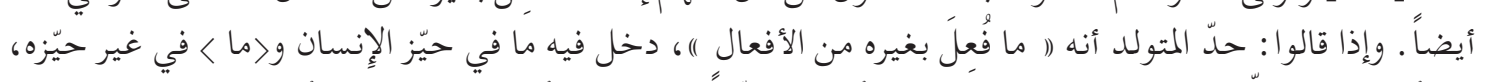

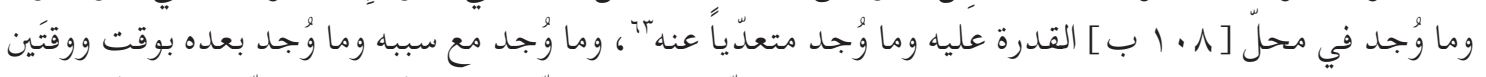

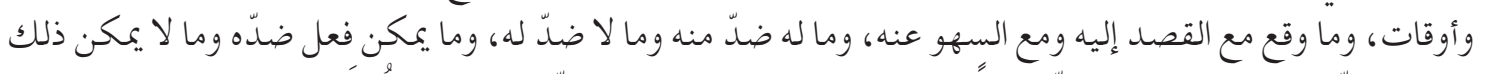

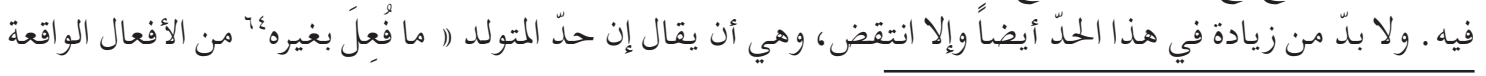

آ ـ الأصل: بسبقهم.

با ـ الأصل: لأنه.

كآ ـ الأصل : عنها.

ع ا ـ الأصل : لغيره. 


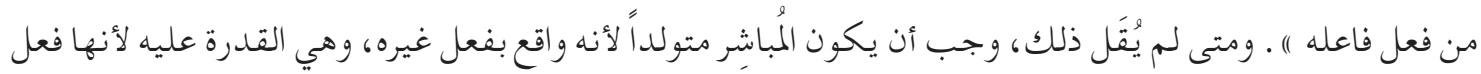

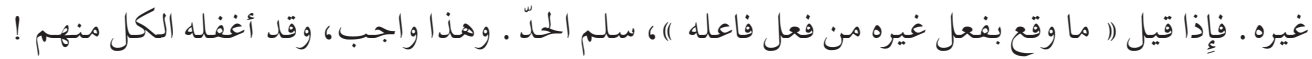

\section{[ن ف صـــ}

وقد اختلفوا في حدّ المتولد من الأفعال. فقال الإِسكافي هب في حدّه : (ا إنه كل فعل أمكن وقوعه على الخطأ

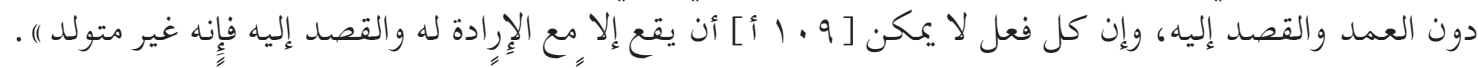

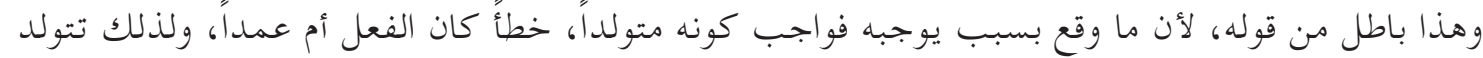

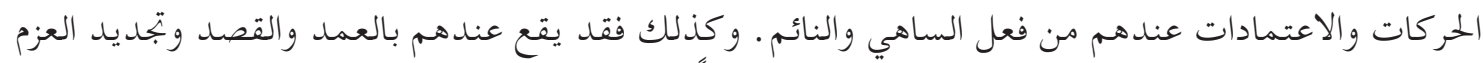

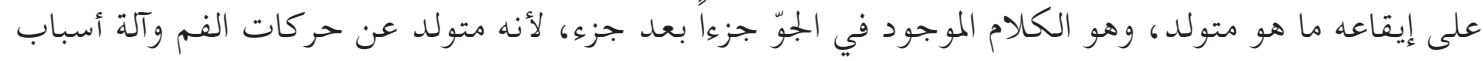
الكام، فبطل ما قالوه.

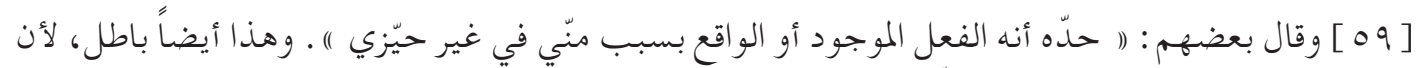

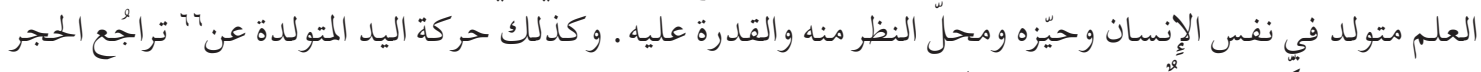

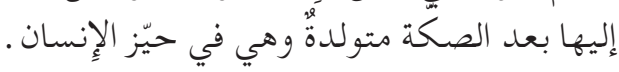

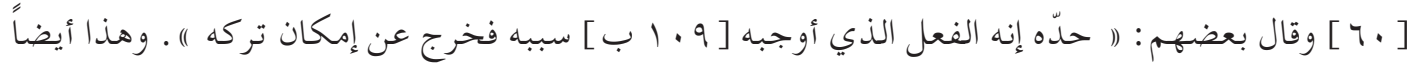

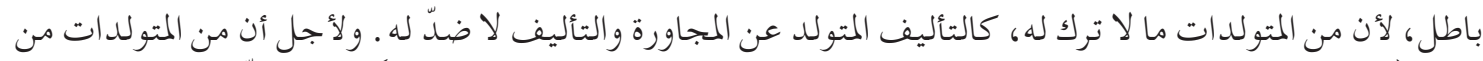

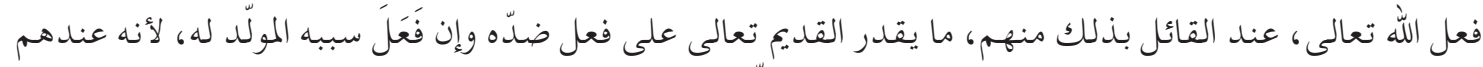

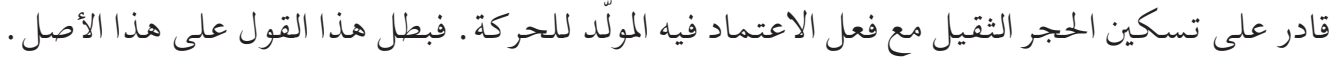

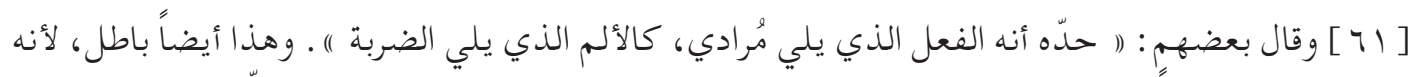

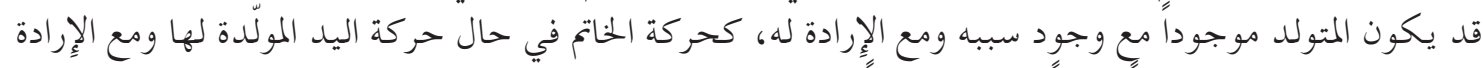

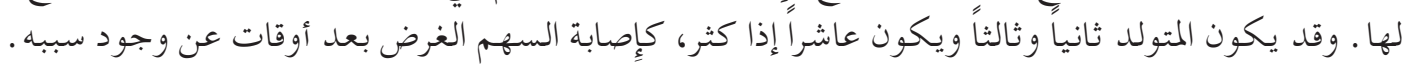

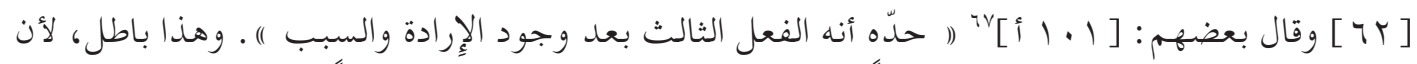

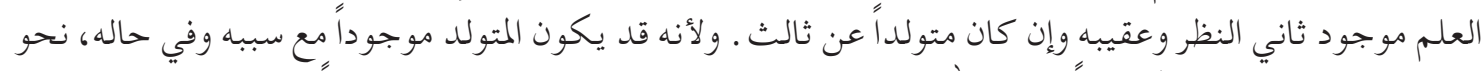

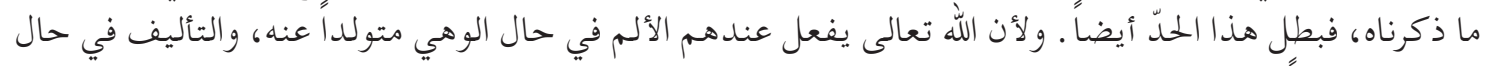

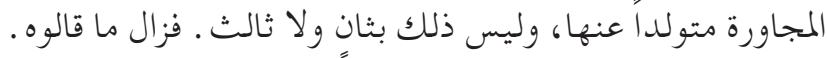

\section{باب ذكر اختلافهم في المولّد للفعل ما هو :

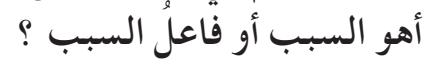

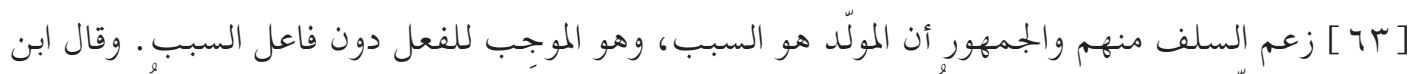

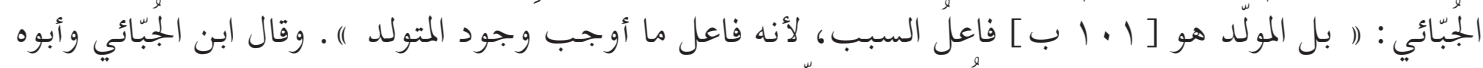

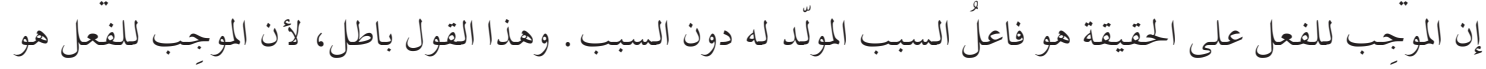


السبب دون فاعله، ولو لم يكن السبب و كان الفاعل لم يجب الفعل ولم يتولد، ولو كان السبب معدوماً والفاعل

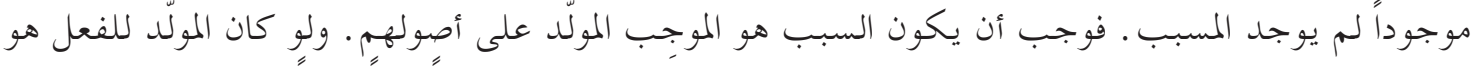

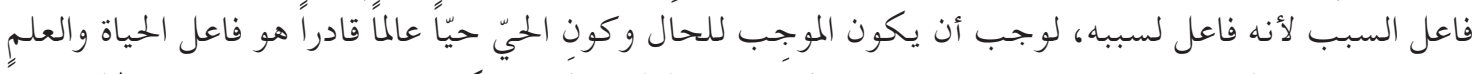

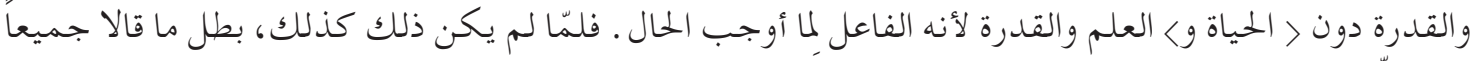

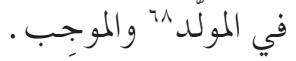

\section{ذكر اختلافهم في الأسباب المولّدة [ 1 11 أ]}

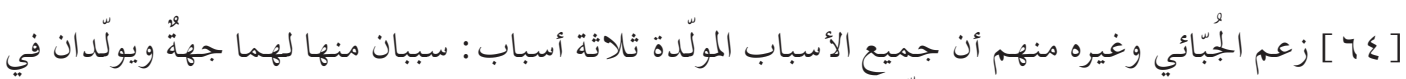

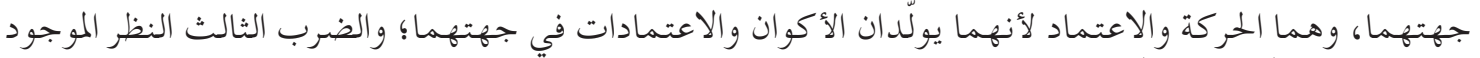

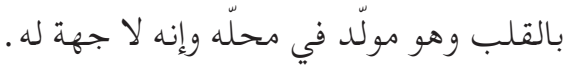

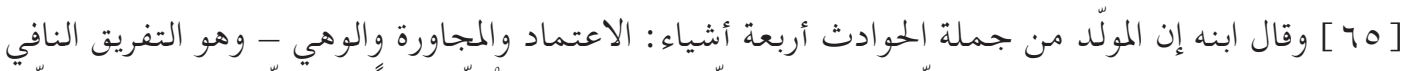

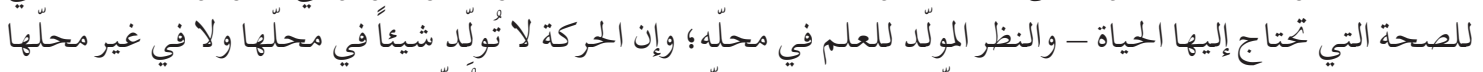

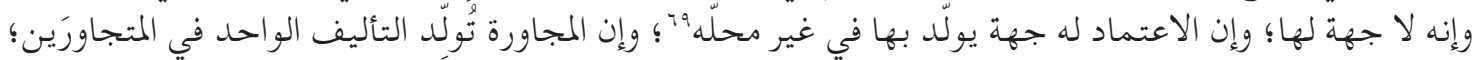

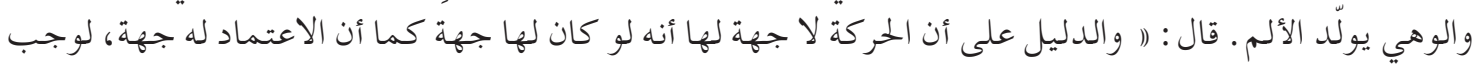

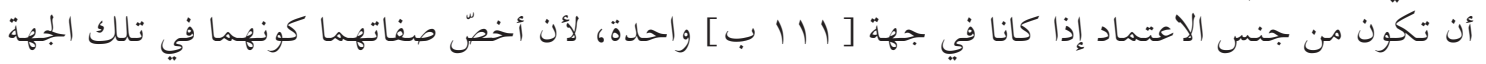

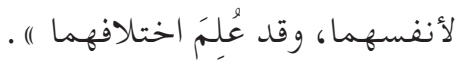

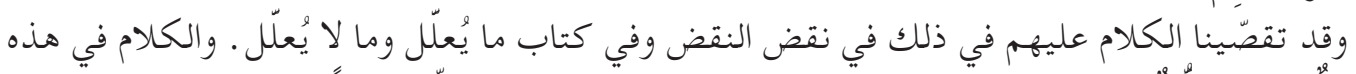

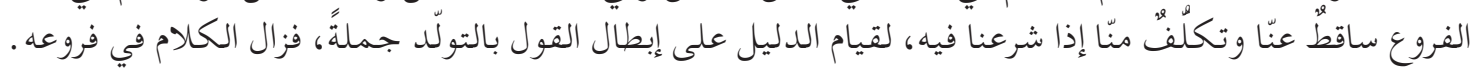

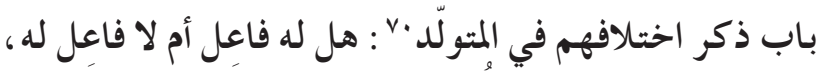

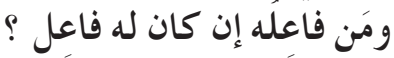

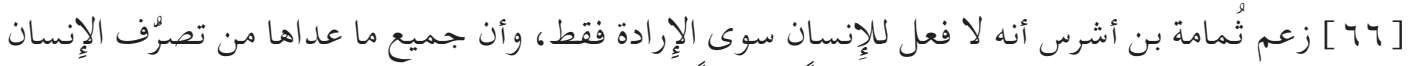

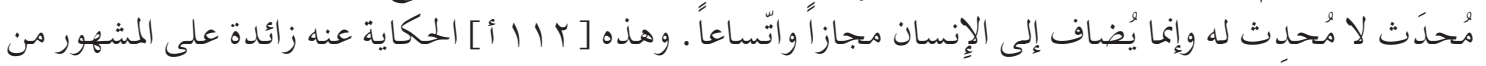

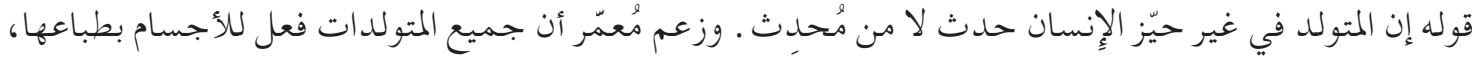

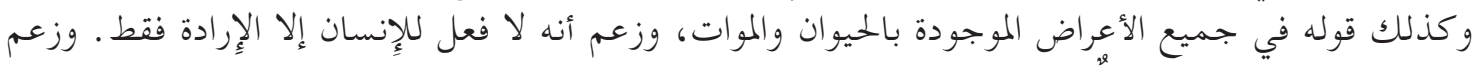

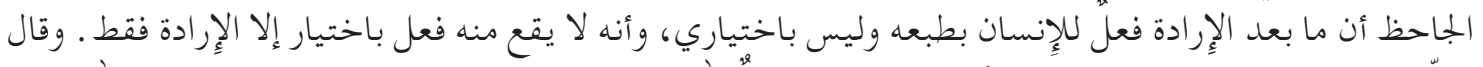

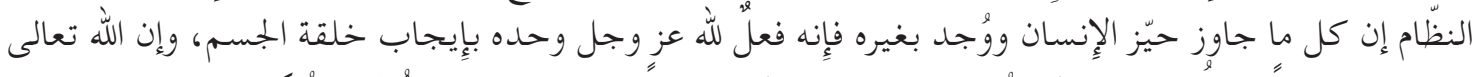

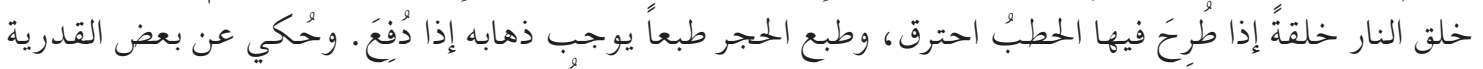

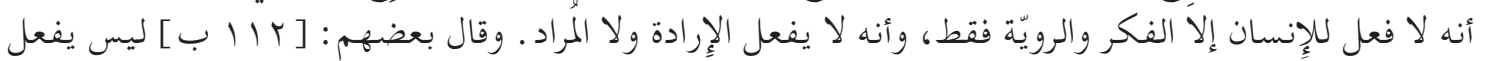

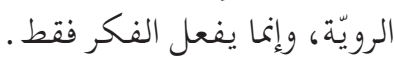

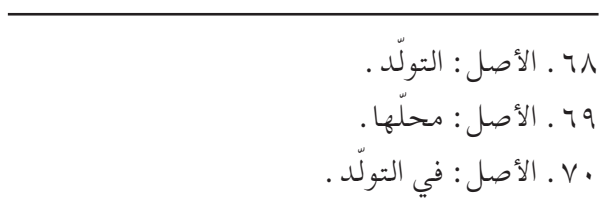




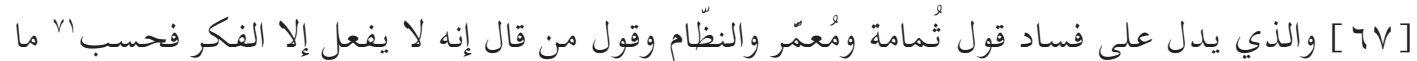

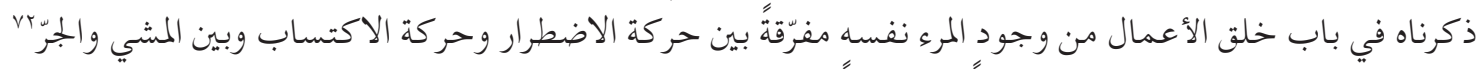

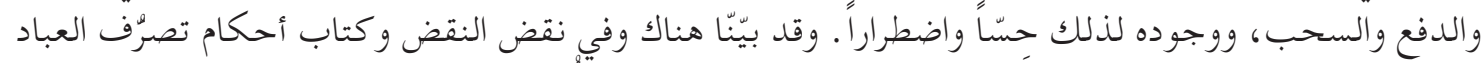

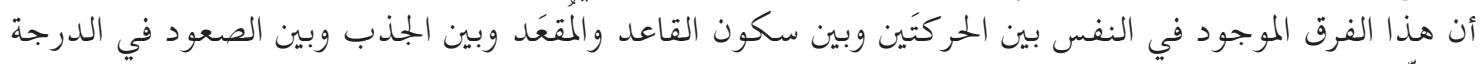

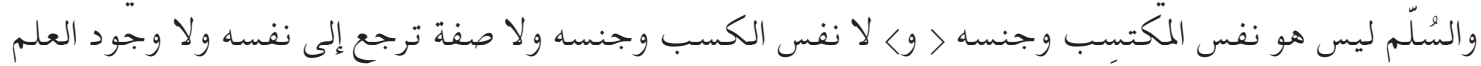

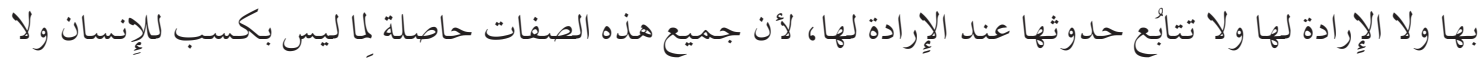

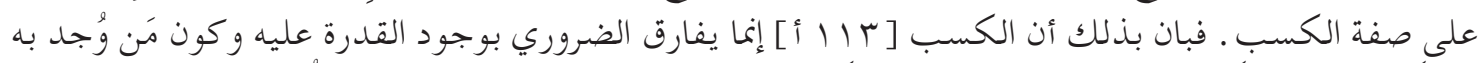

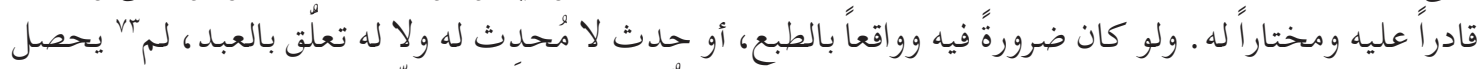

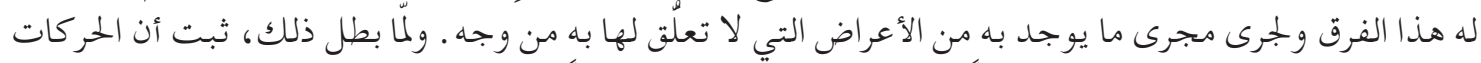

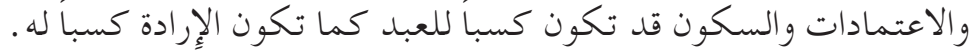

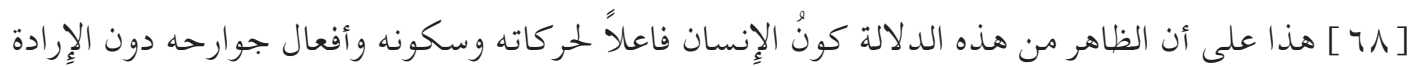

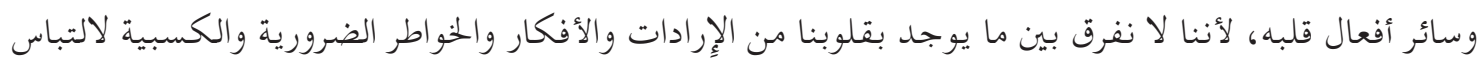

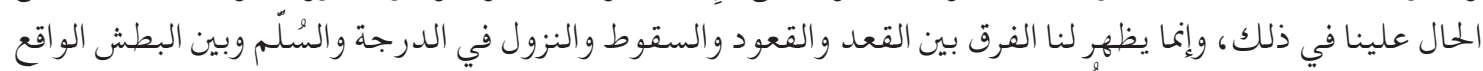

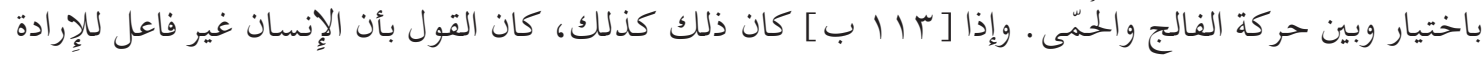

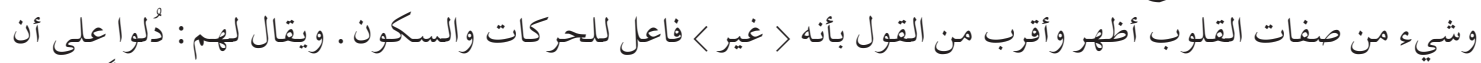

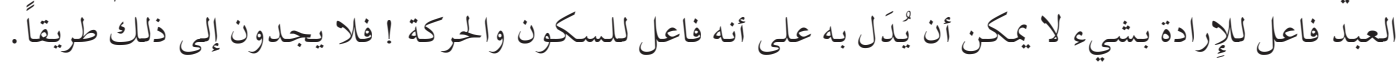

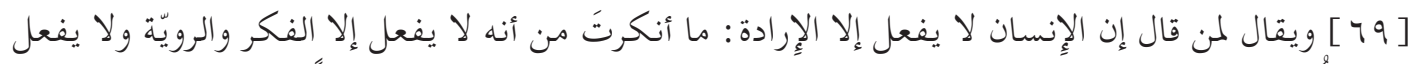

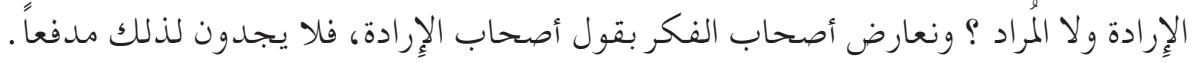

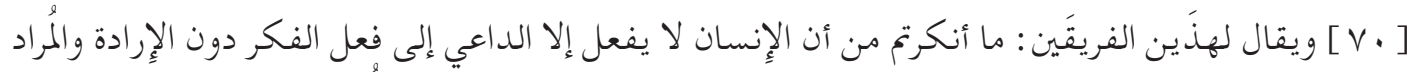

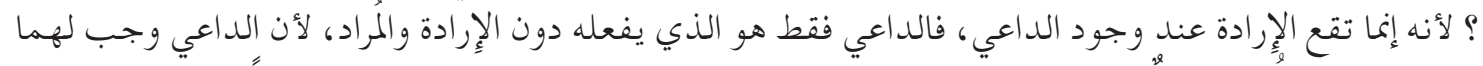

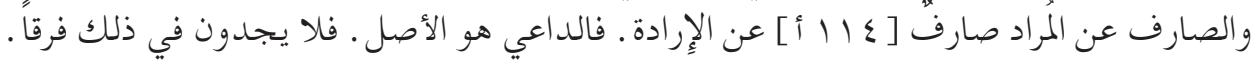

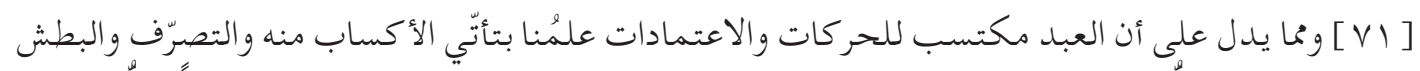

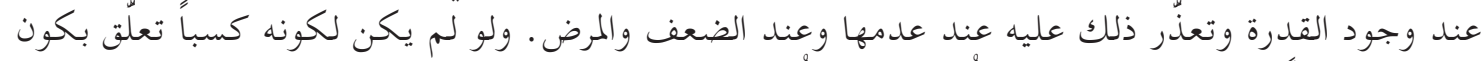

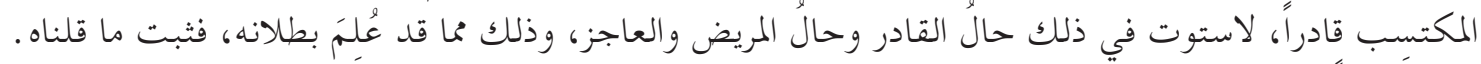

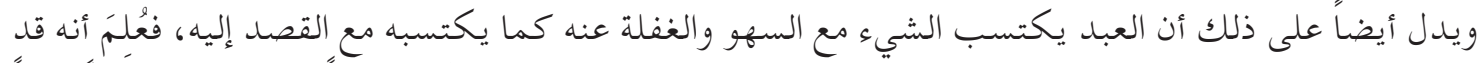

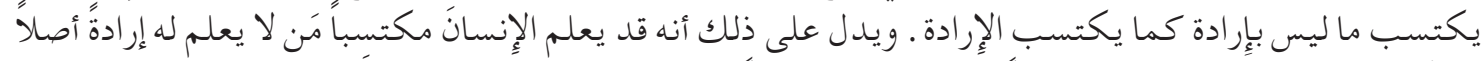

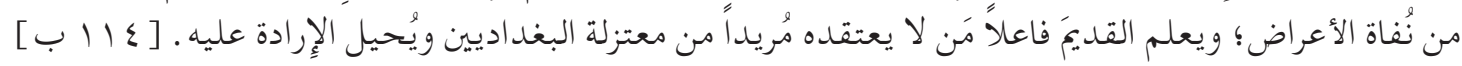

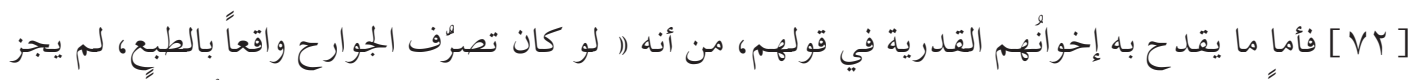

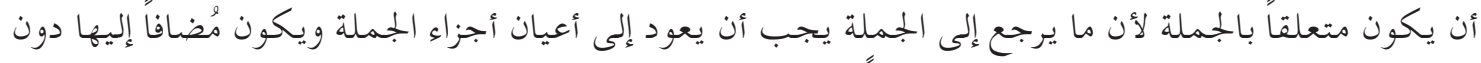

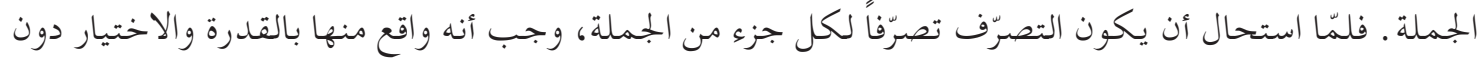

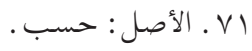

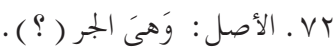

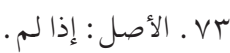




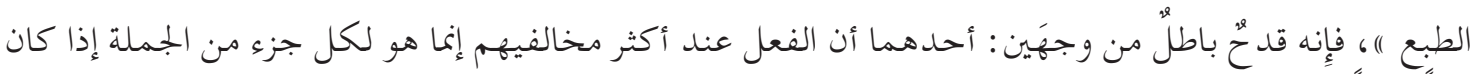

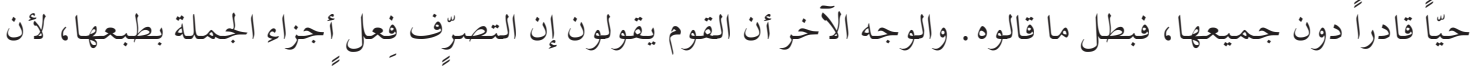

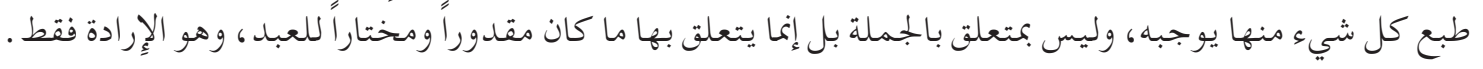
فبطل ما قالوه.

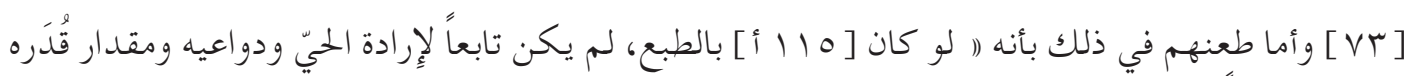

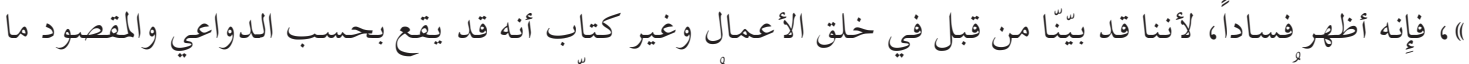

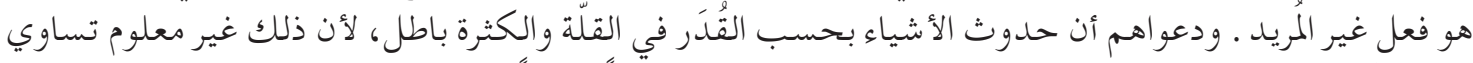

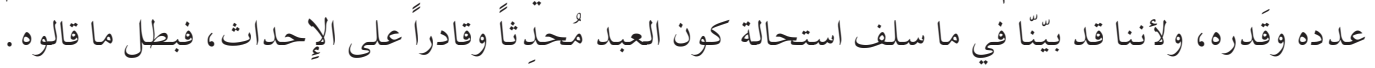

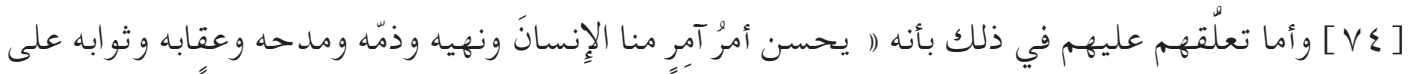

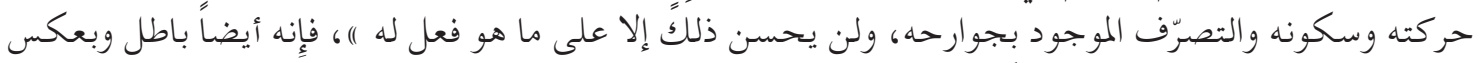

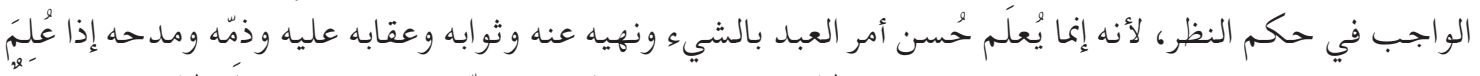
أن ذلك من فعله ومقدور اته، [ [ 110

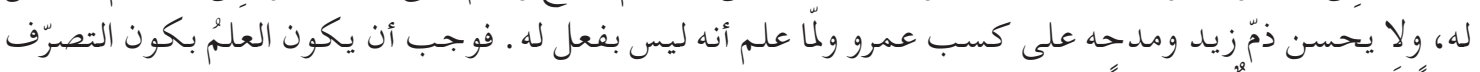

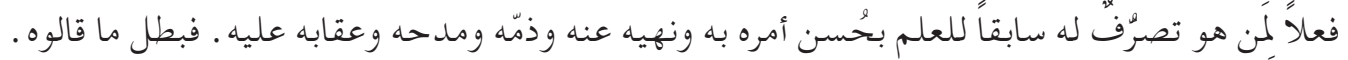

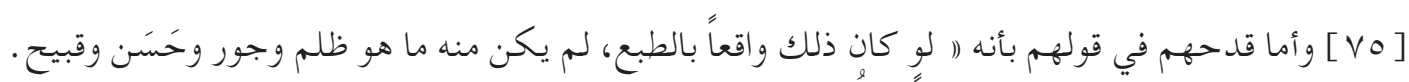

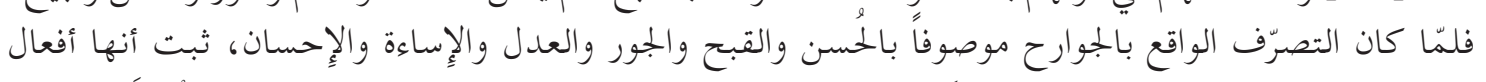

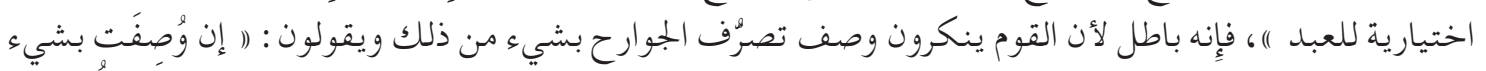

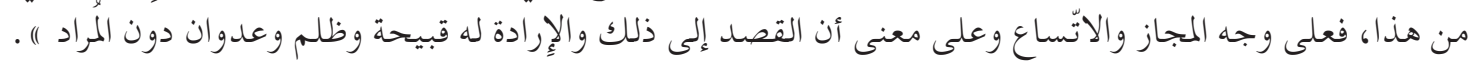

\section{[i 1119$]$}

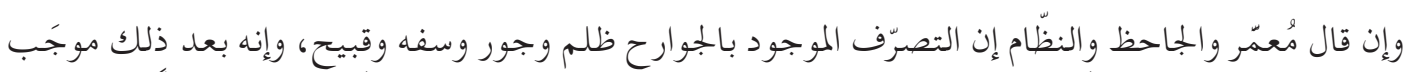

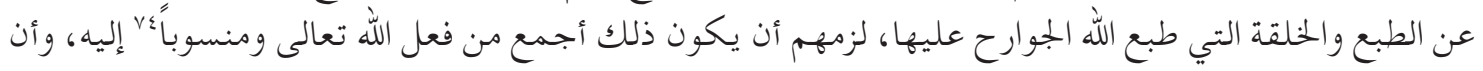

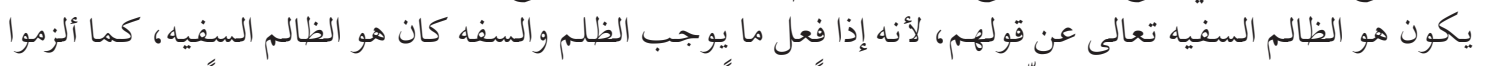

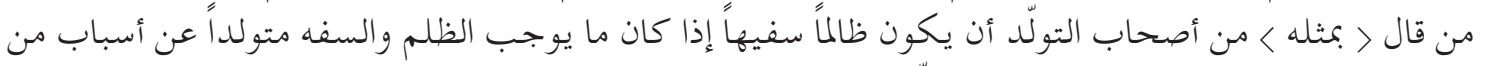

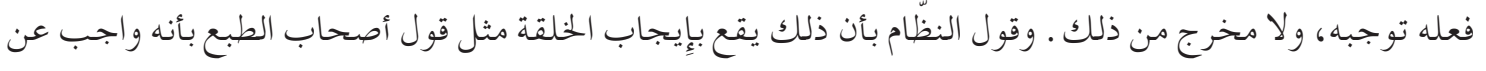

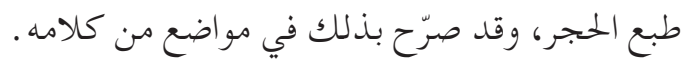

\section{ف ف صــ [V ]}

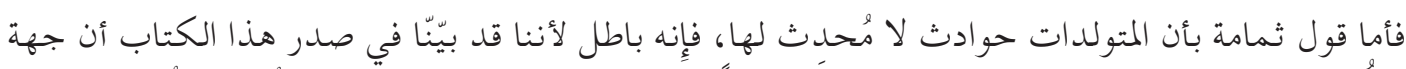

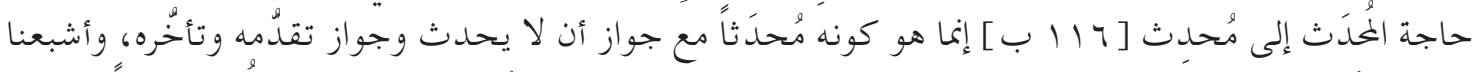

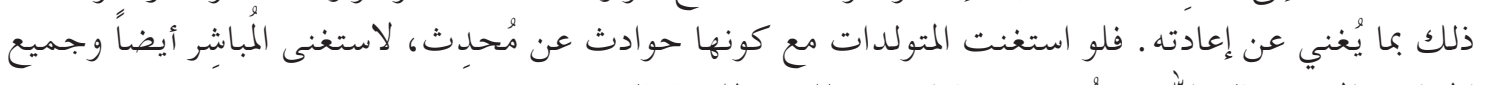

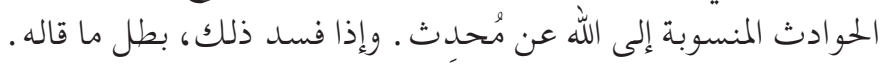




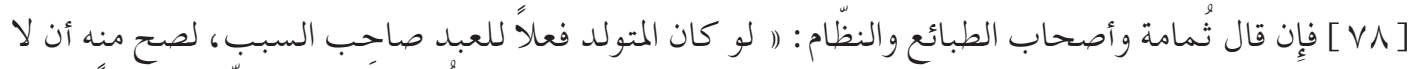

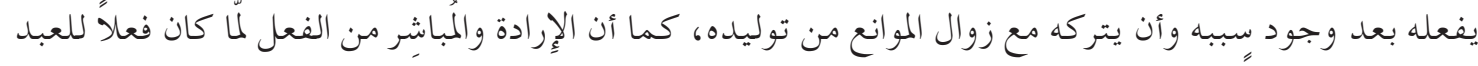

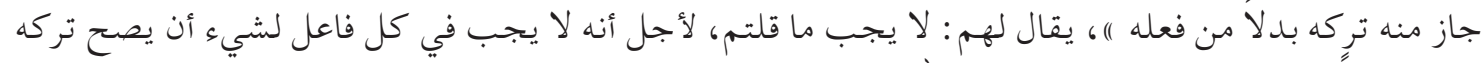

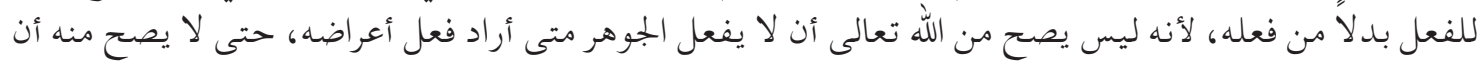

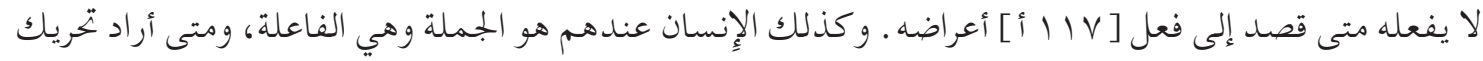

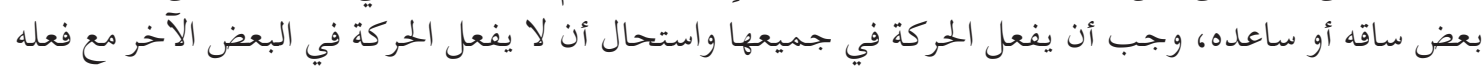

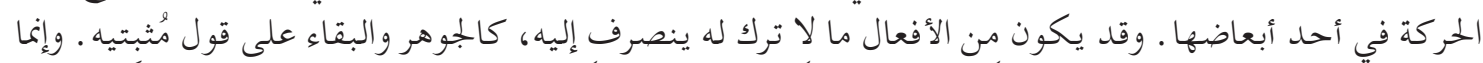

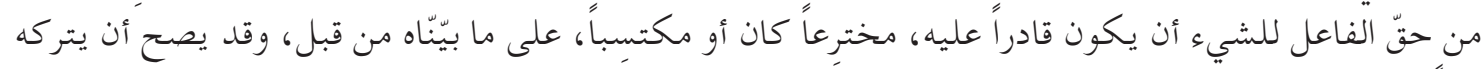
تارةً ولا يصح منه أخرى.

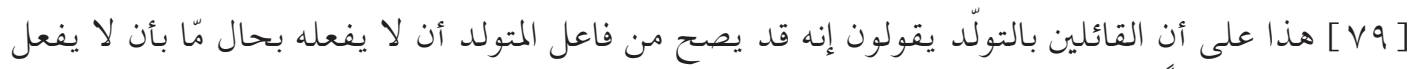

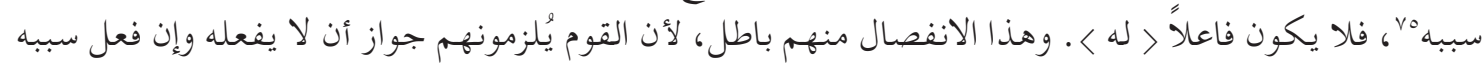

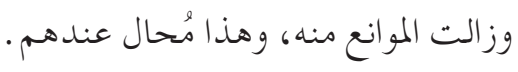

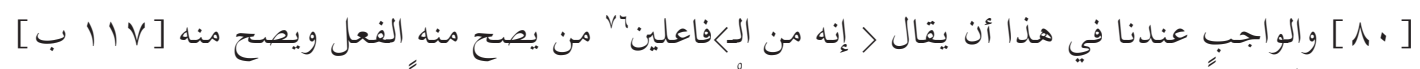

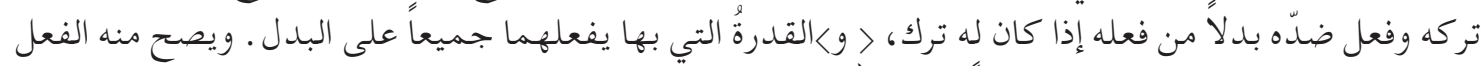

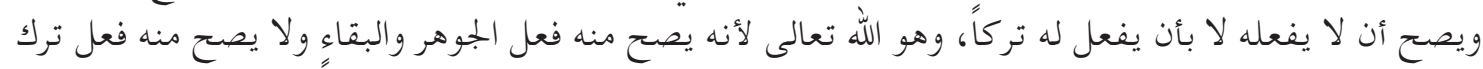

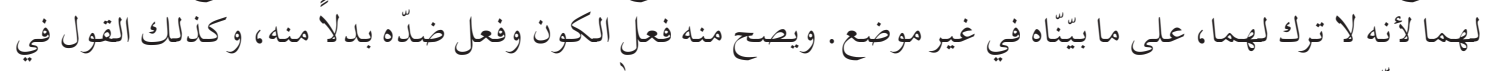

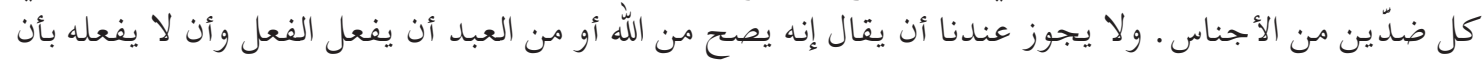

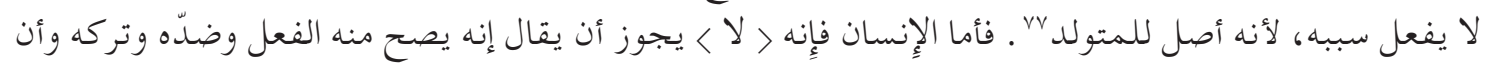

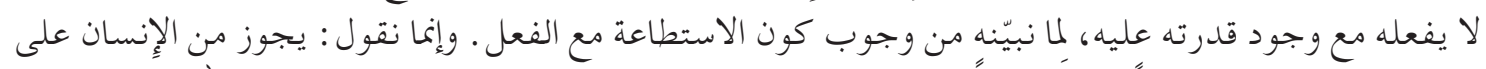

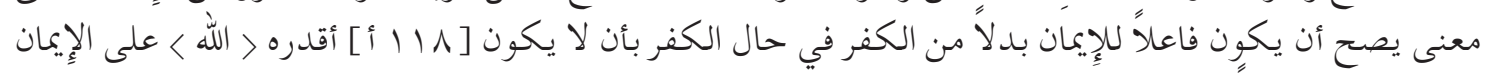

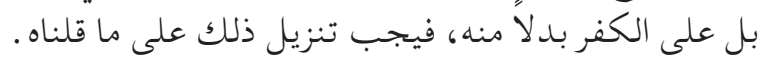

\section{[ ] فــــل}

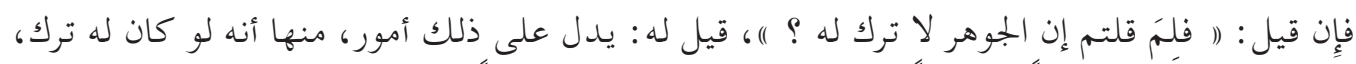

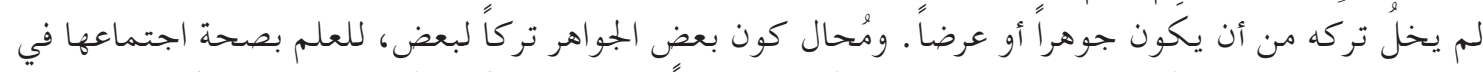

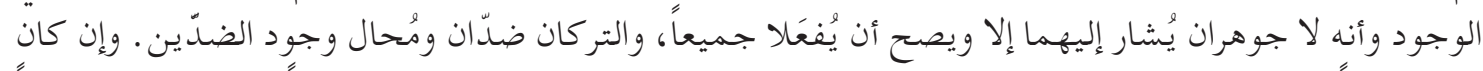

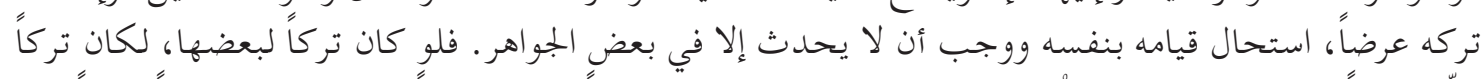

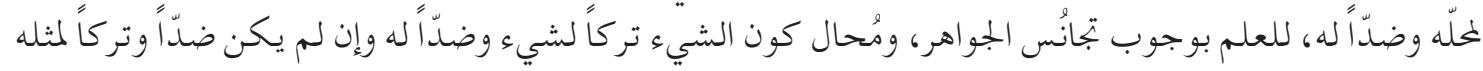

Vo

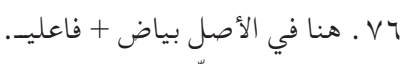

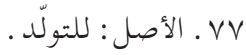




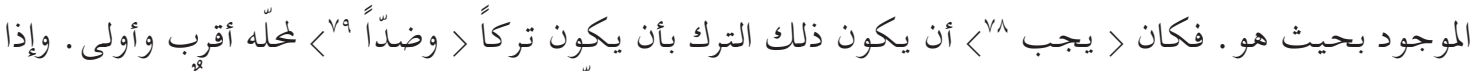

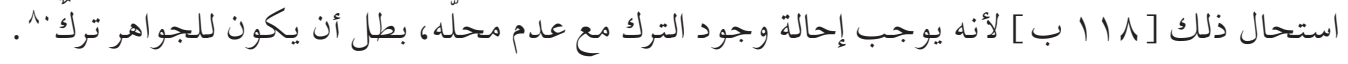

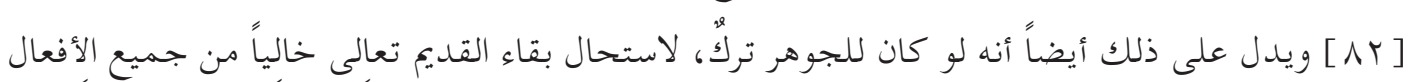

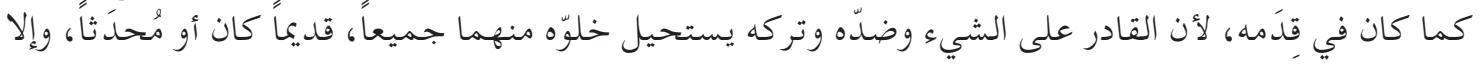

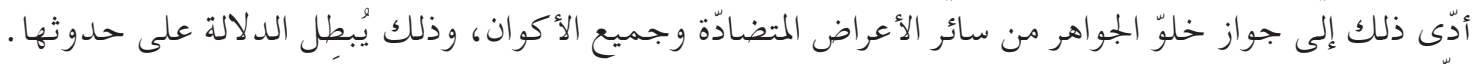

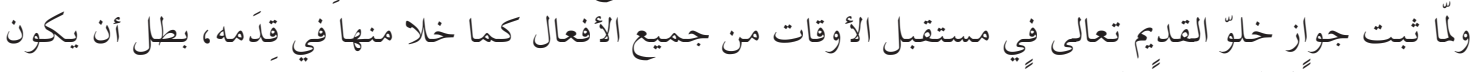

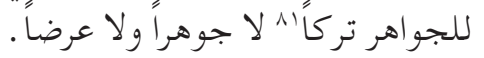

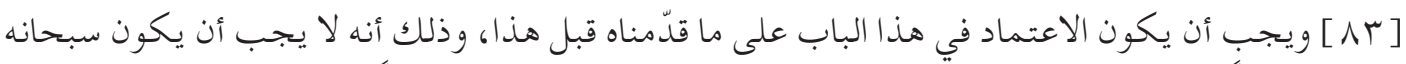

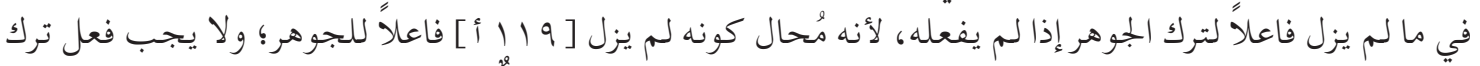

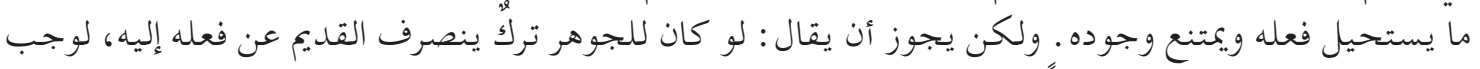

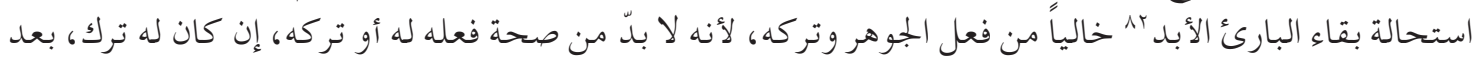

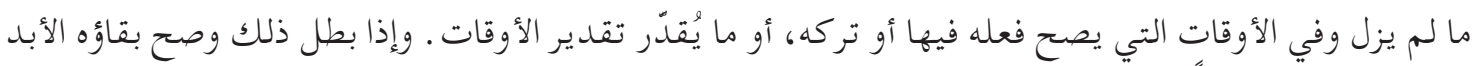

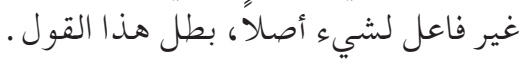

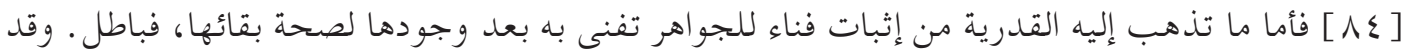

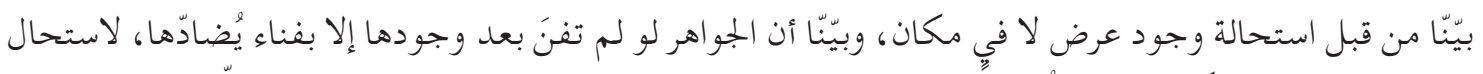

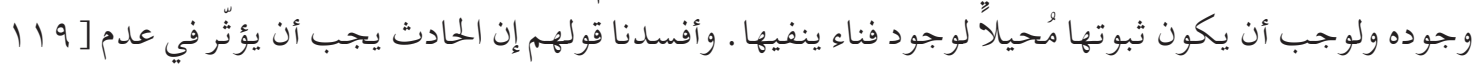

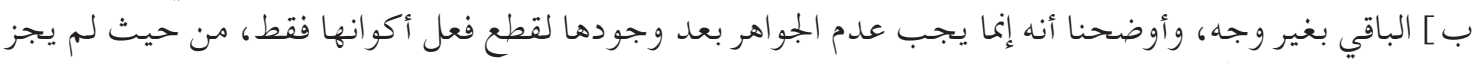

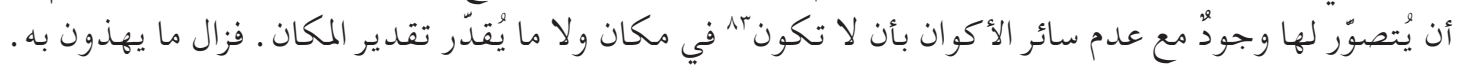

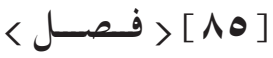

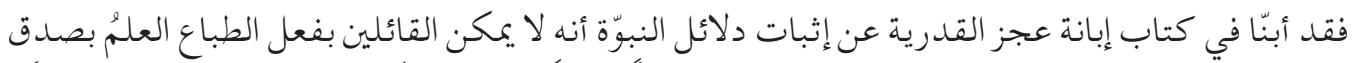

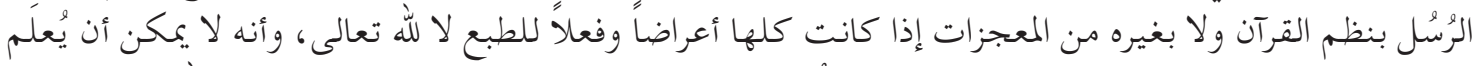

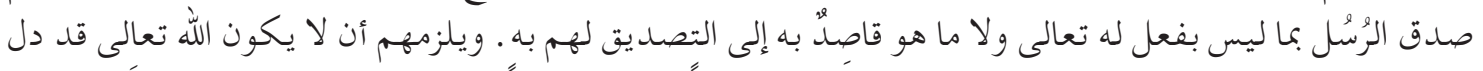

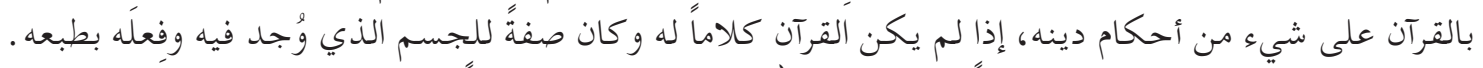

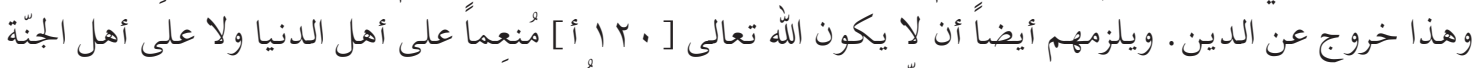

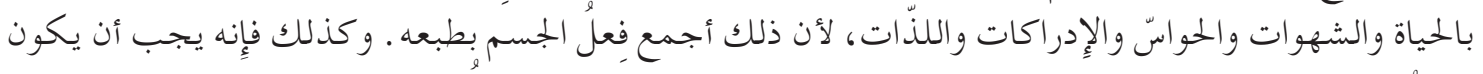

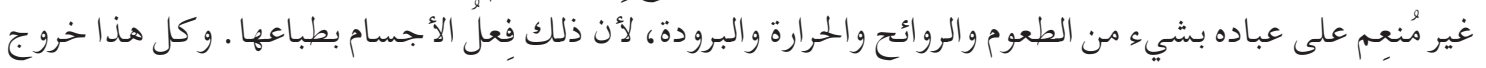

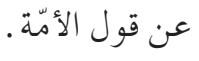

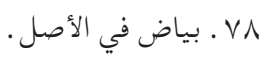

. . . . بياض في الأصل.

• 1. الأصل : تركاً. ترك . 20.

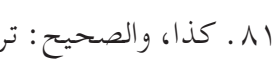

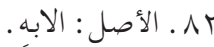

rی الأصل : يكون . الأه . 


\section{] [ ف ف صــل}

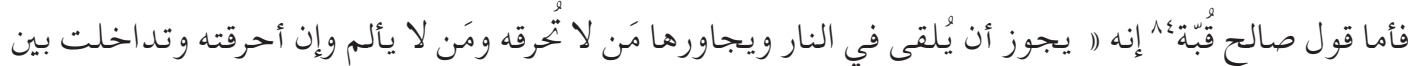

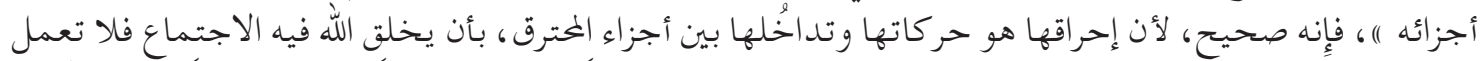

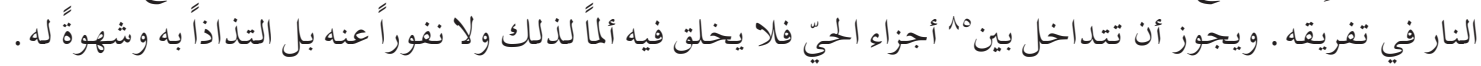

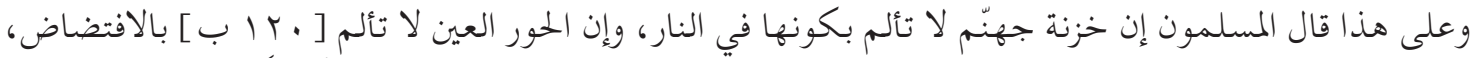

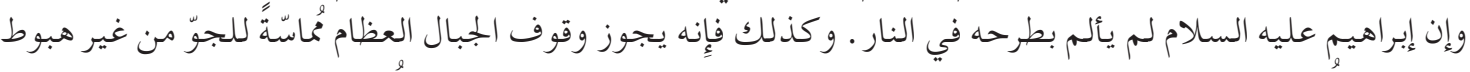

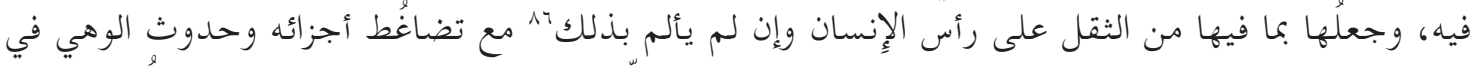

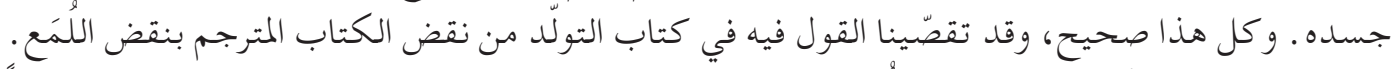

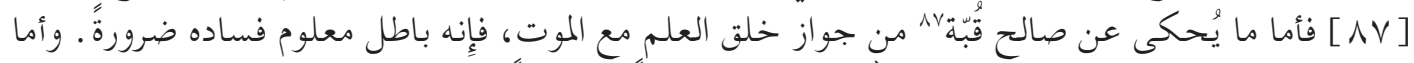

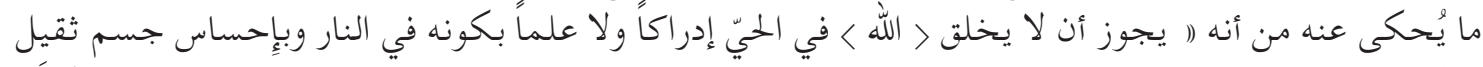

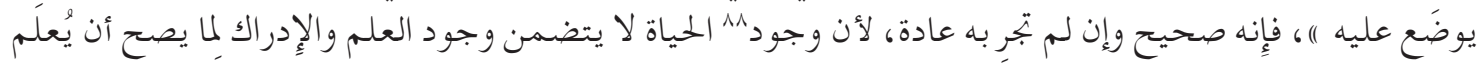

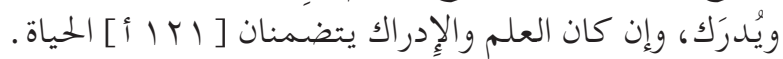

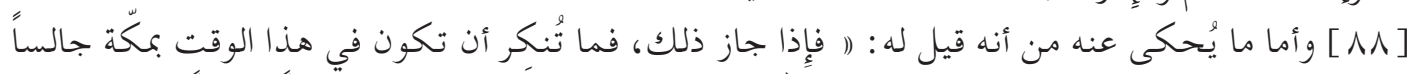

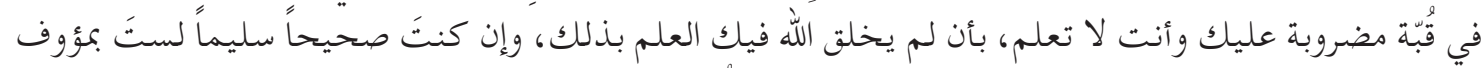

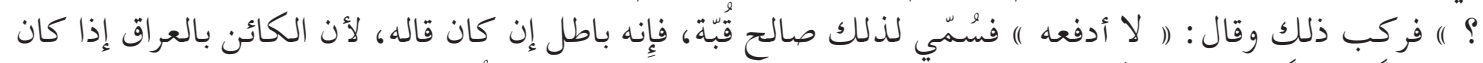

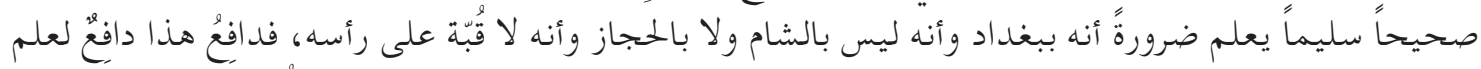

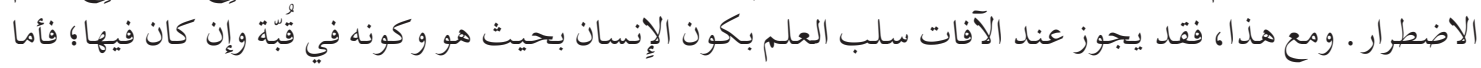

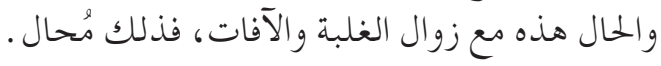

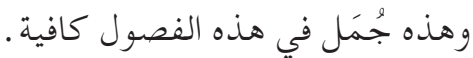

\section{[ ف ف صـــ ]}

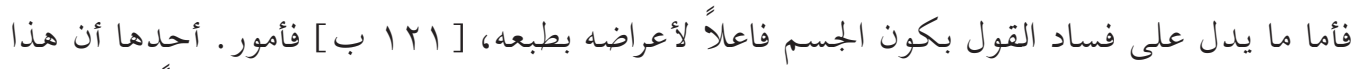

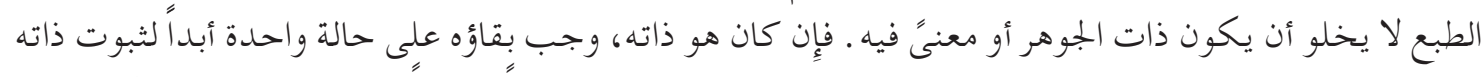

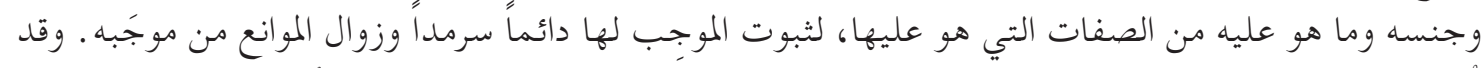

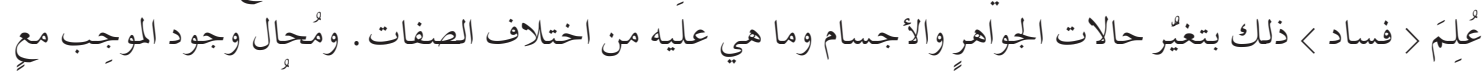

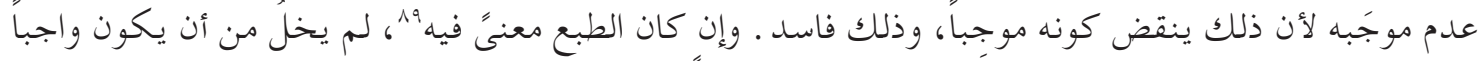

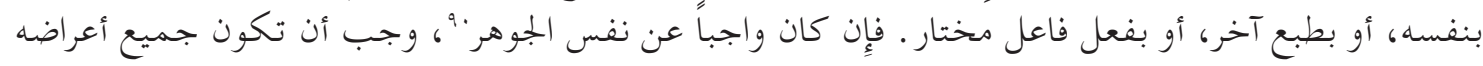

م م. الأصل : فيه

م م ـ الأصل: يتد اخل من.

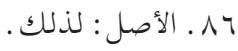

N . الأصل : فيه.

1 ـ الأصل: ورجوه.

و م ـ الأصل : فيها.

• 9 ـ الأصل : الاصو : فئا. 


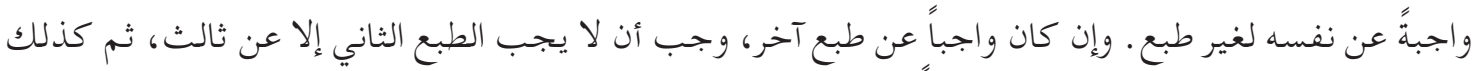

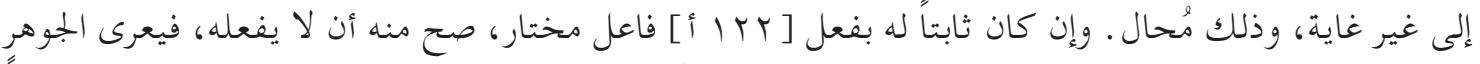

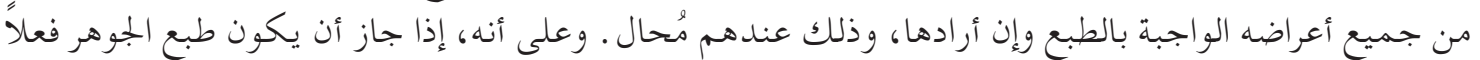

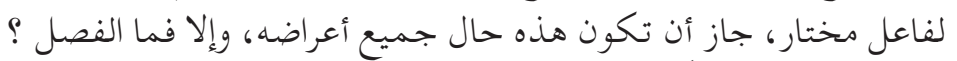

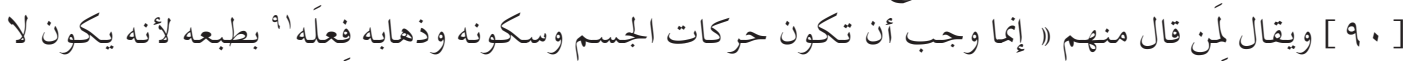

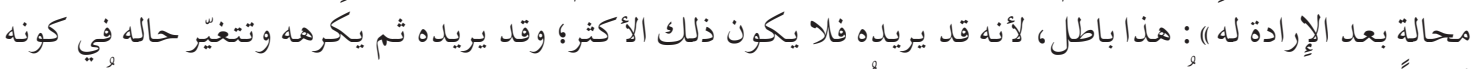

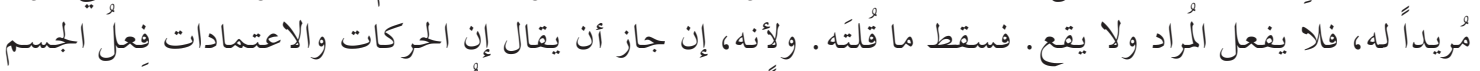

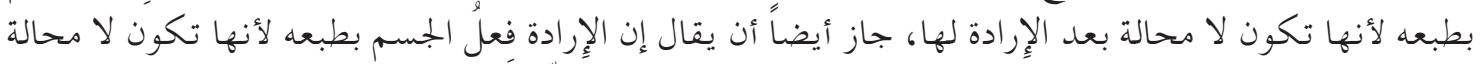

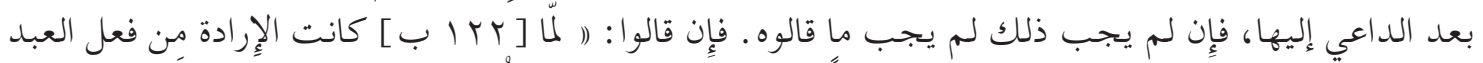

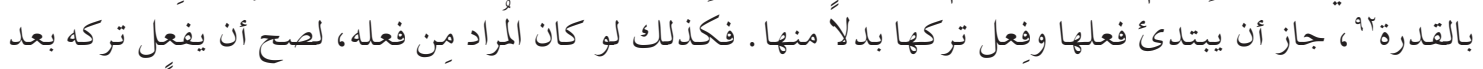

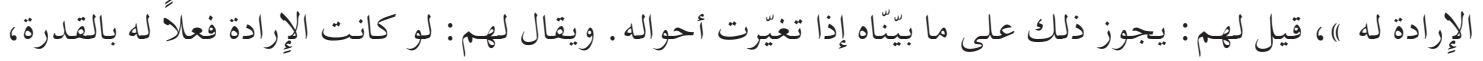

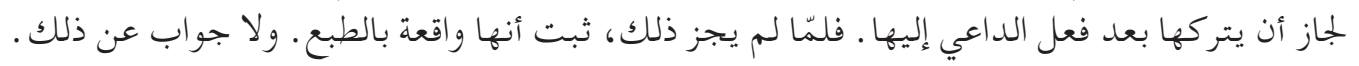

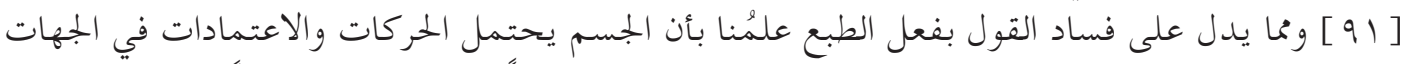

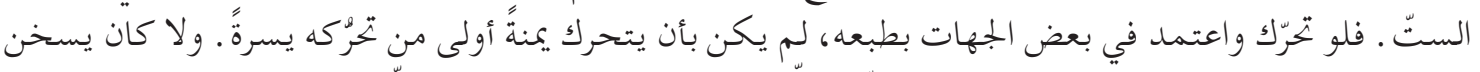

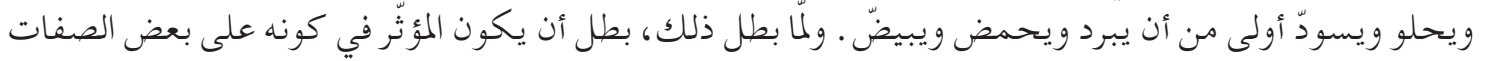

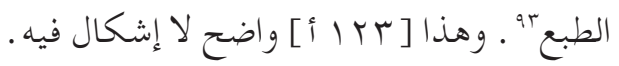

\section{باب ذكر اختلافهم في هل يفعل العباد الإِدراك والعلم في الغير والألوان

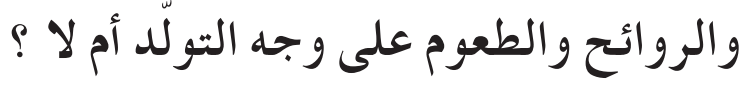

[ بو ] وقد اختلف القائلون بالتولّد ـ فزعم الجمهور منهم أنه لا يصح فعل الإِدراك والعلم في الغير والألوان

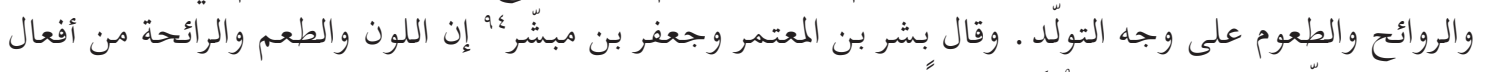

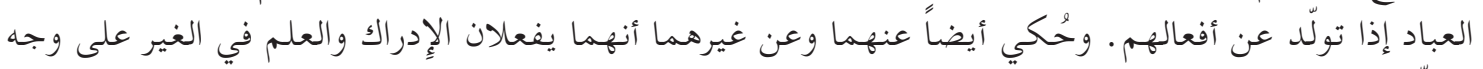

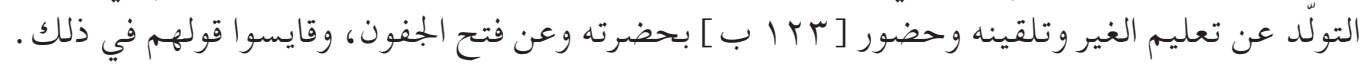

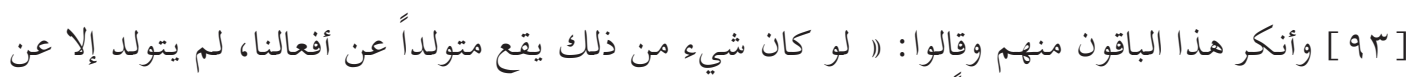

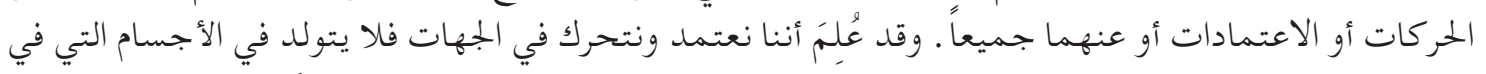

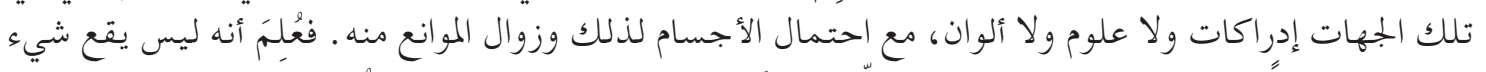

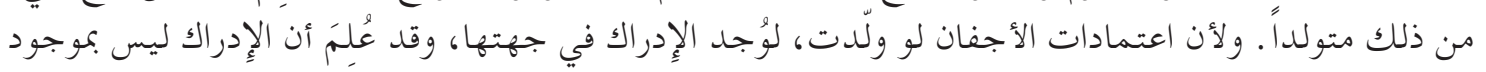

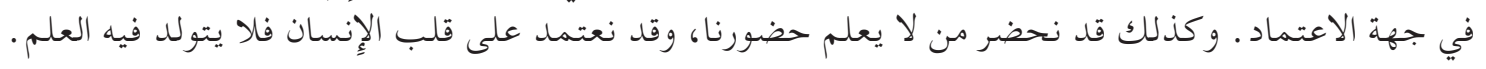

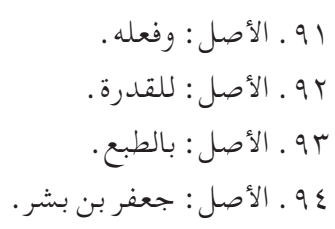




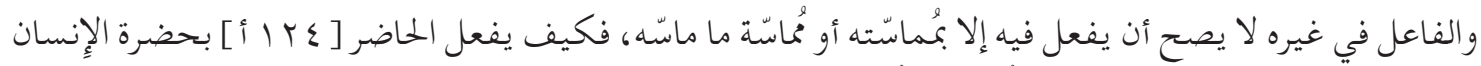

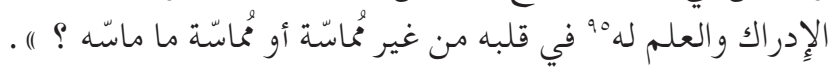

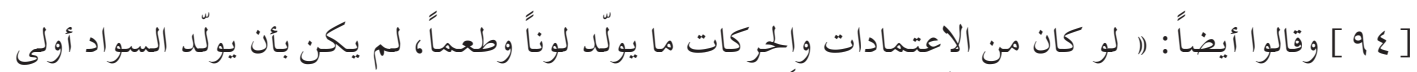

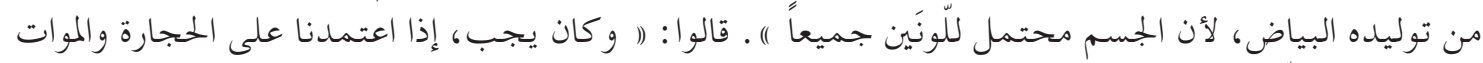

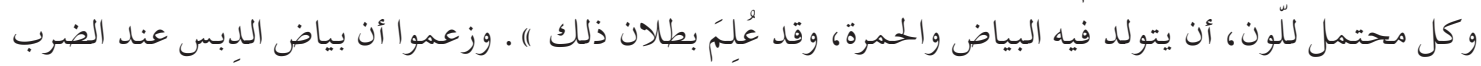

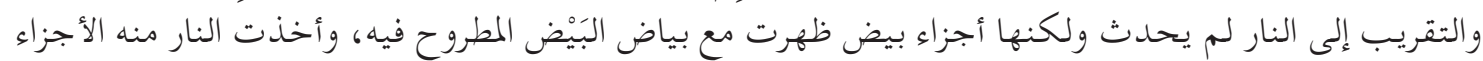

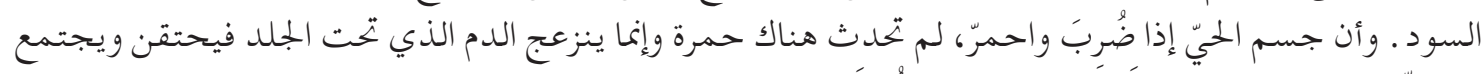

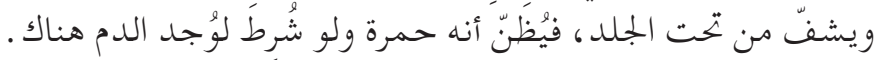

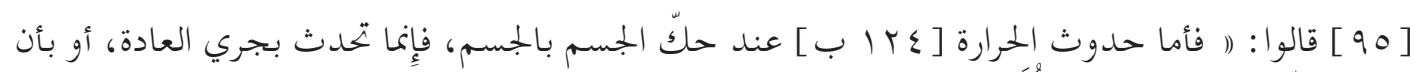

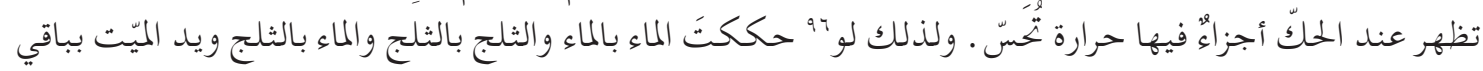

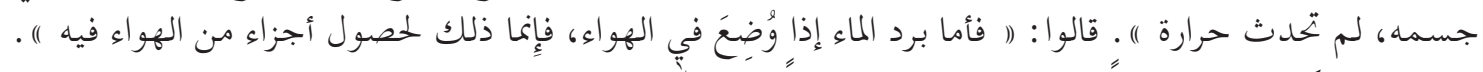

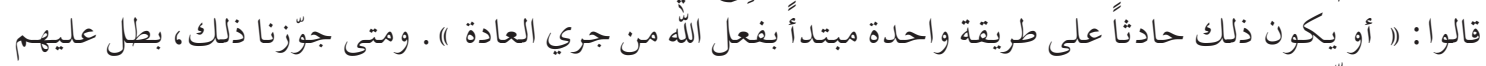

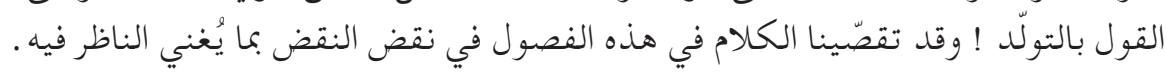

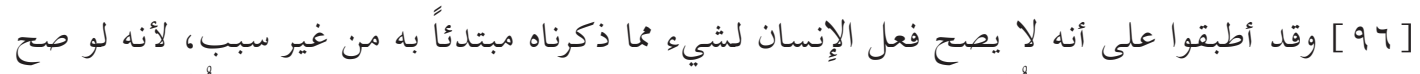

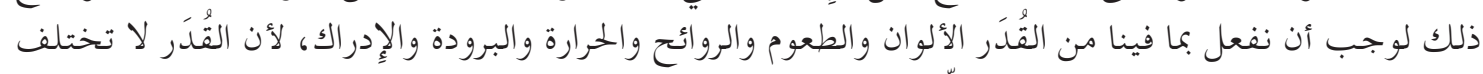

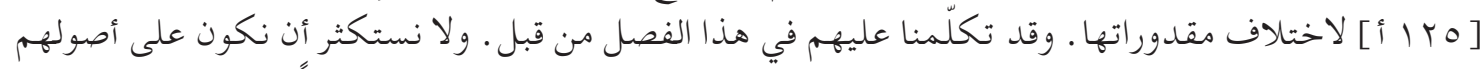

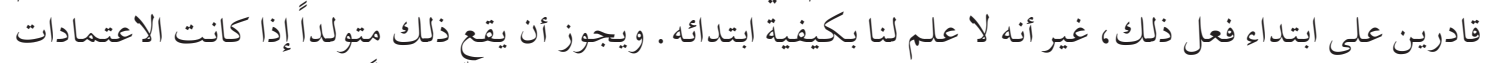

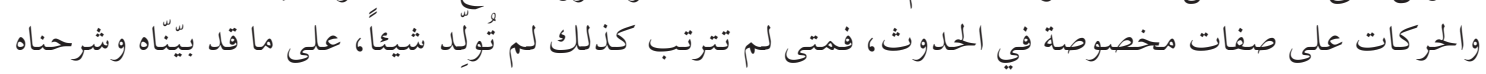

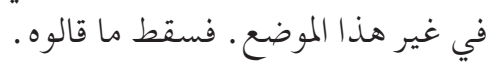

\section{ف $[9 \vee]$}

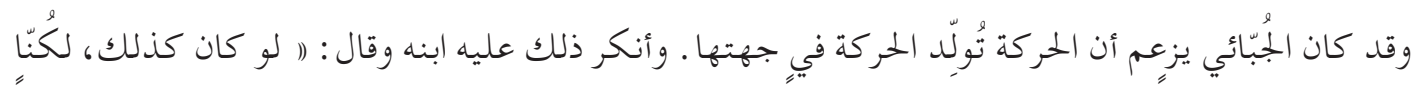

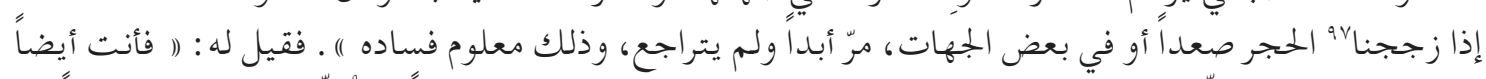

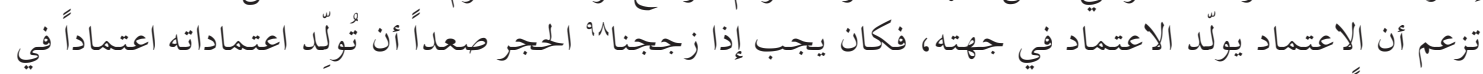

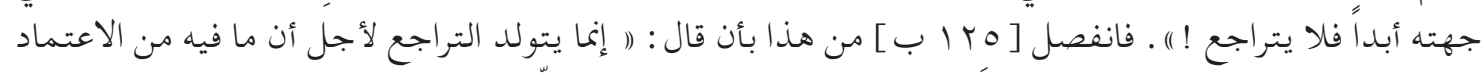

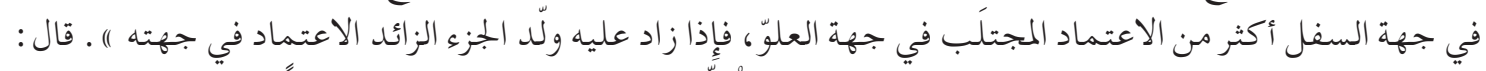

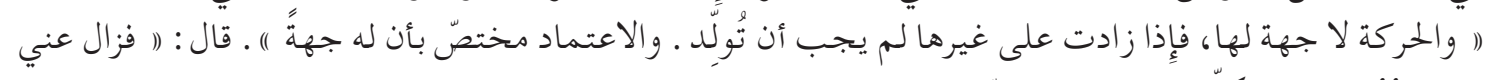

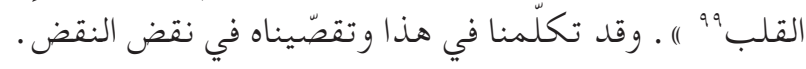

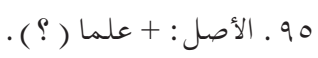

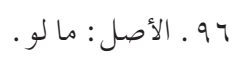

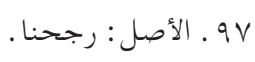

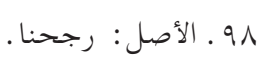
99 9 . أي قلب الإِلزام. 


\section{باب ذكر اختلافهم في ما يصح أن يقع متولداً وما لا يصح أن يقع ذلك في في فيح ان يفع}

[ [ 19 ] قال الكل من القائلين بالتولّد : الإِرادة لا يجوز أن تكون متولدةً وإنما نبتدئ فعلها بالقدرة عليها . فأما

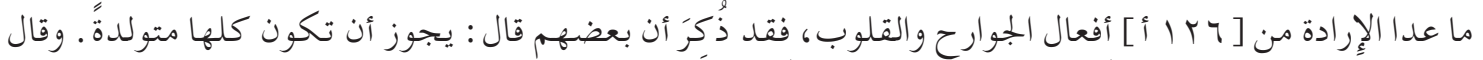

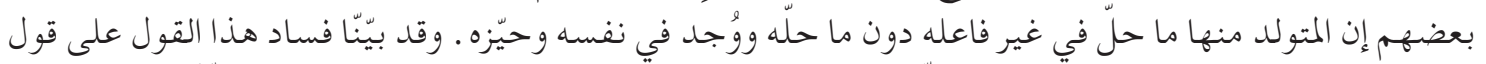

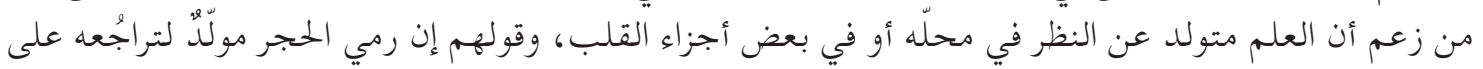

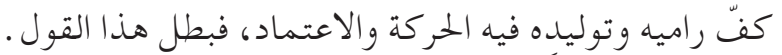

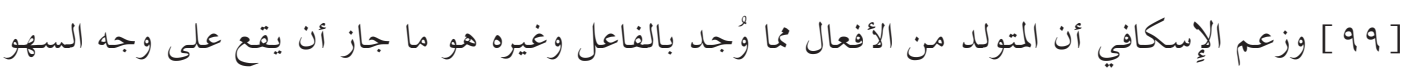

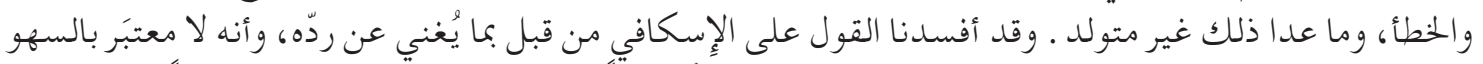

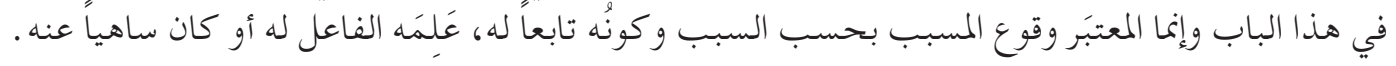

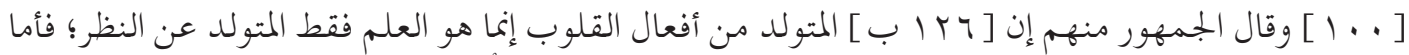

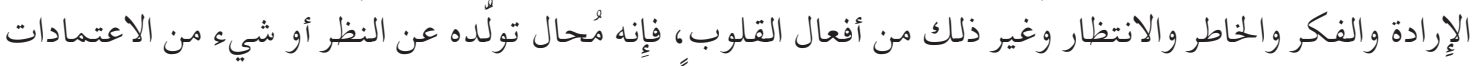

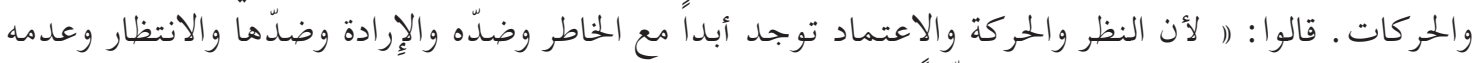

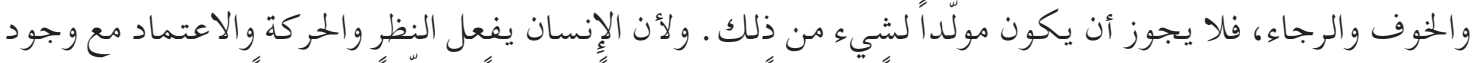

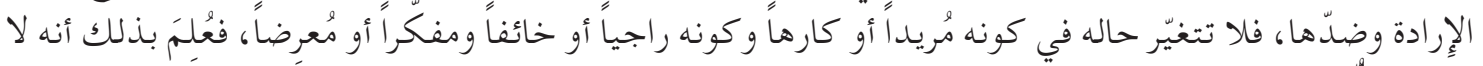

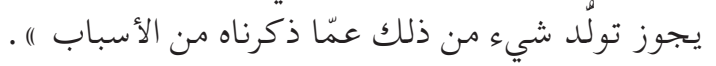

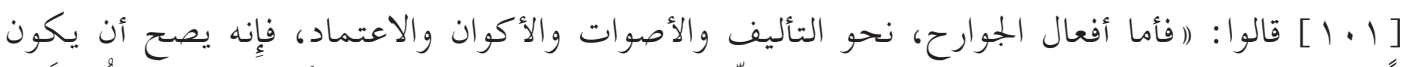

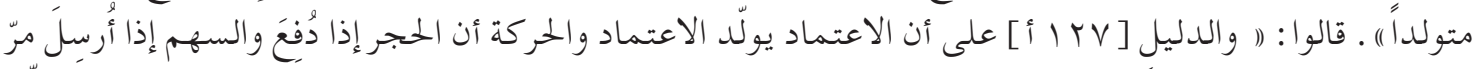

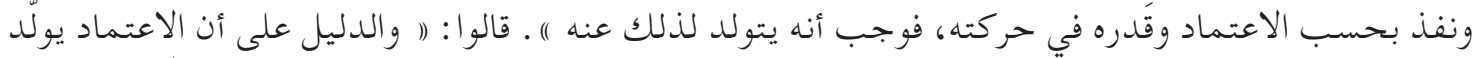

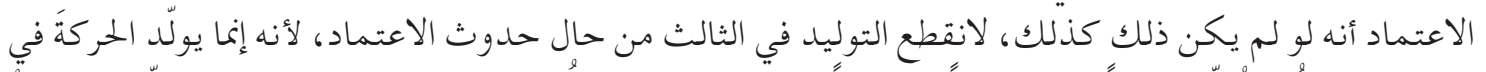

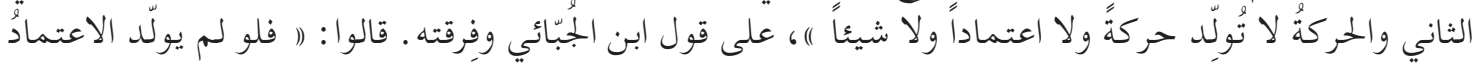

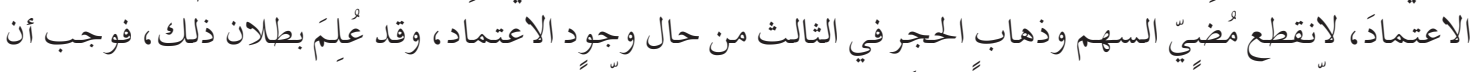

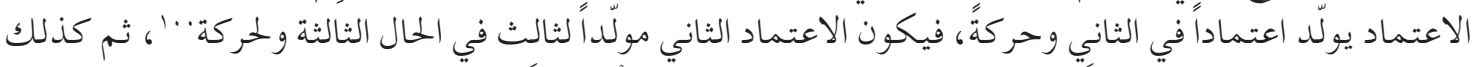

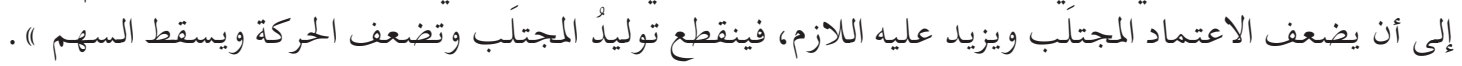

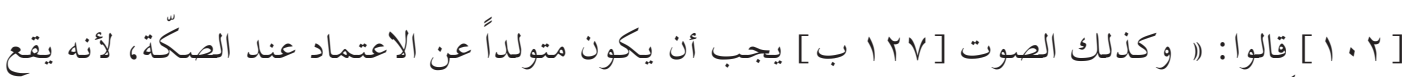

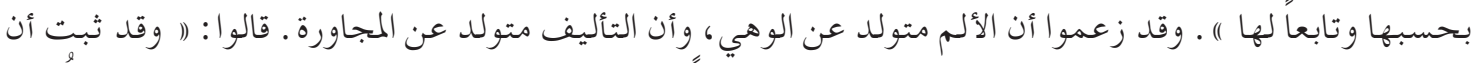

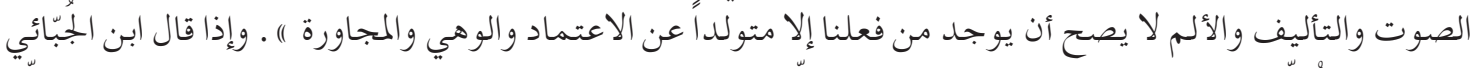

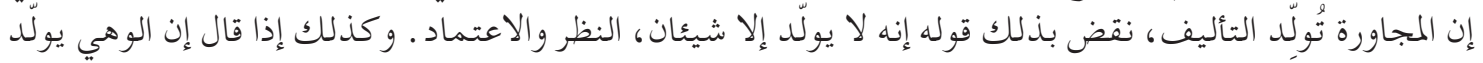

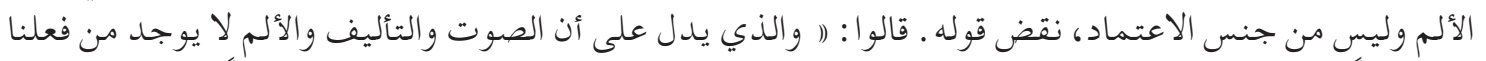

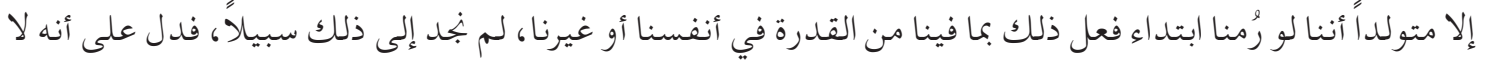




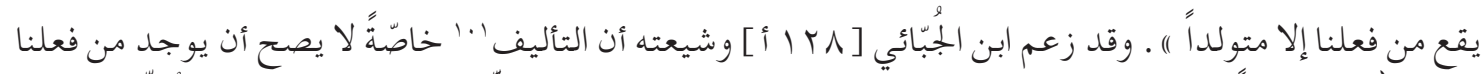

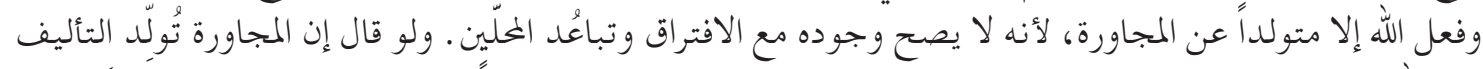

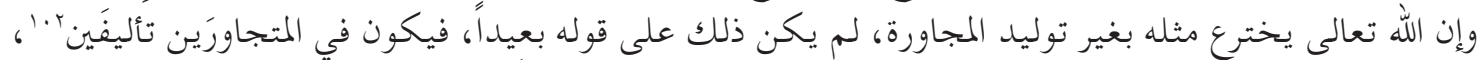

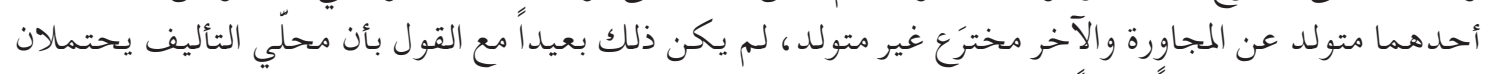

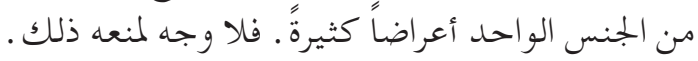

\section{[ [1,}

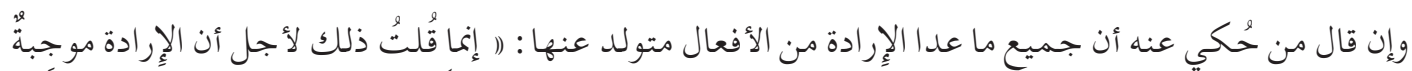

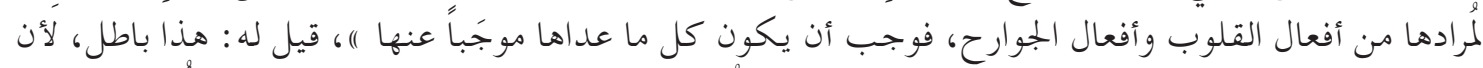

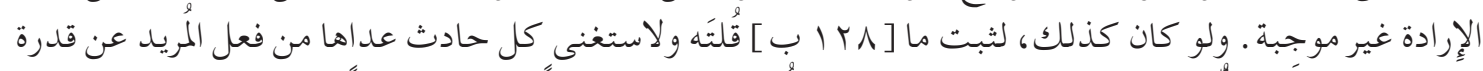

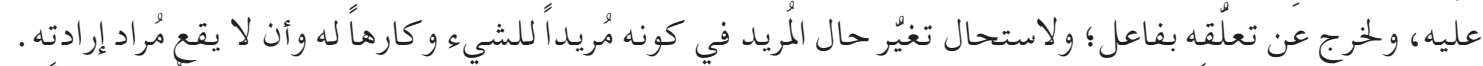

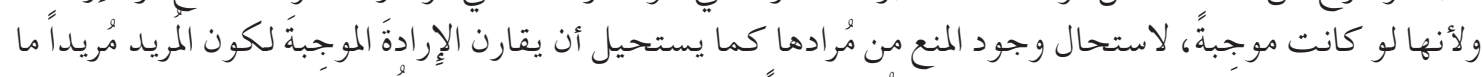

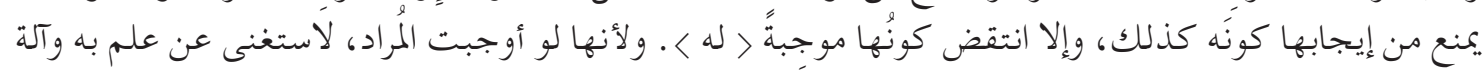

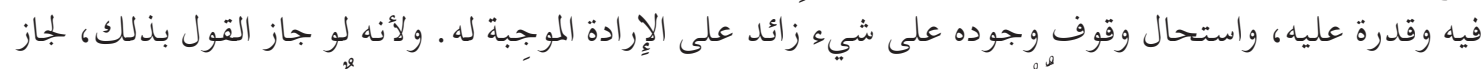

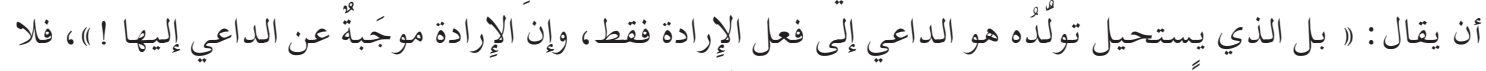

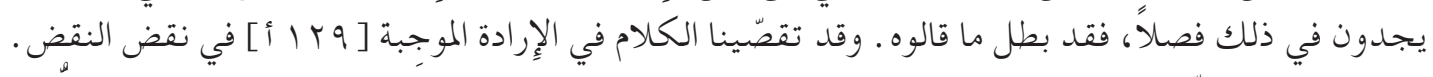

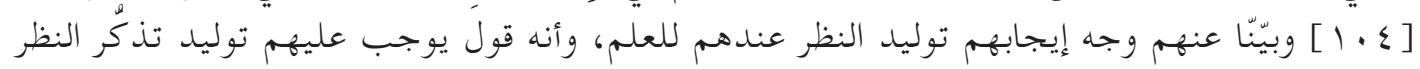

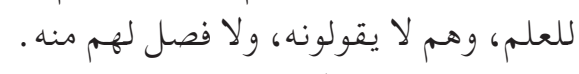

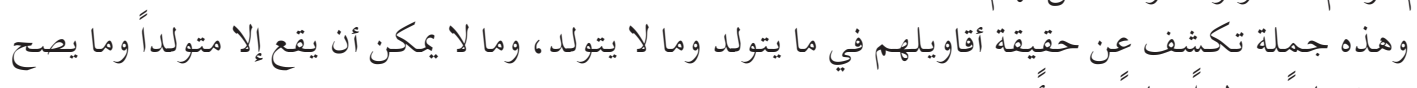

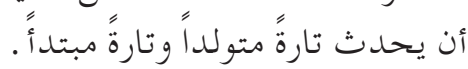

\section{باب ذكر اختلاف القائلين بالتولّد في القدرة ،

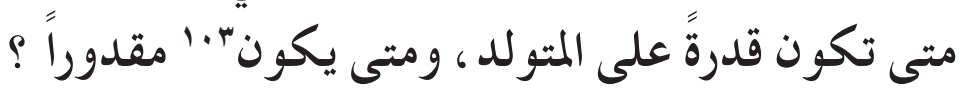

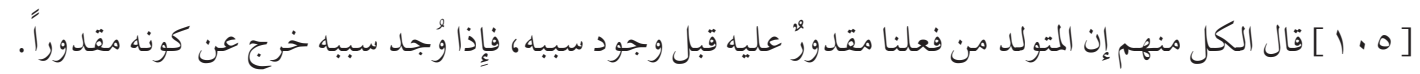

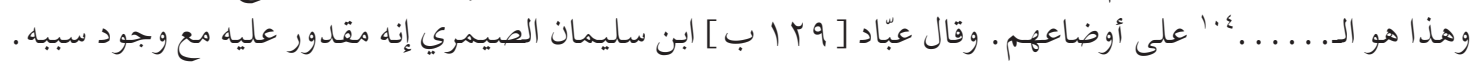

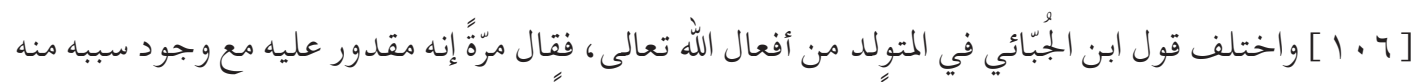

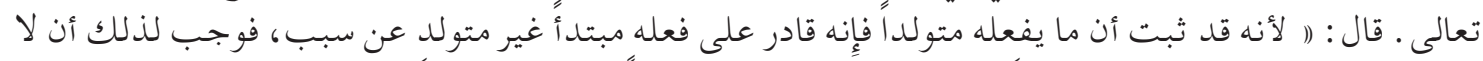

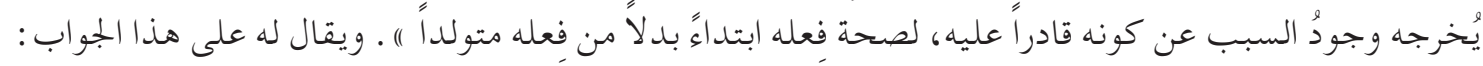

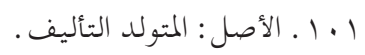

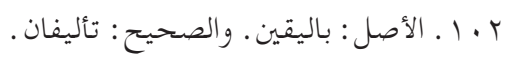

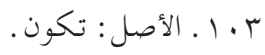
ـ ـ ا ـ كلمة غير مقروءة. 


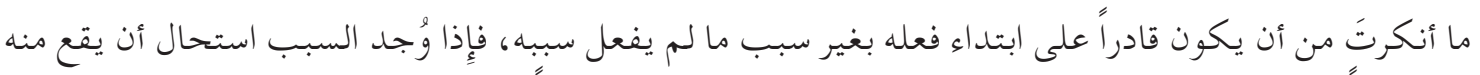

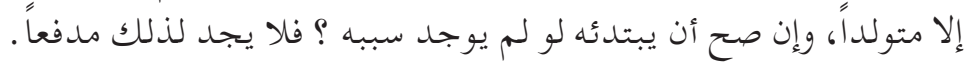

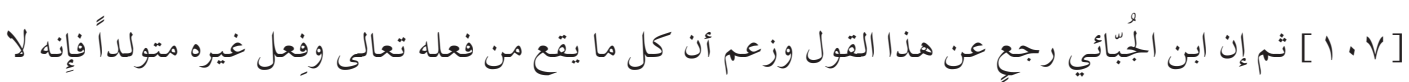

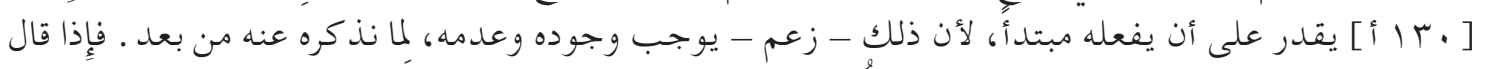

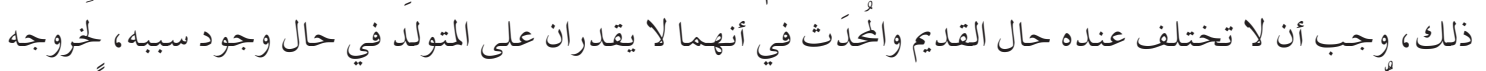

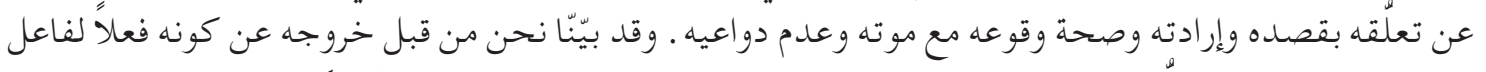

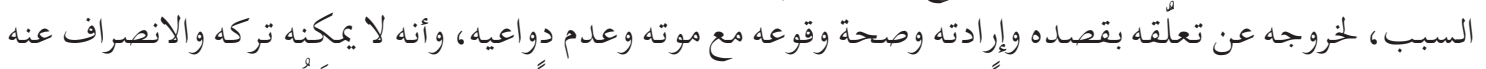

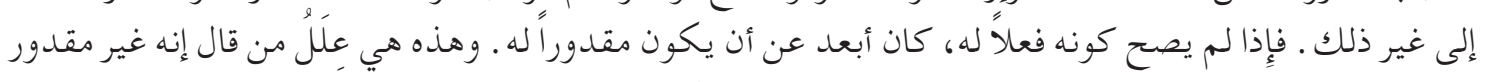

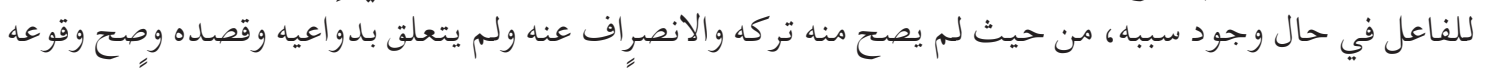

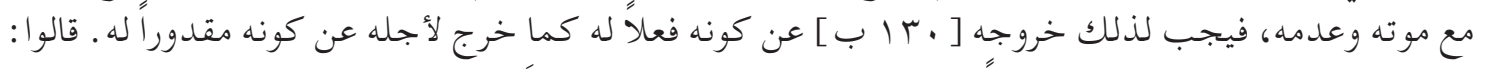

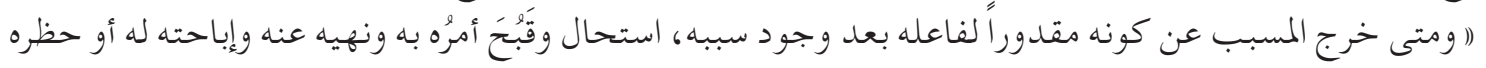

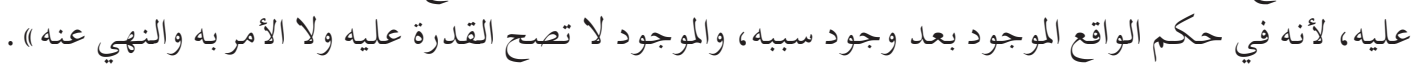

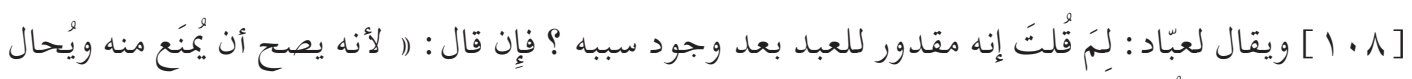

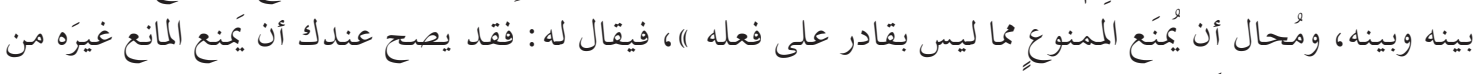

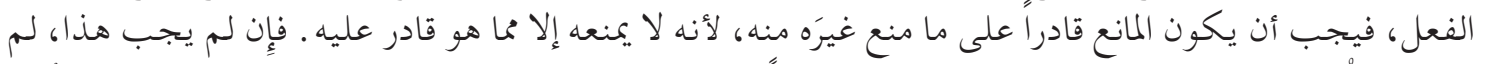

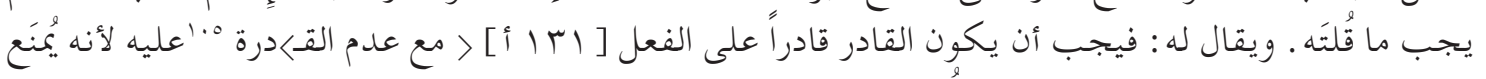

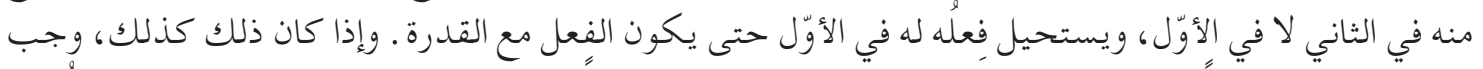

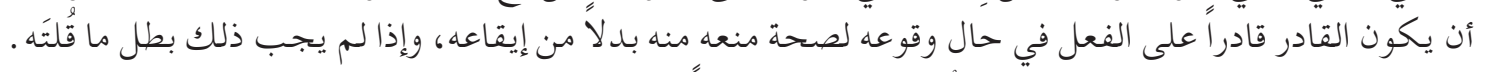

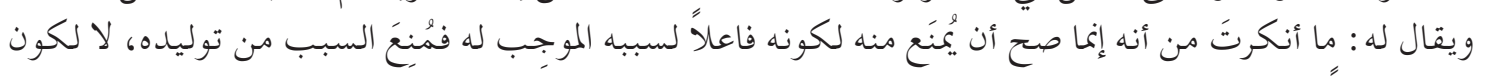

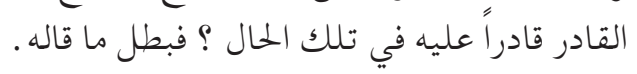

\section{باب ذكر اختلاف القدرية في القديم تعالى،

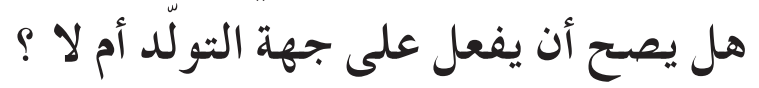

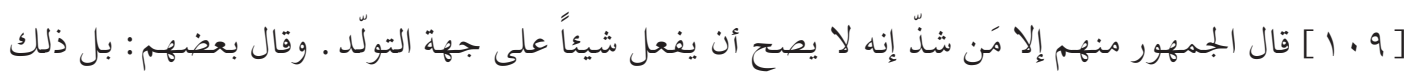

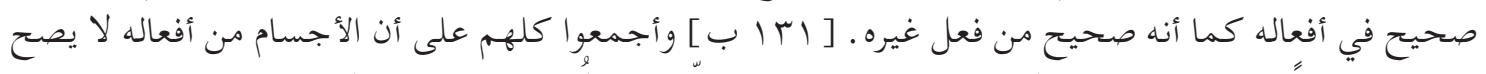

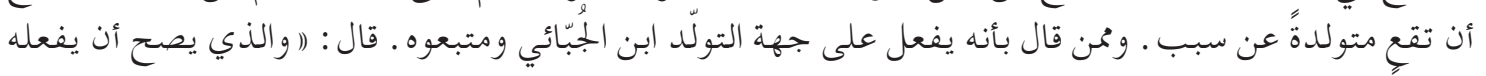

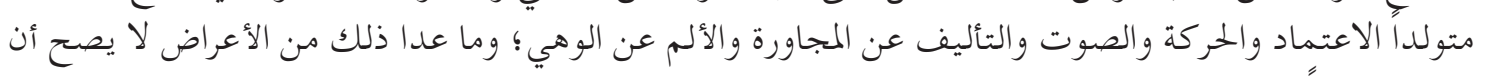
يفعله متولداً ). [ · 11 [ والمستمرّ مع القول بالتولّد قول من زعم أنه تعالى يفعل على جهة التوليد، وإلا بطل أصول القول

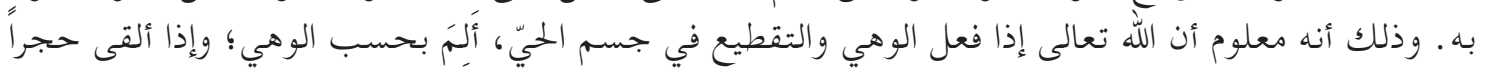




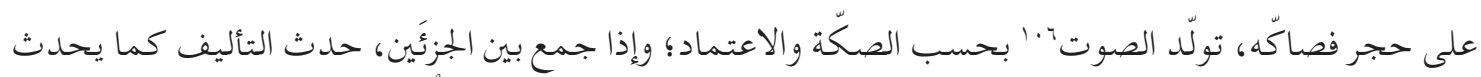

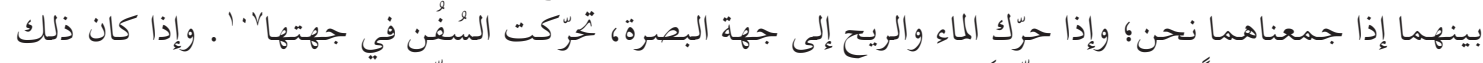

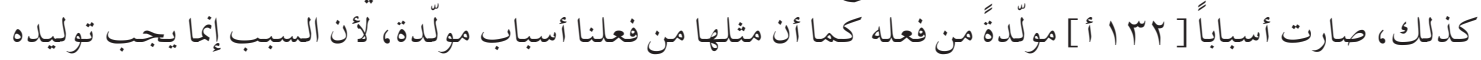

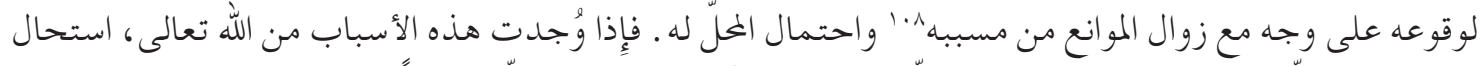

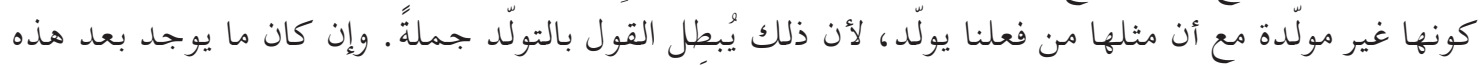

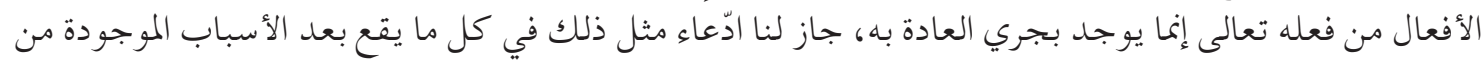

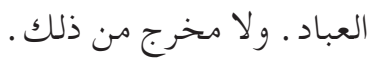

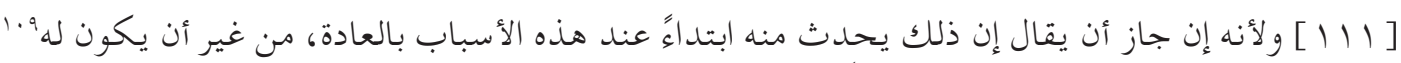

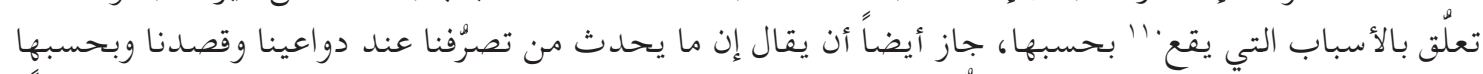

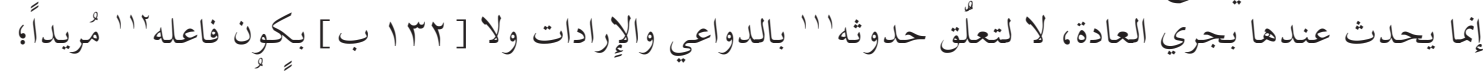

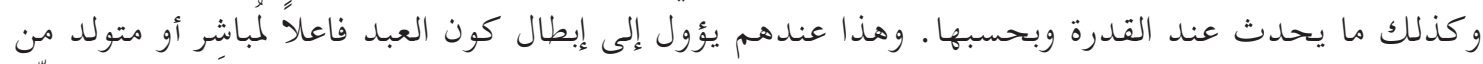

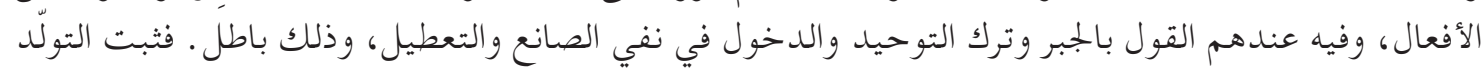
في أفعاله.

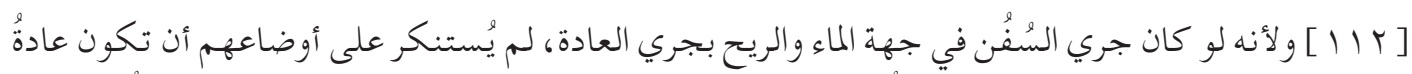

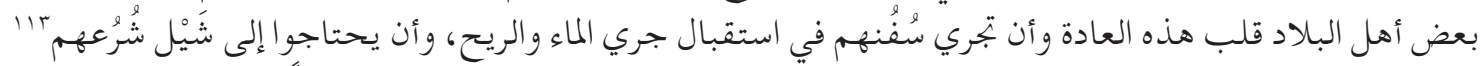

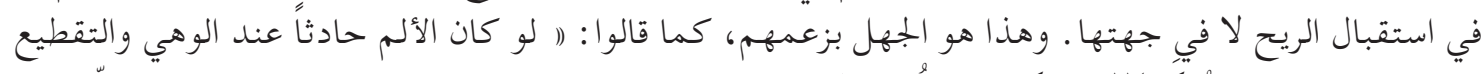

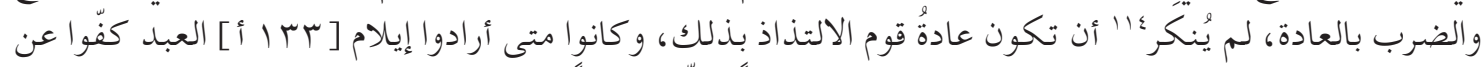

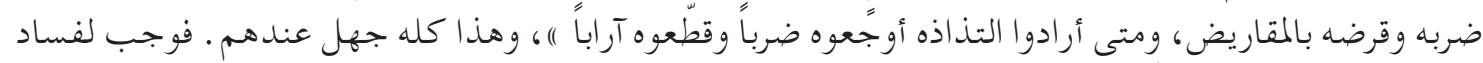

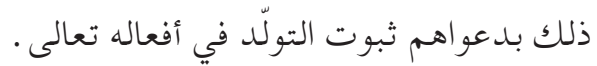

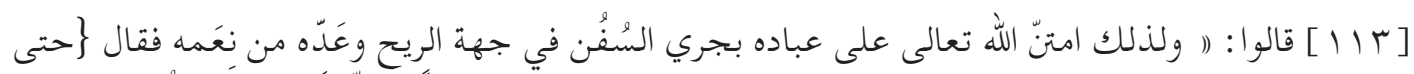

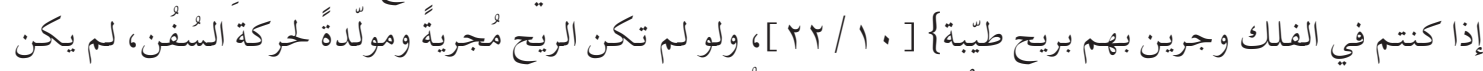

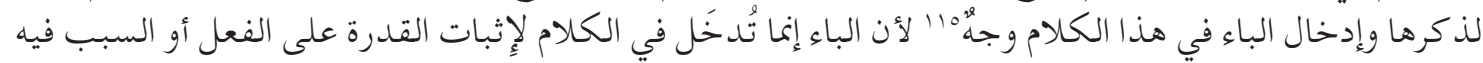

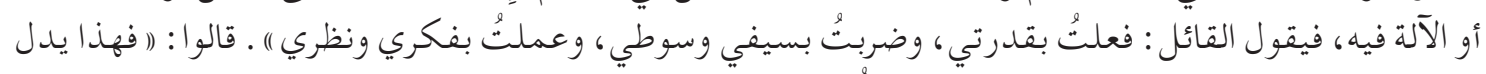

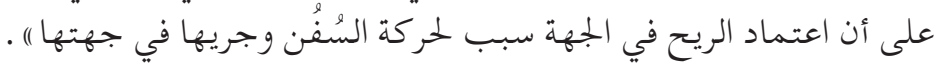

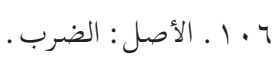

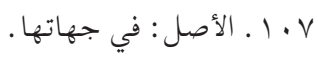

م · م الأصل : من سببه.

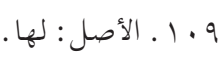

• 11. الأصل: الاصل: تقع.

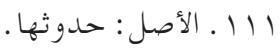

rا 1ا ـ الأصل: فاعلها.

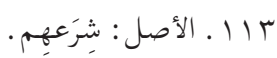

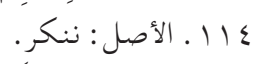

11 11 ـ الأصل: وجهاً. 


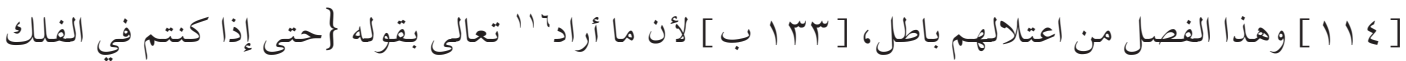

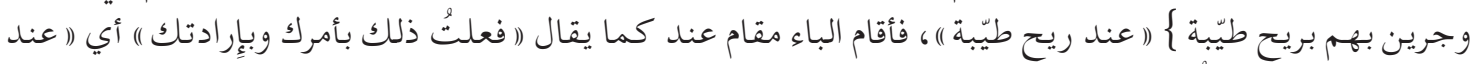

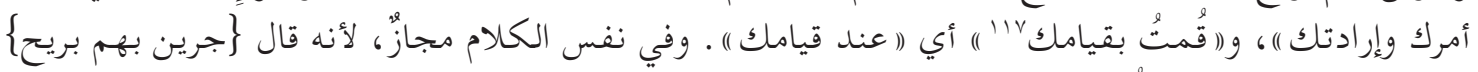

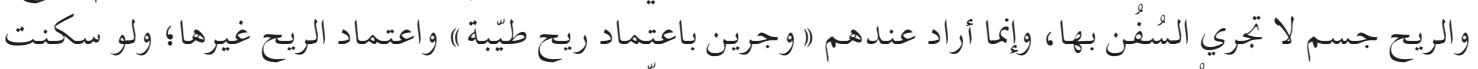

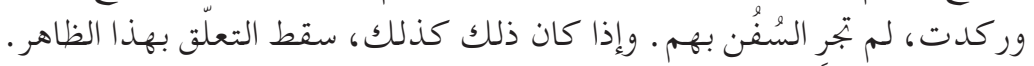

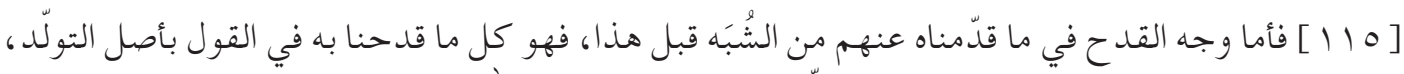

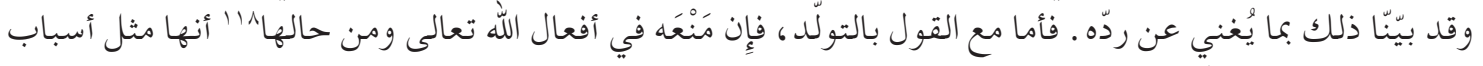

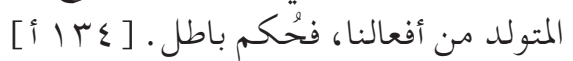

\section{ف}

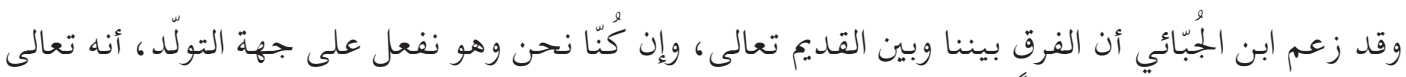

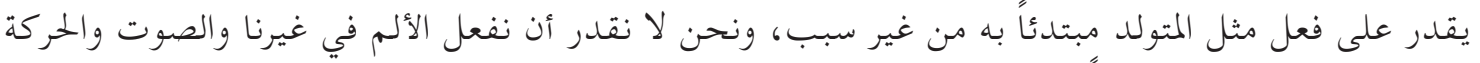

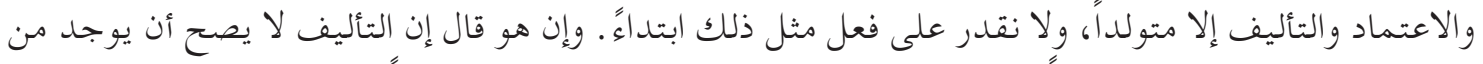

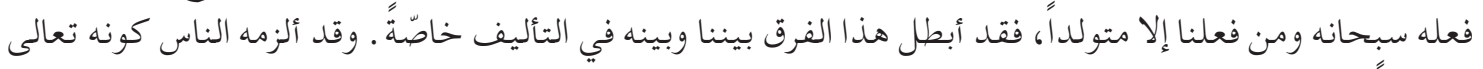

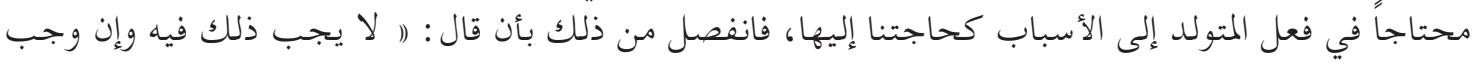

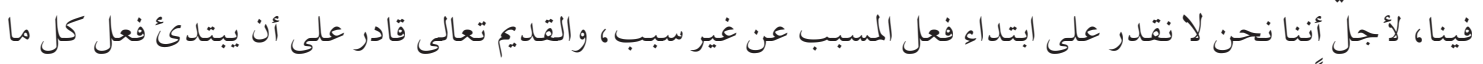

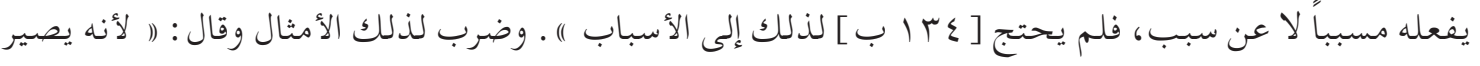

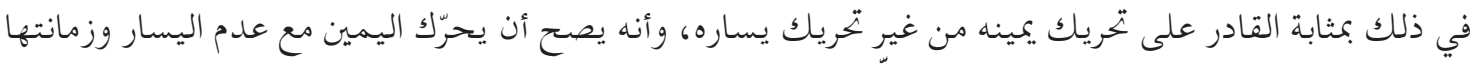

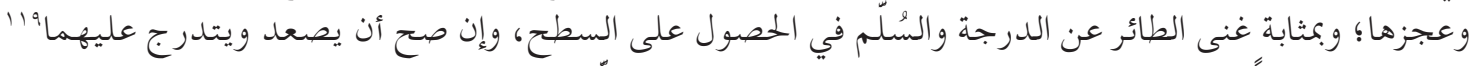

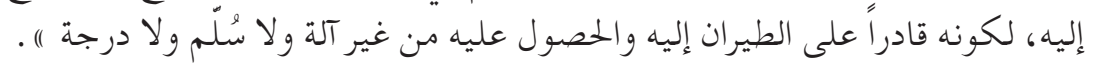

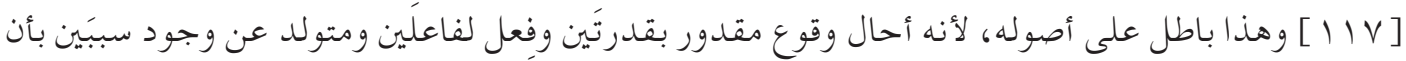

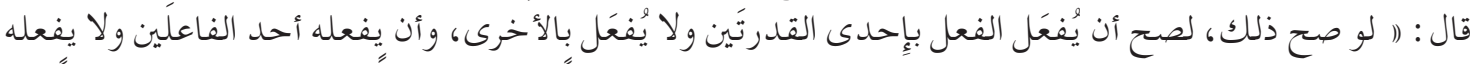

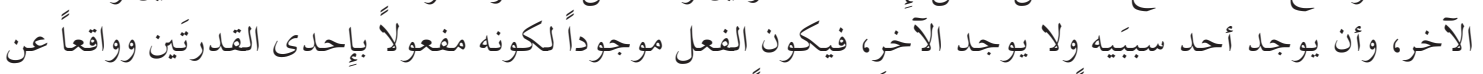

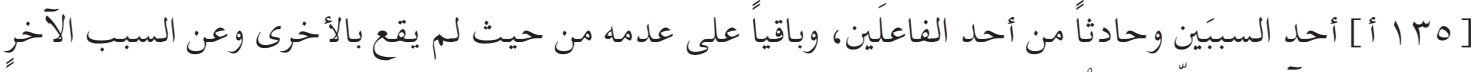

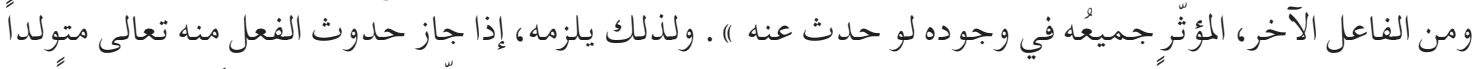

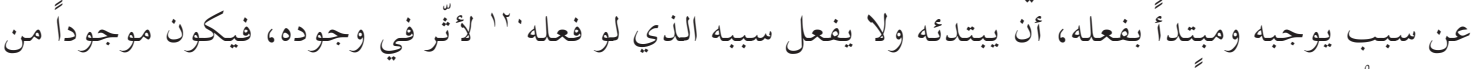

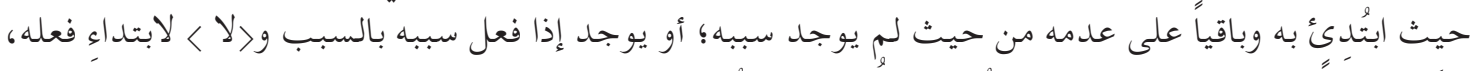

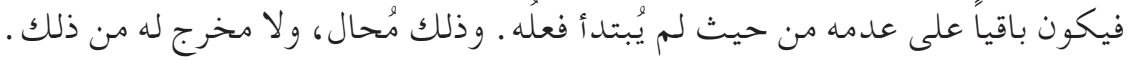

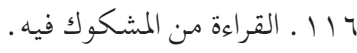

1IV

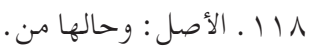

119 119 الأصل: الاصل: عليها.

. با ـ الأصل: لو فعل. الاصل عليها. 


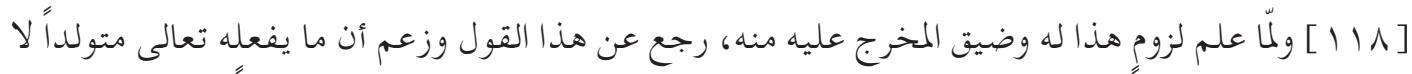

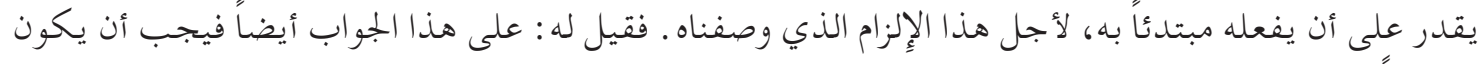

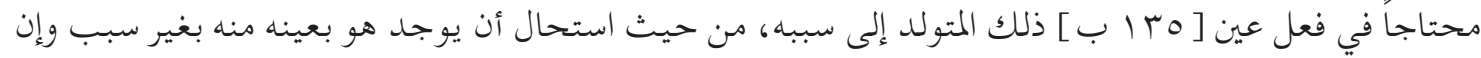

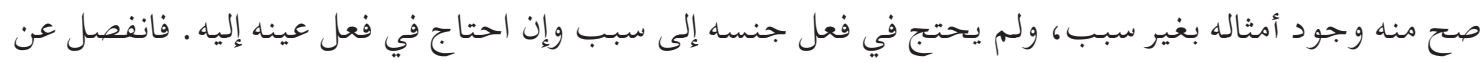

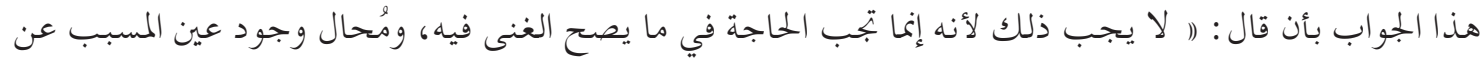

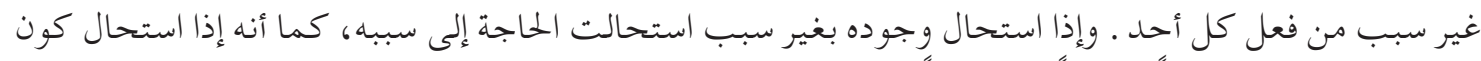

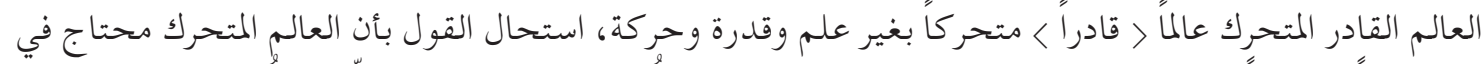

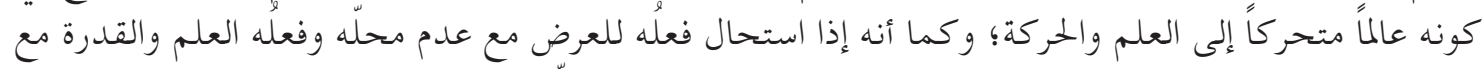

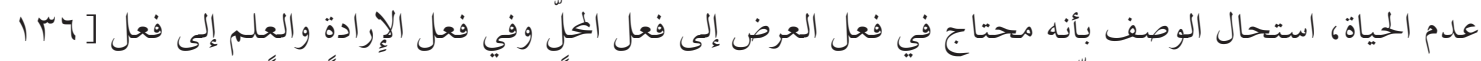

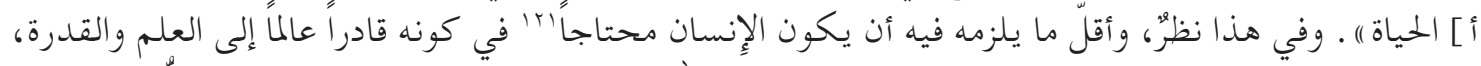

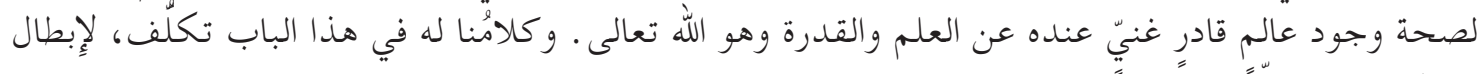

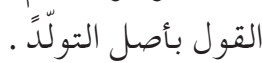

\section{باب ذكر اختالافهم \\ في توليد الطاعة والمعصية}

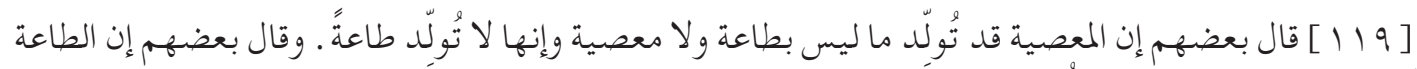

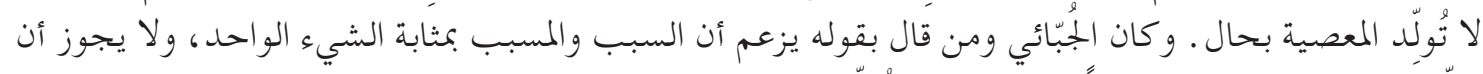

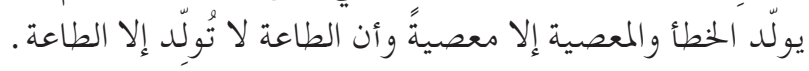

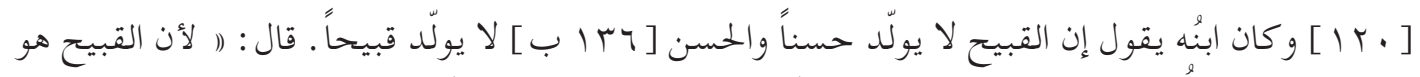

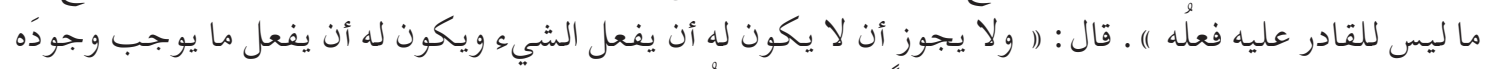

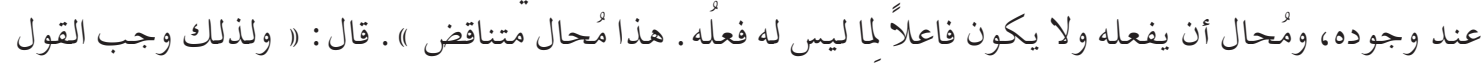

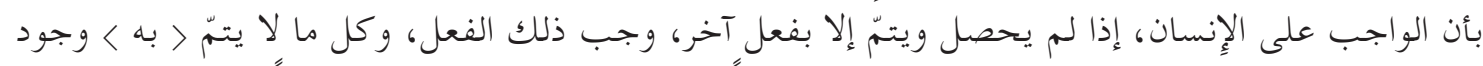

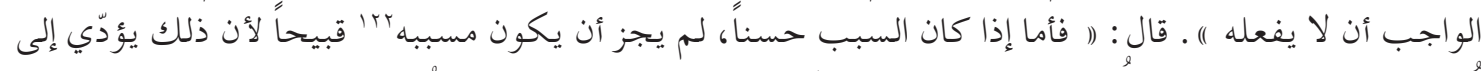

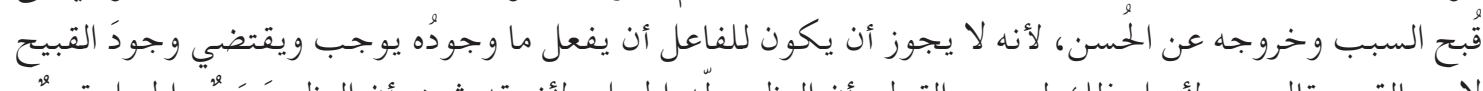

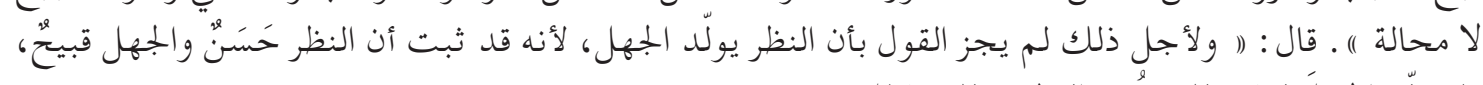

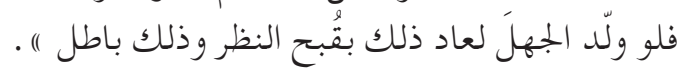

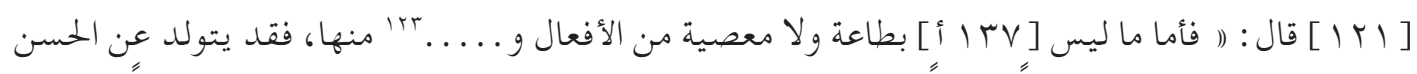

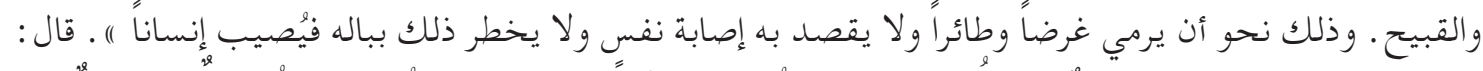

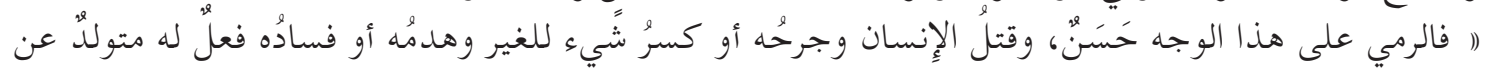

$$
\begin{aligned}
& \text { ا I ا ـ كذا، والصحيح على الأرجح: غير محتاج. } \\
& \text { r r ا ـ الأصل: سببه. }
\end{aligned}
$$

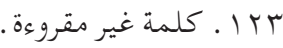




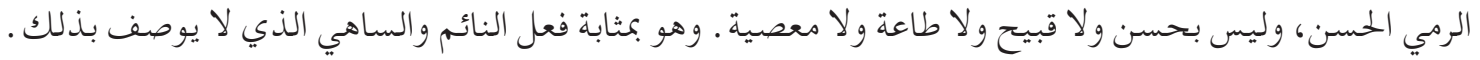

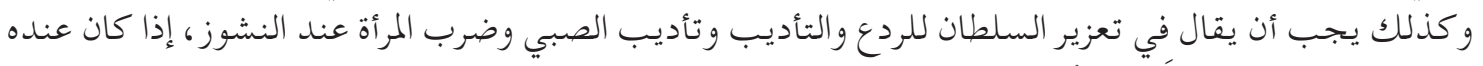

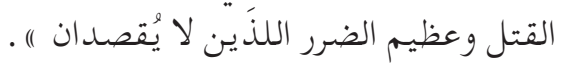

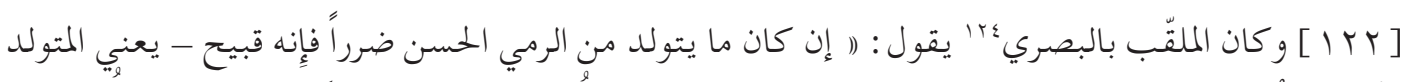

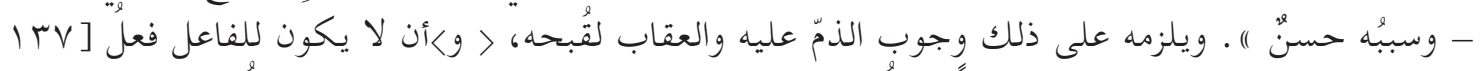

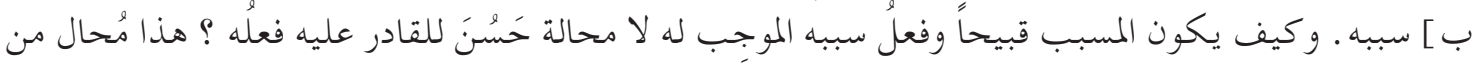
القول.

[ ب r I ] وكان أبو الهذيل العلافف وجعفر بن حرب يقولان إنه لا يتولد عن الحسن إلا حسن وعن القبيح إلا

\section{باب ذكر اختالوف القائلين بالتولّ هل تصـح التوبـة من المتو لل بعل و جود سببـه أم لا ؟}

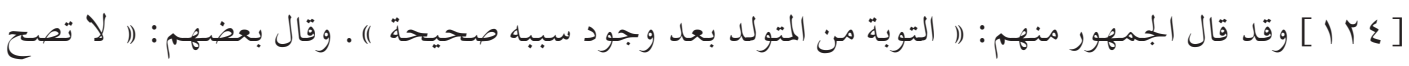

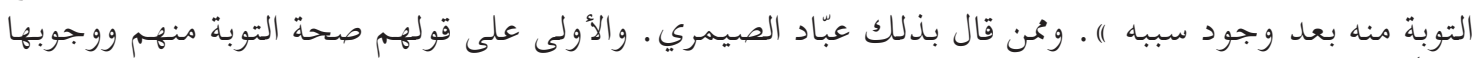

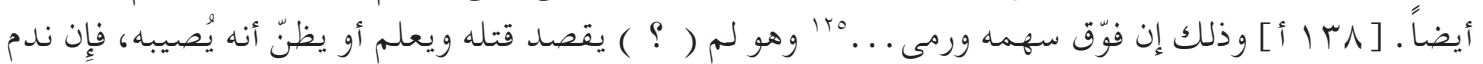

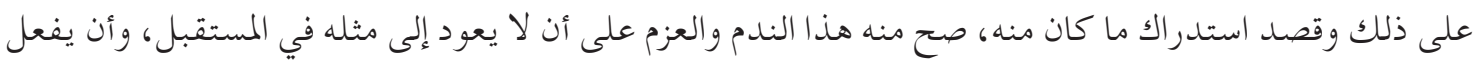

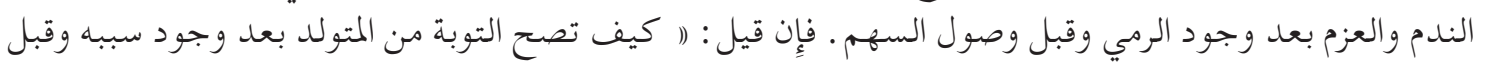

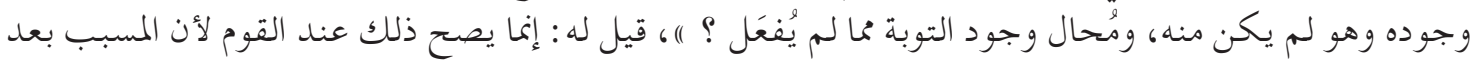

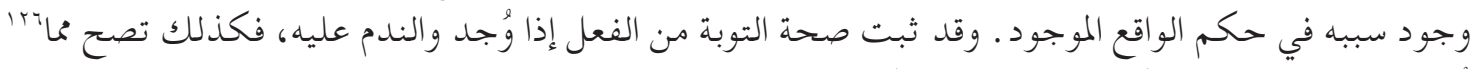

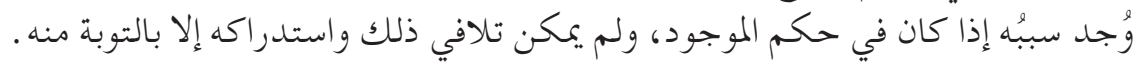

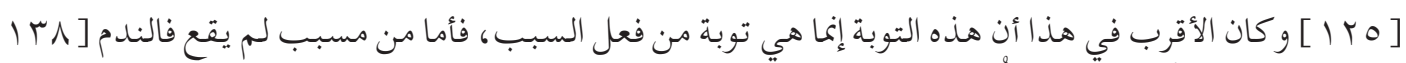

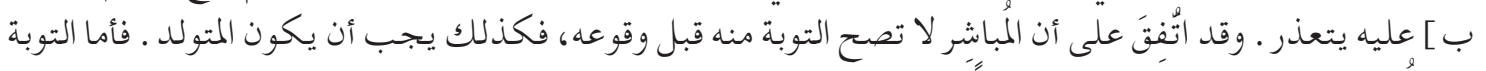

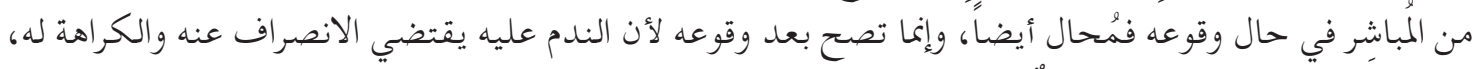

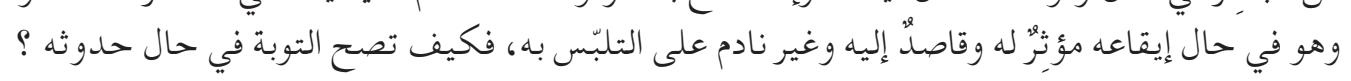

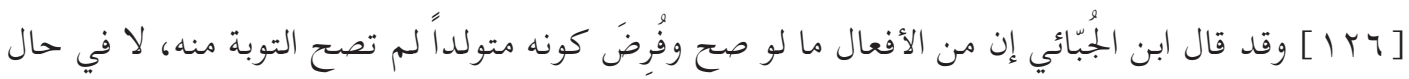

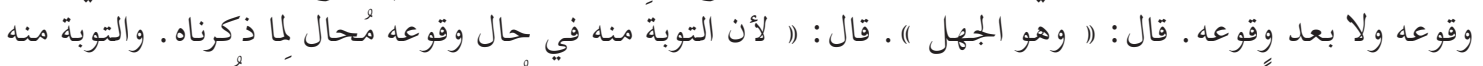

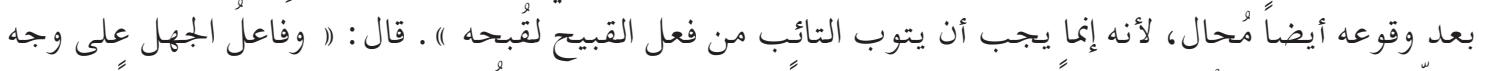

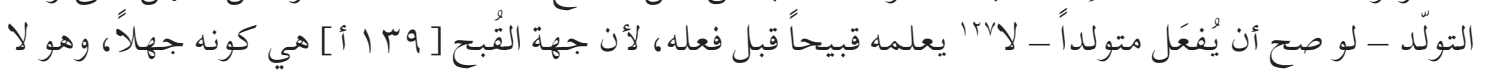

$$
\begin{aligned}
& \text { ـ آ ـ الأصل : البصري. و "البصري" هذا هو الشيخ أبو عبد الله. }
\end{aligned}
$$

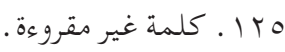

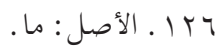

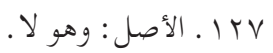




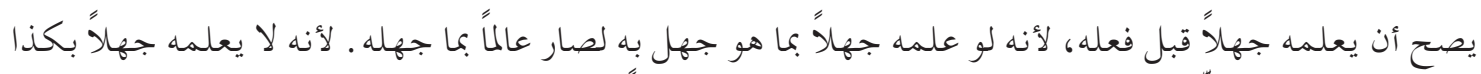

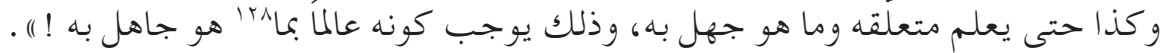

\section{ف [ I Y}

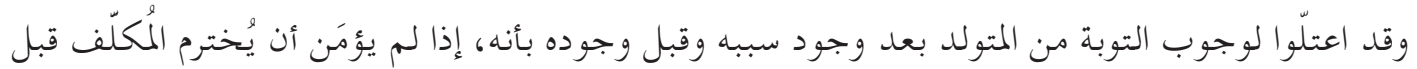

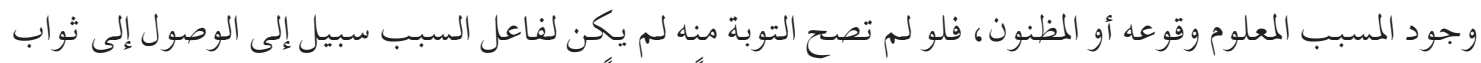

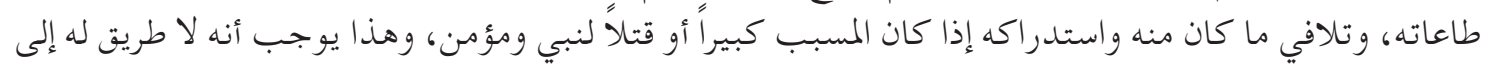

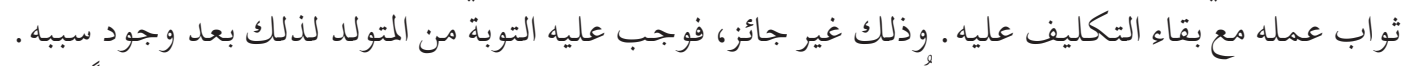

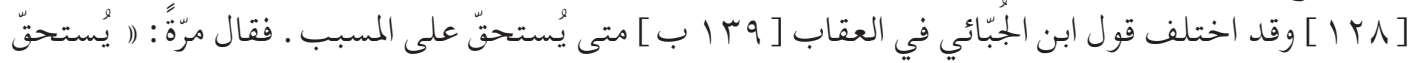

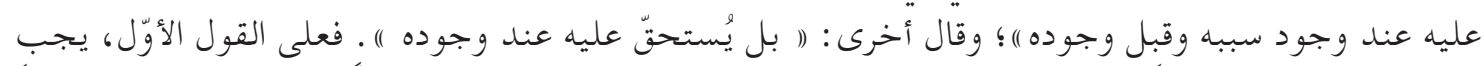

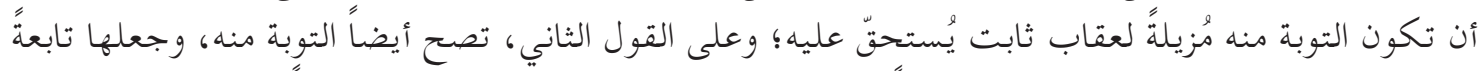

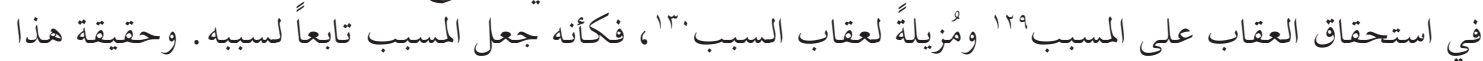

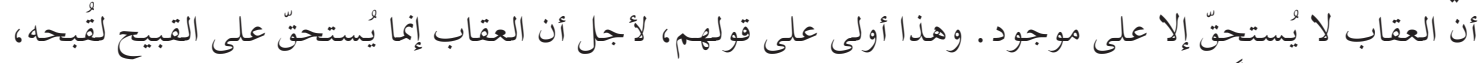

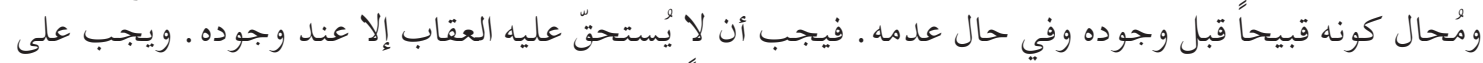

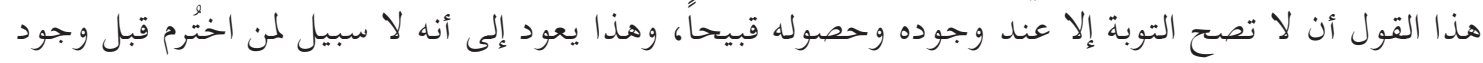

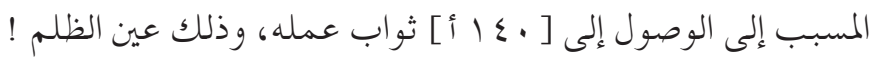

\section{باب ذكر جملة ما يشترك فيه السبب و المسبب وما يفترقان فيه}

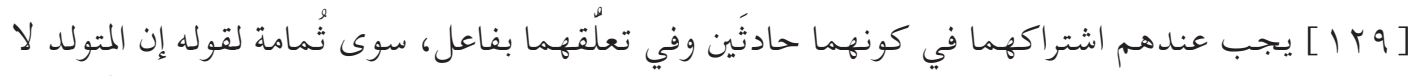

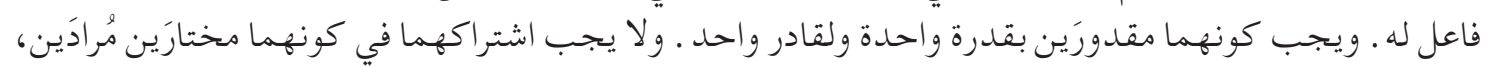

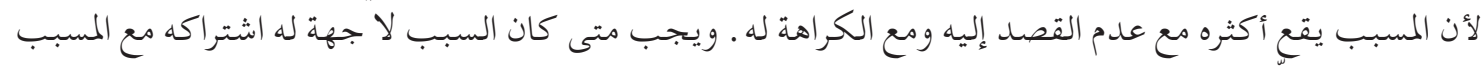

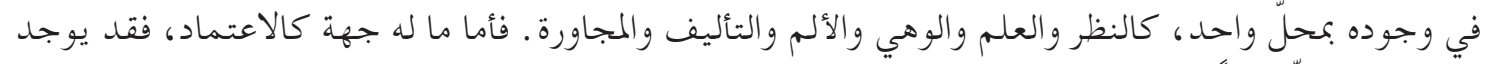

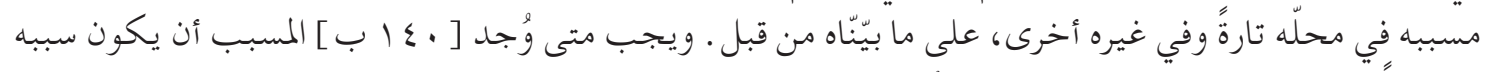

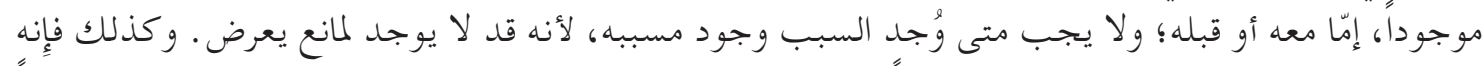

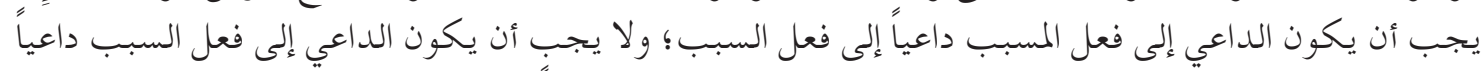

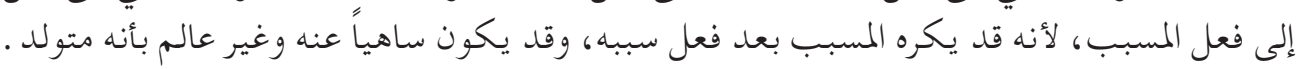

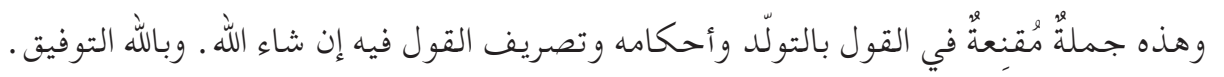

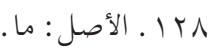

9 ب ا . لعل الصحيح: على السبب.

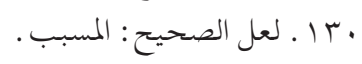




\section{فهرس الأعلام والطو ائف}

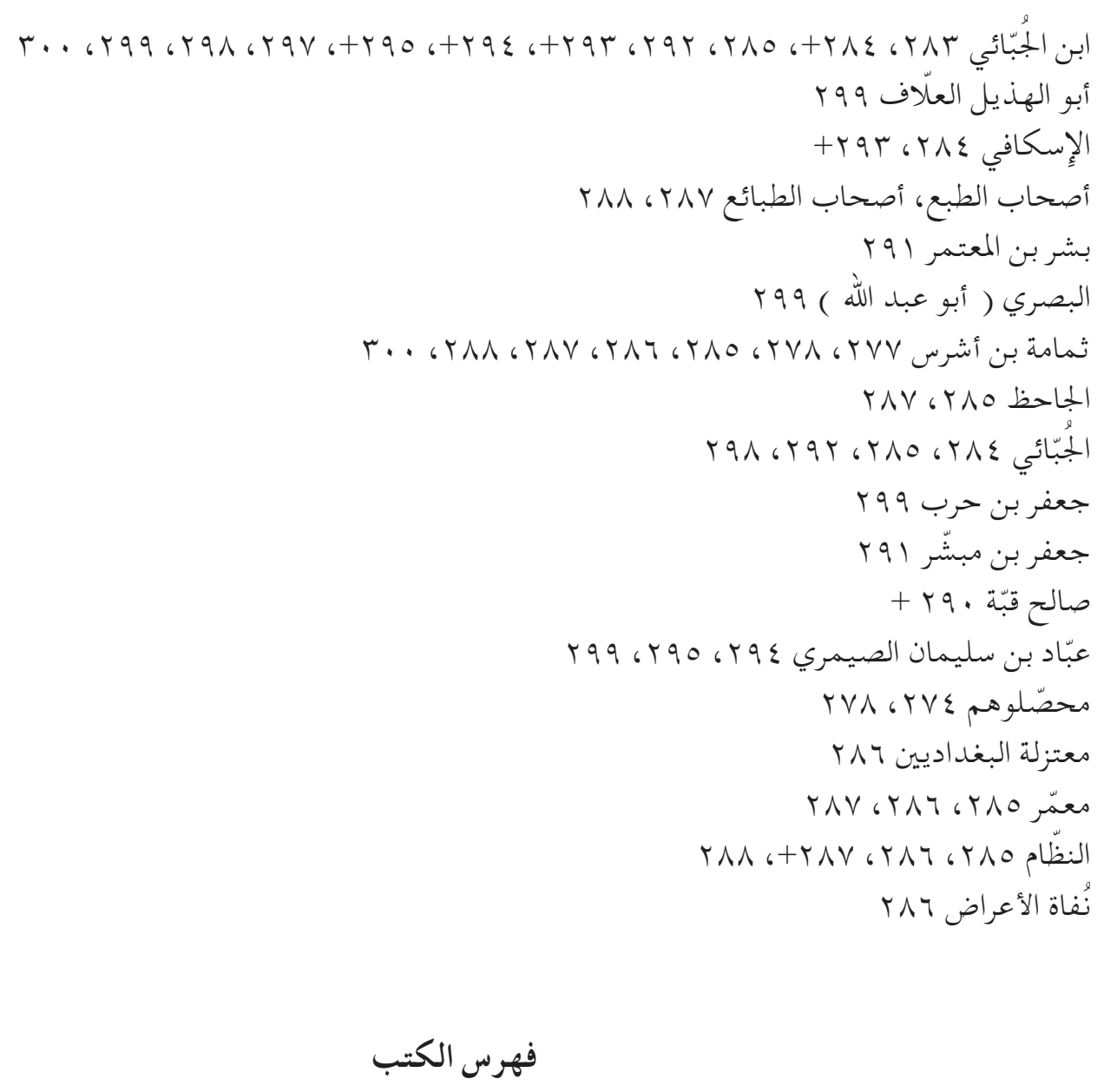

$$
\begin{aligned}
& \text { إبانة عجز القدرية عن إثبات دلائل النبوّة 919 }
\end{aligned}
$$

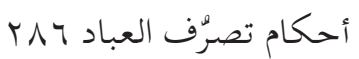

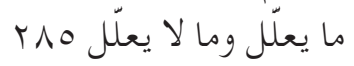

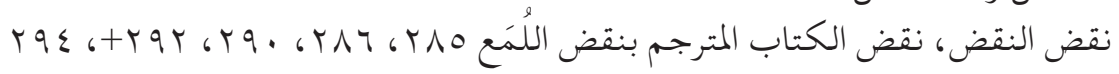


TROISIÈME PARTIE : COMMENTAIRE

Références bibliographiques:

Fì t-tawhīd: fragment, publié sous ce titre par Abū Rīda (Le Caire 1969), d'un commentaire anonyme du Šarh d'Abū 'Alī b. Hallād ${ }^{1}$. Contrairement à Abū Rīda, j'estime que ce commentaire ne saurait être attribué directement à Abū Rašīd an-Nīsābūrī et qu'il est beaucoup plus vraisemblablement l'œuvre d'un disciple de ce dernier.

M : 'Abd al-Ǧabbār, al-Muġnī, Le Caire 1960-65.

Maq : Abū I-Ḥasan al-Aš‘arī, Maqālāt al-islāmiyyīn, 2éd. H. Ritter, Wiesbaden 1963.

Mas : Abū Rašīd an-Nisābūrī, al-Masā’il fì l-hiläf bayna l-Bașriyyīn wa l-Baġdādiyyìn, Beyrouth 1979.

Mǧm: Ibn Mattawayh, al-Mağmū‘ fì l-Muhịt bi-t-taklîf, Beyrouth 1/1965；2/1981; 3/1999.

Šarḥ al-ușūl : [Ta‘līq] Šarḥ al-ușūl al-hnamsa de l'imam zaydite Mānkdīm Šešdīv, attribué faussement à 'Abd al-Ǧabbār par son éditeur A.K. 'Uțmān, Le Caire 1965.

Šm : Imām al-ḥaramayn al-Ǧuwaynī, aš-šāmil fī ușūl ad-dīn, Alexandrie 1969.

Tad : Ibn Mattawayh, at-Taḍkira fĭ aḥkām al-ğawāhir wa l-a'rāḍ, éd. D. Gimaret, 2 vol., Le Caire (Ifao) 2009.

§ 1. L'argument figure pareillement en tête des “pseudo-arguments" (šubah) prêtés au contradicteur dans M IX 64. On notera que ni 'Abd al-Ǧabbār ni Ibn Mattawayh ne contestent le principe qu'un acte engendré puisse en effet se réaliser alors que son agent est devenu mort ou impuissant, cf. Tad 225,11-12;325,5-8;482,1-2.

§ 2. Qātū min haqqi mā yata'allaqu bi-l-fā'il șihhat fitlihi wa an lā yaf'alahu, cf. M IX 73,8-10 : wa qad qāla aš-šayhāan fí gayr mawḍi inna min ḥaqqi l-qādir 'alā š-šay' an yașiḥha an yaf'alahu wa yașihh ha allā yaf'alahu. L'objection selon laquelle la consécution nécessaire de l'acte engendré par rapport à sa cause rendrait précisément impossible, en vertu de ce principe, de le considérer comme l'acte de l'agent humain est une des objections majeures adressées aux mu'tazilites. Elle figure sous deux versions, voisines l'une de l'autre, dans M IX 72,9 sq et 76,18 sq. B. y reviendra deux fois, d'abord au $\S 33$, puis aux $\S \S 78-79$ où curieusement il fera émettre cette objection par d'autres mu'tazilites partisans des "natures".

§ 4. Je ne retrouve cet étrange argument ni dans le Tamhìd, ni dans le texte parallèle de Simnānī (al-Bayān 'an uṣūl al-ìmān, ms Alep, al-Maktabat al-'uțmāniyya, 517, ff. 67a-74a), ni dans les sources mu'tazilites. Ibn Qami'a (ou Qamī’a selon Ibn Sa'd) est un de ceux qui ont combattu et blessé le Prophète à Uhud. Cependant, selon la tradition, ce n'est pas Ibn Qami'a qui est réputé lui avoir brisé une molaire, mais 'Utba b. Abī Waqqāṣ (cf. Ibn Hišām, as-Sīra, Le Caire 1375/1955, 3/84-85 ; Ibn Sa'd, Ṭabaqāt, éd. I. 'Abbās, 2/42, 45, 49.

1. Un disciple d'Abū Hāšim, cf. mon article des Annales islamologiques, 1979, 68-69 et 78. 
§ 7. Wa lammā ttafaqnā 'alā buțlān kawnihà qudratan 'alā mițlayn fì zamanin wāhid fì mahallin wāhid, allusion au principe ğubbā’ite selon lequel ahadunā lā yaqdiru, wa l-waqt wa l-mahall wa l-ğins wāhid, 'alā azyad min ğuz'in wāhịid; cf. Tad 451,23-24 ; 462,14 sq ; 505,18.

Li-qawlihim innahā qudratun 'alà mā lā nihāyata lahu min kulli ğins wa in lam yașihḥa an yuf'ala minhu ițnān fì waqtin wāhid fì mahallin wāhid. Tel est en effet le point de vue ğubbā'ite : la puissance humaine est puissance d'une infinité de possibles du même genre dès lors qu'il y a multiplicité d'instants ou multiplicité de réceptacles, cf. Tad 462,5-13.

Al-mahall yahtamilu 'indakum fì l-waqti l-wāhid amtālan katīiatan min kulli ğins. Contrairement à Aš arī et aux aš‘arites pour qui deux accidents du même genre ne peuvent coexister dans un même réceptacle (cf. ma Doctrine d'al-Ash'arī, Paris 1990, 88-89), les ğubbā’ites admettent en effet cette possibilité de manière systématique, qu'il s'agisse de couleurs (Tad 133,7-8), de saveurs (Tad 153,4-5), de sons (Tad 192,3), d'assemblage/ta'líf (Tad 302,2-6), de pression/ ittimād (Tad 329,6-13) ${ }^{2}$, de vies (Tad 394,19-20), de désirs (Tad 417,14-20), de volontés (Tad $536,3-4)$. La règle vaut également pour les puissances, sauf que leur nombre, pour un même réceptacle, ne peut être supérieur à cinq (Tad 449,3-6).

Wa qad tabata min qawlinā wa qawlihim anna nafs ağzā'i ț-taqīl lā tamna'u min šaylihi. Allusion probable à la thèse de Ğubbā'î et 'Abbād b. Sulaymān selon laquelle un corps est pesant par lui-même, c'est-à-dire en proportion du nombre de ses atomes et de leur tassement (iktināz) (cf. M IX 96,7-9 ; Tad 314,21-22). Abū Hāšim et ses partisans soutenaient quant à eux que le poids d'un corps est dû à la présence en lui d'une "entité" spécifique, l'accident "pesanteur" (tiql) qui est une des modalités de la pression. Et telle sera, en effet, la position de B. (cf. ك̌m 490), contrairement à son maître Aš‘ arī, adepte de l'autre thèse (cf. Doctrine d'al-Ash'arī, 72-73).

§ 8. Raisonnement semblable dans Tad 461,20-23 pour démontrer que c'est une même puissance qui est à la fois puissance de la cause génératrice et puissance de l'acte engendré par elle.

$\S 14$. La thèse selon laquelle la douleur physique a pour cause génératrice non pas directement une pression mais une "déchirure" (wahy ${ }^{3}$ ) engendrée par celle-ci, et à la condition que cette déchirure nuise au "bon état" (șihh ha) dont la vie a besoin pour exister, est la thèse classique des traités gubbā’ites (cf. notamment M IX 52-60), celle qu'Abū Hāšim a soutenue du moins "dans beaucoup de ses livres" (M IX 139,14), car il lui est arrivé aussi de faire de la pression même la cause directe de la douleur (cf. Tad 335,20-21). C'est à lui en tout cas (selon M IX 52,18 sq) que remonte l'argument cité par B. à l'encontre de cette dernière hypothèse, à savoir qu'une pression n'a pas le même effet selon qu'elle s'exerce sur une partie tendre du corps humain ou une partie dure (cf. également M XIII 272-73; Tad 268,16-18 et 337,17-20).

§ 15. Id̄ā 'tamada r-rağul al-ayyid aš-šadīd... Objection identique, pour l'essentiel, en $M$ IX 56,15 sq. La formulation est passablement différente, mais il s'agit toujours de montrer, contre les gubbā'ites, que leur théorie de la douleur devrait les conduire à admettre

2. S'agissant des "localisations" (akwān), les choses sont moins claires, cf. Tad 259,2-8.

3. On dit aussi tafrīq ou taqțì. 
qu'un unique engendré puisse procéder de deux causes génératrices (musabbab wāhid 'an sababayn ) - ici un atome de déchirure pour deux atomes de pression ; chez 'Abd al-Ğabbār une douleur unique pour deux atomes de séparation (iftirāq) - et à admettre du même coup qu'un acte unique puisse être l'œuvre de deux agents, qu'un possible unique relève de deux puissances (cf. encore M XIII 233,1-2 et 272,9-12), contrairement à un principe cardinal du mu'tazilisme concernant la théorie de l'acte humain (cf. encore M IX 117,7-9).

Wa qad qālū hum law ğāza dêalika la-ğāza... L'argument reproduit, transposé au cas d'un sabab 'an sababayn, celui qu'utilisait Abū Hāšim (cf. M VIII 101) pour démontrer qu'un agent ne saurait produire un même acte selon deux modalités (an yuḥdița ššsay' 'alā wağhayn). Sinon, disait-il, il pourrait se faire qu'il le produise selon l'une des deux modalités et non selon l'autre, d'où il résulterait que l'acte soit à la fois existant et inexistant (mawğūadan ma'dūman). B. utilisera à nouveau cet argument contre Abū Hāšim concernant l'idée que Dieu puisse aussi agir par voie de génération (cf. § 117).

§ 17. ... lākinnahu wahyun wāhidun mutawallidun 'an ahadi l-itimādayn bi-gayri 'aynihi. Telle est en effet, longuement argumentée, la réponse mu'tazilite à l'objection, cf. M IX 58 (où lire 1.3 : illā anna ahadahumā là bi-'aynihi yuwallidu l-alam) et surtout XIII 234-236.

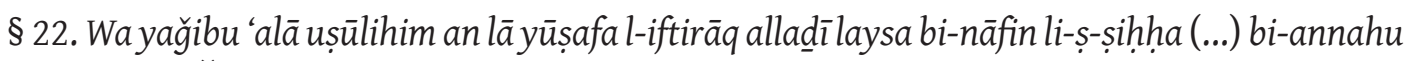
wahyun. 'Abd al-Ğabbār dit tout à fait de même (M IX 54,12-18).

$\S \S 24-25$. L'objection d'une piqûre de guêpe, morsure de serpent, etc, pour contester la proportionnalité entre la douleur et sa prétendue cause génératrice, est mentionnée en M IX 53. La réponse qu'y apporte 'Abd al-Ğabbār est celle indiquée par B. : le surplus de douleur est l'œuvre de Dieu par voie de coutume ( $\min$ filli llăhi bi-l-‘āda), cf. également Tad 465,12-13.

§ 29. ... li-annanā bi-hādā ț-țarīq 'alimnā anna l-mubāšir min al-af'āl filun lanā. Même parallélisme entre acte direct et acte engendré dans les deux premiers arguments du qāḍī 'Abd al-Ǧabbār en faveur de la thèse du tawallud, cf. M IX 37 et 38.

§31. Sur l'objection du 'ilm bi-l-mudrak cf. M IX 38,10-11 et 39,1-5. Sur la remémoration $\mathrm{du}$ raisonnement (tadakkur an-nazar) et qu'elle n'est pas, selon les ğubbā’ites, cause génératrice de science, cf. M IX 126 et Tad 594,17-19.

§ 32. Wa ș-șakkatu muwallidatan li-ș-șawt bi-šarți wuğūd aș-șalāba. Formule en partie inexacte, à nous en tenir du moins aux positions le plus souvent affichées par "Abd al-Ǧabbār et Ibn Mattawayh, pour qui la véritable cause génératrice du son est la pression, le "choc" (le terme usuel est mușākka plutôt que șakka) n'étant que la condition de ce processus : al-ítimād yuwallidu ș-șawt bi-šarți l-mușākka (cf. M IX 56,9 et 147,3-5; Tad $189,18-19 ; 193,15-17 ; 295,5-8 ; 305,5-6)$. Mais il est vrai que les choses n'ont pas toujours été aussi nettes (ainsi la position d'Abū Hāšim dans le Ğāmi', cf. M IX 138,17-18). Quant à la dureté (șaläba) du réceptacle, elle aussi en effet est comprise comme une condition du son (ou comme quelque chose dont le son a besoin pour exister, ce qui revient au même) : le "choc" requis ne peut avoir lieu qu'entre deux corps durs (Tad 186,18 sq ; 189,18-22 ; 
192, 4-5). Une fois, du reste, Ibn Mattawayh dit carrément que la pression engendre le son bi-šarți ș-șalāba (au lieu de bi-šarți l-mușākka) (Taḍ 292,17).

§ 33. Sur cette objection capitale, annoncée déjà au § 2, cf. M IX 39,10-17 et 72,9-19.

§ 35. B. soulève ici la question du ta'lïl et de ses limites, une question, on l'a vu, qu'il s'est lui-même posée, et qu'Ibn Mattawayh aborde en effet à plusieurs reprises dans sa Tadkira. Le talilil, rappelons-le, est cette opération maintes fois pratiquée qui consiste, considérant telle propriété (hukm) d'un existant donné, telle règle le concernant, à en découvrir l'explication, la cause ('illa) - le mot 'illa étant à comprendre ici au sens large, non au sens restreint qui en fait un équivalent de ma'nā ou 'arad (l'accident comme cause d'une qualification). Les possibles façons d'expliquer (wuğūh at-ta'līl) sont multiples et leur énumération est toujours sensiblement la même : cela peut être principalement l'essence ( $\underline{d} \bar{a} t)$ de l'existant considéré ou telle qualification qui lui est attachée ; ou bien l'existence en lui d'une entité (wuğūd ma'nāa); ou bien l'action d'un agent ( $f \bar{a}$ '‘l). Mais cela peut être aussi son fait d'exister, ou de commencer d'être (hudūt), voire son inexistence ou l'inexistence en lui d'une entité ('adam ma'nā), etc (voir, entre autres exemples, comment au début de la section sur les akwān Ibn Mattawayh démontre en vertu de quoi une substance se trouve "localisée" en tel point de l'espace et nul autre). Or, indique l'auteur de la Tadkira, si cette détermination d'une cause est, dans certains cas, impérative (Tad 434,16-19), elle n'est pas toujours possible. L'exemple le plus souvent cité est celui que B. mentionne ici en troisième position et qui est la règle selon laquelle l'accident résidant en tel réceptacle ne saurait en aucune façon résider ailleurs qu'en lui (al-hāll fí mahall lā yașihh wa kāna lā yașihh wuğūùuhu illā fîhi, Tad 138,12) : de cette règle nulle explication pertinente ne se peut déceler, cf. Tad 139,5 sq, et aussi 129,3-4;434,19-20;481,10-14. Un autre exemple est celui cité en premier lieu par B., celui de la "spatialité" (tahayyuz), une qualité que la substance mérite du fait de son essence même, mais qui ne se manifeste que lorsque ladite substance existe (cf. Tad 21,17 sq). En revanche, je ne vois pas confirmation chez Ibn Mattawayh d'une non-justification du rapport (ta'alluq) de la puissance à son objet, IM dit au contraire que ce rapport procède de son essence (li-dātihā, Tad 139,19).

§ 37. Ce "pseudo-argument" attribué aux mu'tazilites rappelle d'assez près M IX 40,4 sq.

§ 40. Ma'a ttifāqikum 'alā anna l-'ilm al-wāhid bi-l-ma'lūmi l-wāhid 'alāl-wağhil-wāhid ğuz'un wāhidun. Sur ce principe, cf. Tad 626,2-3, oū il est précisé que la règle ne vaut que s'agissant d'une connaissance détaillée ('alā haddi t-tafṣill), non globale.

Wa annahu mutawallid 'ani n-nazar al-kațīr fì d-dalīl al-murattabi ba'duhu 'alā ba'd. De fait pour Ibn Mattawayh chaque nazar est instantané (il fait partie des accidents qui ne durent pas), et une réflexion qualifiée de "longue" (țawīl) consiste à faire se succéder une multipiicité d'anzār ba'dahu itr ba'd (Tad 669,4-7).

§ 41. Yuqālu lahum wa idāa țabata anna minhā mā laysa bi-wāqi' bi-qadri l-qudar 'alā asbābihā... Objection comparable en M IX 41,20-23. 
$\S \S$ 42-43. 'Abd al-Ǧabbār répond d'avance à l'objection et assure, comme ici au § 43, que, s'agissant de l'acte engendré, connaissance de l'acte comme acte et connaissance de l'agent comme puissant suivent un ordre inverse que dans le cas de l'acte direct, cf. M IX $40,20 \mathrm{sq}$.

§ 43. Wa ğarā dِālika fī bābihi mağrā ftirāq ḥāI al-ǧism wa l-'araḍ fì mā yumkinu an yustadalla bihi 'alā hudūtihimāa . Même parallèle en M IX 41,7-11.

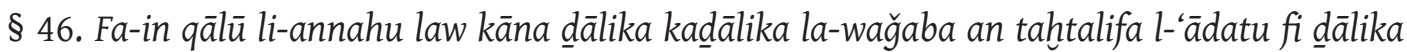
ihtilāfan. Thème récurrent chez les auteurs ğubbā'ites : tout ce qui relève de la coutume est susceptible de varier selon les temps et les lieux, cf. par exemple M XV 353,12-13:mā țarīquhu l-'āda yağūz an yahtalifa bi-l-awqāt wa l-amākin.

$\S 48$. Je ne trouve pas trace d'un tel argument dans les textes mu'tazilites actuellement disponibles. La question de l'origine du mouverment des os et des poils indissociable du mouvement de la partie vivante du corps humain y intervient certes, mais dans un autre contexte, sur la question de savoir s'il peut y avoir mouvement sans une pression qui l'engendre, cf. M IX 142 ; Tad 56,16 sq ; Fì t-tawhīd 149-150; Šm 504-505.

Lam takun min ğumlati l-ḥayy. Tel est en effet le point de vue d'Abū Hāšim. Mais Abū 'Alī pensait le contraire, cf. Tad 391,15-17.

§ 49. Fa-ammā l-'aẓmu fa-qad uhtulifa fïhi. Même variation d'opinion chez Abū Hāšim, qui a pensé parfois que les dents devaient être vivantes du fait qu'on y éprouve de la douleur. Abū 'Alī puis Ibn Mattawayh sont d'avis opposé (Tad 391,10-12).

$\S 54$. Je ne retrouve pas pour l'instant dans mes sources habituelles (y compris Maq) la définition de l'acte "direct" attribuée ici à "la grande majorité" des mu'tazilites. Celle qui suit en revanche - elle est reprise plus bas sous une autre forme - selon laquelle l'acte mubāšir se définit comme celui qui se produit "dans qui en a puissance et dans le réceptacle de la puissance qu'il en a” (et cela par opposition à l'acte engendré qui se produirait par principe hors de ce réceptacle), est bien en substance celle que le commentateur anonyme du Šarh d'Ibn Hallād (Fī t-tawhīd 390) attribue à "nos anciens maîtres" (mašāyihunūā al-mutaqaddimūn): al-mubāšir huwa mā yahillu mahalla l-qudrati 'alayhi. Une définition à laquelle le dit commentateur adresse les mêmes objections que celles faites ici par B., à savoir que, parmi les actes engendrés (ou que les mu'tazilites considèrent comme tels), il en est qui se produisent dans le réceptacle de la puissance de qui les accomplit. Les exemples concernés sont identiques : il y a d'une part la science engendrée par le raisonnement; d'autre part cet exemple très inattendu du retour de la pierre dans la main de qui l'a lancée et du mouvement que ce retour y produit (Fì t-tawhìd 391,3-4, cf. M IX 76,1 et 113,21).

§55. La définition de l'acte mubāšir que B. juge la plus pertinente, et qui se caractérise par l'introduction du verbe ibtada'a, est en effet, sous des formulations voisines, celle que proposent les auteurs ğubbā'ites : mā yuf'alu mubtada'an bi-l-qudrati fì mahallihā (Fì t-tawhīd 391, cf. presque à l'identique Šarh al-ușūl 223 et Tad 458,12); mā yaf'aluhu ibtidā'an fì mahalli l-qudra min dūni fi'lin siwāhu (Mğm 1/3 67). 
§ 56. La définition d'Abū Hāšim est ainsi rapportée par 'Abd al-Ǧabbār : mā wuğida 'an gayr muqaddima (M IX 138,21-22).

§57. Cette définition de l'acte engendré, que B. estime être la plus appropriée, n'a pas son équivalent, autant que je sache, ni dans les textes ğubbā’ites, ni dans Maq 408-09.

$\S \S 58-62$. Toutes les définitions ici rapportées se retrouvent, sous des formulations plus ou moins semblables, dans Maq 408-09.

§ 58. Cf. Maq 409,3-6.

§ 59. Cf. Maq 408,14.

§ 60. Cf. Maq 408,15-16. Noter que la lecture awğabahu fournie par B. est visiblement préférable au awğabtu du texte d'Aš‘arī.

Min al-mutawallidāt mā lā tark lahu ka-t-ta'līf. Cf. en effet M IX 73,23-24; Tad 252,15 et 301,2-13.

Li-annahu 'indahum qādir 'alā taskīn al-ḥağar aț-taqïl ma'a fili l-i'timād fïhi al-muwallid li-lharaka. Cf. Tad 277,16.

$\S \S 61-62$. Le texte de B. permet de corriger celui, incompréhensible sous sa forme actuelle, de Maq 409,1-2. Il faut y lire:

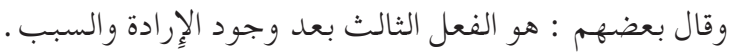

$$
\begin{aligned}
& \text { وقال بعضهم : هو الفعل الذي يلي مُرادي مثل الألم الذي يلي الضرالي الضربة ومثل الذهاب الذي يلي الدفعة. }
\end{aligned}
$$

§ 63. Je ne vois ce problème formellement soulevé que dans Maq 412,14 sq puis 414,13-15. Mais une réplique d'Abū Rašīd (Mas 70,2-3) semble bien confirmer le point de vue ici attribué aux ğubbā'ites : qìla lahu inna s-sabab fïl-haqīqa lā yūğibu wuğūd al-musabbab, wa l-mūğib huwa l-fā'il yaf'alu l-musabbab 'inda filihi li-s-sabab.

§ 64. Sababāni minhā lahumā ğihatun wa yuwallidāni fi ğihatihimā wa humā al-haraka wa l-i'timād. Faux, si l'on en croit les sources mu'tazilites. Pour Ǧubbā'̄î, seul le mouvement était cause génératrice : al-muwallid huwa l-haraka (Tad 275,6-7 ; 279,2-4 ;284,16-17) ; il niait qu'il en fût de même de la pression (lam yağ al al-ítimād muwallidan, Tad 270, 10). Pour lui, c'est le mouvement qui cause le mouvement (voir ici § 97), ainsi que, dans certains cas, la fixité (sukūn) ; c'est lui également qui est cause du son (Tad 271,9-10). Cf. encore, dans le même sens, Šm 503,13-16.

§65. Qālabnuhuinnal-muwallidminğumlatil-hawāditarba'atu ašyā'al-i'timād wal-muğāwara wa l-wahy (...) wa n-nazar. Exact, sauf que dans la postérité d'Abū Hāšim on considérera que ces différentes causes génératrices ne sont en réalité que trois (cf. Tad 3,14-15), du fait que muğāwara et wahy (lequel n'est qu'une modalité de la séparation / tafrīq, iftirāq) appartiennent l'un et l'autre à la catégorie du kawn (cf. Tad 268,5 sq).

Wa inna l-harakata lā tuwallidu šay'an (...) wa innahu lā ğihata lahā wa inna l-i'timād lahu ğihatun yuwallidu bihā fì gayri mahallihi. Cf. M IX 140,4-7.

Qāla wa d-dalī 'alā anna l-ḥaraka lā ğihata lahā annahu law kāna lahā ǧihatun (... ) la-wağaba an takūna min ğinsi l-i'timād. Cf. de loin M IX 141,2-6. 
$\S$ 66. Sur l'ensemble du § cf. M IX 11. Sur Tumāma, cf. Maq 407,9-11. Sur Mu'ammar, Maq 405, sauf que le texte de B. ne s'accorde pas avec celui d'Aš‘arī : selon ce dernier, Mu'ammar ne soutenait pas comme Tumāma et Ǧāhị que l'homme n'a d'autre action que sa volonté, il lui attribuait aussi d'autres "actes du cœur" tels que connaître, refuser, raisonner, comparer. Sur Ǧāhiz, Maq 407,12-13. Sur Naẓẓām, Maq 404,4-9 (où manque cependant l'exemple du feu, comme chez 'Abd al-Ǧabbār M IX 11, 19-2 1).

Sur les tenants de la théorie selon laquelle l'homme n'a d'autre action que sa réflexion (fikr), cf. exclusivement M IX 11,6-8. L'étrange distinction établie par certains d'entre eux entre fikr et rawiyya n'est attestée nulle part ailleurs qu'ici.

$\S \S 72-75$. Ces objections adressées aux așhāb aț-țab par les tenants du tawallud devraient se retrouver dans le ch. 19 du livre IX du Muginì (cf. M IX 8,20-21) intitulé : Faṣl fì ibțāl qawl man qāla fì- l-mutawallidāt innahā wāqi'atun bi-ț-țab'wa mā yattașilu bi-d̄ālika. Ce chapitre, manquant dans l'éd. du Caire, figure au nombre des mss mu'tazilites de la collection Firkovitch de Saint-Pétersbourg (ci-devant Bibliothèque publique de Léningrad, cf. l'art. d'A. Borisov ${ }^{4}$ p. 95).

§ 72. Cf. M IX 31,15-19. Mais le texte n'est pas clair, peut-être faut-il lire : li-anna mā lā yarğíu ilā l-ğumla. Sur cette opposition entre l'ensemble humain (al-ğumla) et les parties

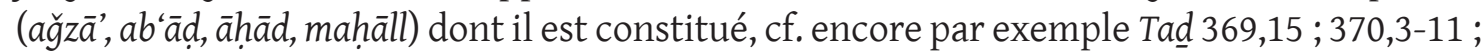
$443,15-16 ; 548,12 ; 582,7$.

$\S 78$. Sur cette objection adressée aux tenants du tawallud, déjà présente aux $\S$ 2 et 33 mais mise cette fois dans la bouche d'autres mu'tazilites partisans du țab', cf. M IX 39,10-17 et 72,9-16.

Wa matā arāda tahrīk ba'ḍi sāqihi aw sā'idihi wağaba an yaf ala l-harakata fì l-ba'ḍi l-āhar. Cf. M IX 143,5-8. Ibn Mattawayh explique ce phénomène par l'absence d'articulation (mafșil) entre les parties concernées, cf. Tad 457,14-15 ; 460,14-16 ; 461,5-6 et 14-15 ; 671,2-3.

Wa qad yakūnu min al-af'āl mà lā tarkun lahu yanșarifu ilayhi. Même réponse de la part de 'Abd al-Ǧabbār : al-maqdūr qad yağūzu an yakūna mimmā lā ḍiddun lahu (M IX 72,21).

§ 79. Yaqūlūna innahu qad yașiḥhu min fā'ili l-mutawallid an lā yaf'alahu bi-an lā yaf'ala sababahu. Telle est en effet une des réponses du qāḍī 'Abd al-Ǧabbār, cf. M IX 78,5-8 et 90,3-4.

§ 81. Inna l-ğawhar lā tark lahu. On notera qu'en vertu du même principe énoncé plus haut - tout acte n'a pas nécessairement un contraire - et tout en affirmant comme Abū 'Alī la réalité du fanā' comme contraire de la substance, Abū Hāšim estimait pour sa part qu'on n'en pouvait démontrer l'existence par voie rationnelle, cf. M IX 75,6-14 (et pareillement 'Abd al- Ǧabbār, cf. M XI 433,16-19).

§ 84. Sur ce que disent du fanā’ les théologiens ğubbā'ites, cf. M XI 432-451; Tad 101-118.

4. Référence, entre autres, dans mon article du Journal asiatique 1976, 280. 
Istiḥālata wuğūdi 'aradin lā fì makān. B. s'exprime ici comme Aš'arī dans Maq 367-68. Les ğubbā'ites préfèrent dire lāfìmahall. Telle est en effet selon eux la particularité de l'accident fan $\bar{a}$, par quoi il se distingue de tous les autres, de ne pouvoir exister que sans réceptacle, cf. Tad 3,7-8 et 106,21 sq.

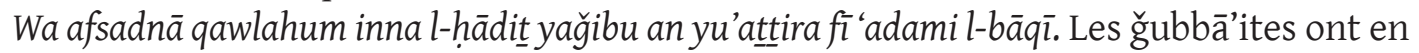
effet pour principe que, de deux accidents contraires se succédant dans un même réceptacle, celui qui commence d'être (al-hāadit) ou "survient" (aț-țāri') l'emporte nécessairement sur celui qui continue d'être ou "dure" (al-bāqì), c'est le premier des deux qui a capacité d'empêcher le second d'exister et non l'inverse. La raison en est, disent-ils, que l'accident qui survient est en rapport avec le puissant qui le produit, alors que, pour celui à l'état de durée, ce rapport n'existe plus. Cf. notamment Tad 151,12-14 et 471,18-20 ; Mas 125,10-19. Et cf. encore Tad $143,16-17 ; 144,15-16 ; 262,14-16 ; 319,5-7 ; 514,5$.

§ 85. Que la doctrine du tab‘ aurait pour conséquence, d'une part, que les miracles, n'étant plus l'œuvre de Dieu mais production d'une "nature", ne pourraient plus être preuve de la véridicité des prophètes ; d'autre part, que Dieu ne pourrait plus être considéré comme bienfaiteur des hommes dès lors que la vie, le désir, etc, qui sont en eux ne seraient plus également que d'origine "naturelle" : les deux objections se retrouvent dans Mğm $1 / 405,1-4$.

§§ 86-88. Sur les thèses de Șālih Qubba, cf. Maq 406-07 ; M IX 12,19 sq.

$\S \S 89-91$. Cette réfutation de la thèse du tab offre des ressemblances avec celle développée par 'Abd al-Ğabbār à partir de M IX 25,21.

§ 92. Wa qāla Bišr b. al-Mu'tamir wa ̌̆a'farb. Mubaššir ... Les deux hommes sont pareillement associés dans M IX 12,5 ; Aš‘arī pour sa part ne mentionne que Bišr (Maq 401-02).

§ 93. Wa l-fā́il fì gaayrihi lā yașiḥhu an yaf'ala fihi illā bi-mumāssatihi aw mumāssati mā māssahu. Cf. Maq 410,9-15 ; M VIII 121,2-4 ; IX 60,7-61,8 et 81,12-13. Sur le principe que la pression n'engendre en autrui qu'à condition qu'il y ait contact (bi-šarți l-mumāssa), cf. encore Tad 254,8 ; 267,18-19;333,17-18 ; 342,1-2 ; 705,23-24.

§ 94. Wa anna ğisma l-hayy id̄ā duriba wa ḥmarra ... Que la rougeur de la peau consécutive au coup vient de ce que le sang a été chassé de sa place (inza'ağa 'an makānihi), cf. M IX 61, 21-22; Tad 147,12-15.

§ 95. Aw bi-an tazhara 'inda l-ḥakk ağzā'un fihā harāra. C'est l'explication que retient Ibn Mattawayh qui a recours ensuite au même argument que celui ici invoqué : si le frottement engendrait de la chaleur, il devrait en aller de même en frottant l'un contre l'autre des glaçons ou les membres d'un mort, cf. Tad 160,7-8.

§ 97. L'objection d'Abū Hāšim, sous forme d'ilzām, à l'encontre de la théorie d'Abū 'Alī qui faisait du mouvement même la cause génératrice du mouvement, puis l'objection de même nature qui lui fut adressée en retour contre sa propre doctrine qui, elle, faisait de la pression la cause du mouvement, enfin la réponse donnée par lui à ce contre-ilzām consistant à expliquer le retour au sol de la pierre lancée en l'air par l'action combinée de 
la pression propre (ítimād lāzim) de la pierre vers le bas et de la pression importée (itimād muğtalab) en elle vers le haut, tout cela se retrouve en substance en M IX 52,8-16 et 147,20 sq ; Mas 205,20-206,4 ; et par allusion Tad 272,1-6.

§98. Qālal-kull(...) al-irādalāyağūzuan takūna mutawallida.Cf. Maq 414,1-2. Démonstration de ce principe est faite dans Tad 549,5-15.

$\S 99 . \mathrm{Cf}$ § 58.

§ 101. Qālū wa d-dalì 'alā anna l-i'timād yuwallidu l-i'timād annahu law lam yakun deālika

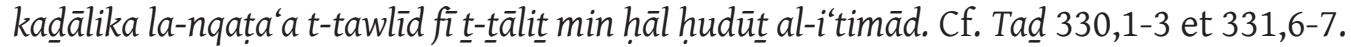

Li-annahu innamā yuwallidu l-harakata fi t-t-tānī. Cf. Tad 332,15-16.

Tumma kad̄âlika ilā an yad 'ufa l-ítimād al-muğtalab ... Sur le détail du processus selon Abū Hāšim, cf. M IX 148,3-9 ; Tad 351,13-19 ; Mas 205,24 sq.

§102. Qālū wa qad tabata anna ș-șawt wat-ta'lîf wal-alam lāyașihh an yūğad illā mutawallidan. Cf. M IX 13,19-20;50,13-14; 124,4-5;139,19-20.

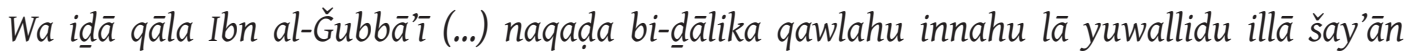
an-nazaru wa l-ititimād. Assertion surprenante, en contradiction flagrante avec ce qui a été dit au § 65. Pour Abū Hāšim et ses partisans, rappelons-le, les causes génératrices sont au nombre de trois : al-itimād, al-kawn (sous deux de ses modalités : al-muğāwara, al-wahy), et an-nazar.

Za'ama Ibn al-Ğubbā'̄ (...) anna t-ta'lîf lā yașihh an yūğada min fillinā wa fili llāh illā mutawallidan (...) li-annahu lā yașihh wuğūduhu ma'a l-iftirāq wa tabā'ud al-mahallayn. Que le propre de l'assemblage ( $t a^{\prime} l i f$ ) soit d'avoir besoin pour exister de deux réceptacles voisins l'un de l'autre (iftiqāruhu 'inda l-wuğūd ilā mahallayn mutağāwirayn) est en effet, pour les ğubbā’ites, un principe bien établi (cf. Tad 297,17-18 ; 299,18-19; 307,2 ; 313,2-3 ; 321,6-7 ; et aussi 252,$21 ; 268,5 ; 301,10-11)$. Mais je ne vois attesté nulle part que, selon eux, Dieu lui-même serait dans l'impossibilité de le produire autrement que par génération ${ }^{5}$. Plus loin (§ 109), B. dira plus justement que, pour Abū Hāšim et les siens, l'assemblage fait partie des accidents que Dieu peut produire de la sorte. 'Abd al-Ğabbār pour sa part affirme sans restriction que tout ce que Dieu peut produire par génération Lui est pareillement possible par voie directe (M IX 50,16-17). B. reviendra longuement sur le sujet aux §§ 106-107 et 109-118.

§ 103. L'idée que la volonté serait cause nécessitante du voulu (mūğiba li-murādihā) est de paternité incertaine. À en croire Aš́arī (Maq 415), beaucoup de théologiens l'auraient admise, du moins quand volonté et voulu se font immédiatement suite, ainsi notamment Abū l-Hudayl, Naẓzām, Mu'ammar, Ğa'far b. Ḥarb, Iskāfī, etc. Abū Rašīd et Ibn Mattawayh l'imputent essentiellement, quant à eux, à Abū l-Qāsim al-Balhī ( Mas 357 ; Tad 561,1-2). Elle est rejetée par les ğubbā’ites, cf. notamment $M$ VIb 84-88; Tad 561,5 sq.

\footnotetext{
5. Il est arrivé du reste qu'à la suite d'Abū 'Alī, Abū Hāšim ait soutenu qu'un certain mode d'assemblage pouvait être produit par acte direct (mubāširan), une position qu'il a définitivement abandonnée par la suite, cf. M IX 124,5-7 et $127,23 \mathrm{sq}$.
} 
§ 105. Cf. Maq 415,1-4, sauf que n'y figure pas le nom de 'Abbād. La thèse majoritaire est en accord avec le principe qui sera énoncé aux $\S \S 107$ et 124 : une fois qu'existe la cause génératrice, ce qu'elle engendre a le statut d'une chose existante (al-musabbab ba'd wuğūd sababihi fĭ ḥukmil-wāqi' al-mawğūd, cf. M IX 69,20-21 et 71,16). Or pour un mu'tazilite, comme cela a été dit au §12, il ne saurait y avoir puissance d'une chose existante (cf. Tad 510,7-8).

$\S \S$ 106-07. Wa htalafa qawl Ibn al-Ğubbā̄i fì l-mutawallid min af'āli llāh. La question soulevée au § précédent - s'il y a puissance de l'acte engendré dès lors qu'existe sa cause génératrice - conduit B. à anticiper dès maintenant ce qu'il exposera plus loin en détail d'une célèbre volte-face d'Abū Hāšim, voir les §§ 116-118.

§ 108. Muḥāl an yumna'a l-mamnū' mimmā laysa bi-qādir 'alayhi. Cf. Tạd 513,3-6.

§ 110. Que Dieu aussi peut agir par voie de génération est démontré ici de la même façon que dans M IX 57,11-15 et 58,22 sq ; Tad 343,17-18.

§ 112. Lam yustankar (...) an tağriya sufunuhum fï stiqbāl ğaryi l-mā’ wa r-rīh ... Même raisonnement par l'absurde sous la plume d'Abū Hāšim, cf. M IX 96,16-24.

§ 113. Cf. M IX 97,4-5, qui cite également Cor. 30/48: Allāhu llad̄i yursilu r-riyāḥa fa-tutīiru sahāban.

$\S \S 116-118$. Une fois admis - comme le pensent Abū Hāšim et ses partisans, et comme B. lui-même s'est employé à le démontrer dès lors qu'on accepte le principe du tawallud que Dieu aussi peut agir par voie de génération, la question se pose de savoir si précisément ce qu'Il produit par l'intermédiaire d'une cause (bi-sababin), Il aurait pu tout autant le produire par voie directe (ibtidā'an).

La réflexion d'Abū Hāšim sur ce point l'a conduit à adopter successivement deux thèses opposées, une palinodie dont font état très explicitement les sources mu'tazilites (cf. M IX 119-21; Tad 346,19-21; Mğm 1/419,26 sq) et dont B. présente ici une version quelque peu “arrangée" (peut-être à dessein). Le premier point de vue d'Abū Hāšim (ici théoriquement § 116), et qu'il soutenait, dit-on, dans al-Ğāmi' al-kabīr, était que l'acte même ('ayn al-fill) produit par Dieu par voie de génération - non pas seulement un acte semblable (mițl al-mutawallid) comme l'écrit B. - aurait pu l'être tout autant par voie directe. Pareille chose, expliquait-il, n'est pas possible pour l'homme, du fait qu'il est puissant par une puissance ; mais elle l'est pour Dieu qui, Lui, est puissant par Lui-même (cf. M IX 113,4-5 et 114,23 sq). Mais cette thèse avait pour inconvénient, comme le montre B. au $\$ 117$, qu'elle conduisait à admettre qu'un même acte puisse être produit selon deux modalités (min wağhayn, cf. M IX 110,24 et 115,19 sq), un principe qu'Abū Hāšim, par ailleurs, récusait formellement (cf. M VIII 101). C'est pourquoi, dans son K. al-Abwāb (ou Naqd al-Abwāb), il en vint à soutenir (ici § 118) que cela même ('ayn al-fi'l) que Dieu a produit par génération, il était impossible (istahāla) qu'Il l'eût produit directement - sans que cela, du reste, affecte en rien la différence fondamentale qui Le sépare de nous en l'occurrence, à savoir que tout ce qu'Il produit par tawlìd, Il a pouvoir, contrairement à l'homme, de produire un acte semblable (mițl al-fill), voire une infinité d'actes semblables, par voie directe. Telle est la position que reprendront par la suite 'Abd al-Ǧabbār (cf. M IX 81,21-23) puis Ibn Mattawayh. 
§ 116. Alzamahu n-nās kawnahu ta'ālā muhtāğan fī fili l-mutawallid ilā l-asbāb kahāăğatināa ilayhā. C'est l'argument majeur contre le principe général que Dieu puisse agir par voie de génération (cf. M IX 102,3-8 ; Tad 345,8-9) ; mais il vise aussi en particulier la seconde des thèses d'Abū Hāšim (cf. M IX 121,12-15 et ici § 118).

Wa bi-mațābati ġinā ațțā’ir ... Cf. M IX 102,20 sq ; Tad 345,12-14 ; Mğm 1/417,20-21.

§ 117. Ahāla wuqū' maqdūr bi-qudratayn wa fiłl li-fāilayn (...) bi-an qāla... Cf. plus haut $\S 15$.

§118. Fa-nfasala 'an hādā l-ğawāb bi-an qāla ... La réponse attribuée à Abū Hāšim est en substance celle de 'Abd al-Ǧabbār dans M IX 102,8-20 : s'il est intrinsèquement impossible que tel acte existe indépendamment d'une cause génératrice, on ne peut dire dans ce cas que qui le produit dans ces conditions a besoin de cette cause pour le faire exister ${ }^{6}$; de même, dès lors que tel acte par nature requiert un réceptacle (ce qui est le cas de tout accident, sauf rarissimes exceptions), on ne saurait dire que qui le produit a besoin de ce réceptacle pour agir.

§119-123. Les questions ici abordées n'apparaissent pratiquement pas dans les sources actuellement disponibles : trois lignes en Maq 413 (voir ci-dessous) ; deux brèves allusions dans la partie éditée de M IX ; peut-être le sujet a-t-il été traité dans la partie manquante, comme le suggère M IX 111,19: 'alā mā nufașșiluhu min ba'd (bien que la liste des chapitres manquants citée en M IX 8-9 n'annonce expressément rien de tel).

$\S 119$. Seule la première phrase se retrouve dans Maq 413,7-9 7 . La thèse y est attribuée aux "baġdādiens". Dans ce passage des Maq, le couple țā'a/ma șiya est curieusemenrt associé au couple haraka/sukūn (seul pris en considération par la suite), une association dont la logique m'échappe. Il n'est pas interdit de supposer à cet endroit une importante lacune, que le texte de B. permettrait de combler.

§ 120. Wa kāna bnuhu yaqūlu inna l-qabịh lā yuwallidu hasanan. Cf. M IX 111,19.

Qāla li-anna l-qabịh huwa mā laysa li-l-qādir 'alayhi fituhu. Au nombre des définitions qui ont été données de l'acte mauvais, 'Abd al-Ǧabbār cite en effet une formule comparable : al-qabīh huwa llad̄ī laysa li-fāilihi an yaf'alahu (M VIa 27), mais sans l'attribuer expressément à quiconque.

Al-wāğib 'alā l-insān idāa lam yahșul wa yatimma illā bi-fillin āhar wağaba dِālika l-filu. Une application de ce principe (dont je n'ai pu retrouver ailleurs la trace, y compris en M XIV) se rencontre en Tad 122,9-10: du moment qu'il y a obligation pour Dieu d'accorder récompense ou compensation à ceux qui y ont droit, il y a obligation pour Lui de les ressusciter, leur résurrection ( $\left.i^{\star} \bar{a} \mathrm{~d} a\right)$ "est obligatoire puisque l'obligatoire ne peut s'accomplir sans elle" (wağabat li-anna l-wāğib laysa yatimmu dūnahā).

§ 121. Fa-ammā mā laysa bi-țā'a wa lā masṣiya (...) faqad yatawalladu 'ani l-ḥasan wa l-qabīh. Cf. M IX 111, 17-18.

\footnotetext{
6. Cf. également Tad 174,4-5 : lā talzamu l-ḥāğa id̄ā lam yașiḥh fí filin bi-'aynihi illā an yaf alahu bi-sababin.

7. Avec une différence : B. écrit qad tuwallidu mā laysa ... ; Aš`arī dit tuwallidu tout court.
} 
Wa lāyahtururu dālika bi-bālihi ... Cf. M IX 67,11-13 (où il est précisé que cette position était également celle d'Abū 'Alī).

Wa huwa bi-matābati fill an-nā’im wa s-sāhī llad̄i lā yūṣafu bi-dālika. Cf. M VIa 11,3-17.

§ 122. Wa kāna l-mulaqqab bi-l-Bașrī... Il s'agit d'Abū 'Abd Allāh al-Bașrī qui considérait en effet, contrairement aux "deux šayh-s", qu'un acte engendré involontaire, s'il a un caractère d'injustice (zulm), doit être tenu pour mauvais, même si son auteur ne mérite pas le blâme (cf. M IX 67,13-15). Il en disait autant, du reste, de l'acte inconscient (M VIa 11,18 sq).

$\S \S 124-128$. Sur la question du repentir touchant l'acte engendré, trois petites lignes en tout et pour tout dans Maq 413,3-5 (où le mot énigmatique est à lire évidemment at-tawba), un indice de plus de possibles lacunes dans l'ouvrage d'Aš‘arī, que le texte de B. permettrait de combler. En dehors des Maq, des références sont à chercher surtout dans M XIV, Kitāb at-Tawba.

§ 124. Pas plus qu'au § 105, la mention faite ici du nom de 'Abbād n'est confirmée par ailleurs (à ma connaissance du moins).

In fawwaqa sahmahu wa ramā... Le cas du tireur, et de son repentir possible entre l'instant où il tire (hăl ar-ramy) et celui où il atteint sa cible (hâal al-ișāba), est l'exemple classique en la matière, cf. M IX 68,1-2 ; XIV 350,18-21 ; 392,6-13 ; 418,15-18; Mğm 3/405.

Li-anna l-musabbab ba'd wuğūd sababihi fi hukmi l-wāqi' al-mawğūd, voir plus haut sur $\S 105$.

§ 126. Waqad qāla Ibn al-Ǧubbā̄ì inna min al-afāl mā law șahhha kawnuhu mutawallidan lam tașihh at-tawbatu minhu ( ... ) wa huwa l-ğahl. Cf. M XIV 416,8-16.

$\S 127$. Cette hypothèse d'une mort subite survenant dans le laps de temps qui sépare l'acte générateur de l'acte engendré, et l'obligation qu'elle entrainerait d'un repentir anticipé afin de se préserver du châtiment dans l'au-delà, n'est explicitement évoquée, et de façon fort brève, que dans Mğm 3/405,4-5 (et cf. aussi allusivement M IX 68,1-3).

$\S 128$. Sur cette autre variation dans la pensée d'Abū Hāšim, cf. M IX 68,21 sq (où lire en 69,1 al-'iqāb et non at-táwāb) ; Mğm 1/424,21-22 et 425,6-7;3/267,5-7. Le texte de B., cependant, n'est pas parfaitement clair, et peut-être, s'agissant des implications de la seconde thèse, faut-il lire, comme je le suppose (et comme je l'ai déjà fait en d'autres occasions), al-musabbab au lieu d'as-sabab et vice-versa. 